UNIVERSIDADE DE SÃO PAULO

INSTITUTO OCEANOGRÁFICO

CAMILA SAYURI SANTOS OBATA

Comparação entre estimativas de taxas de produção primária no canal de São Sebastião e a influência das condições oceanográficas

São Paulo 
CAMILA SAYURI SANTOS OBATA

Comparação entre estimativas de taxas de produção primária no canal de São Sebastião e a influência das condições oceanográficas

Dissertação apresentada ao Instituto Oceanográfico da Universidade de São Paulo, como parte dos requisitos para obtenção do título de Mestre em Ciências, programa de Oceanografia, área de Oceanografia Biológica

Orientadora: Prof., ${ }^{\mathrm{a}}$, Dr. ${ }^{\mathrm{a}}$ Áurea Maria Ciotti

São Paulo 
UNIVERSIDADE DE SÃO PAULO

INSTITUTO OCEANOGRÁFICO

\section{Comparação entre estimativas de taxas de produção primária no canal de São Sebastião e a influência das condições oceanográficas}

\section{CAMILA SAYURI SANTOS OBATA}

Dissertação apresentada ao Instituo Oceanográfico da Universidade de São Paulo, como parte dos requisitos para obtenção do título de Mestre em Ciências, programa de Oceanografia, área de Oceanografia Biológica.

Versão corrigida

Julgada em 01/04/2019

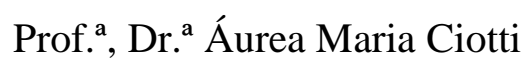

Instituição: Centro de Biologia Marinha da Universidade de São Paulo

Prof. ${ }^{\mathrm{a}}$, Dr. ${ }^{\mathrm{a}}$ Estela Maria Plastino

Instituição: Instituto de Biociências da Universidade de São Paulo

Prof. ${ }^{\text {, }}$, Dr. ${ }^{\text {a }}$ Mariana Guenther

Instituição: Instituto de Ciências Biológicas da Universidade de Pernambuco 
Dedico este trabalho à minha Batiã, pelo carinho e incentivo, e ao vô Careca, pela genética do amor e respeito ao mar 


\section{AGRADECIMENTOS}

"O presente trabalho foi realizado com apoio da Coordenação de Aperfeiçoamento de Pessoal de Nível Superior - Brasil (CAPES) - Código de Financiamento 001”.

Agradeço primeiramente a Universidade de São Paulo e ao Programa de Pós-Graduação do Instituto Oceanográfico pela oportunidade de inserção na vida acadêmica.

Ao Centro de Biologia Marinha (CEBIMar), pela ótima estrutura e enorme suporte técnico para elaboração deste trabalho, além da disponibilização dos dados da estação meteorológica.

Agradeço especialmente à minha orientadora, Áurea Ciotti, pelo conhecimento, confiança, paciência e dedicação durante cada etapa desta caminhada, sempre me incentivando a dar o meu melhor.

À Maria Fernanda Giannini e à Aurore Regaudie-de-Gioux pela disponibilização de dados e auxílio no tratamento e interpretação dos mesmos.

À banca da defesa, prof $^{a}$ dra. Estela Maria Plastino e prof $^{a}$ dra. Mariana Guenther, obrigada pelos comentários preciosos para aprimorar este trabalho.

Aos técnicos Zeilto (Zé), Eduardo, Alex e Jerônimo por todo o suporte durante as coletas e utilização dos laboratórios. Em especial ao Zé, pela dedicação, momentos de alegria e conhecimento transmitidos ao longo de toda a pesquisa.

Ao Sistema de Monitoramento de Costa brasileira (SIMCosta) pela disponibilização dos dados da boia meteo-oceanográfica e pelo suporte técnico. Em especial as técnicas do projeto, Stella Coelho e Raquel Renó, que não só me ajudaram nas coletas e análises de dados, mas que se tornaram grandes amigas.

Aos exemplos de sabedoria e força feminina das alunas do CEBIMar, pela amizade, risadas, confiança e aprendizado: Stella, Aline, Carla P., Carla K., Ewa, Inês, Karine, Andréia, Claudia, Juliana, Leilaine, Isabela, Laiza e Raquel.

Aos amigos, que mesmo distantes continuam me incentivando: Micael, Ana Caroline, Daniel, Rafaela, Anthea, Julia e Marina. Em especial ao Micael, pelo suporte infinito a cada momento.

À minha família, pelo carinho e incentivo pelas escolhas pouco comuns que fiz. 
Ao meu irmão, que me deu de presente os maiores amores da minha vida, Lucca e Miguel, além do melhor presente de grego, a Moa.

Por fim, aos meus pais, Renata e Osmar, pelo amor imensurável, confiança, incentivo, dedicação e força. Vocês são a minha base, obrigada por tudo. 


\section{RESUMO}

OBATA, C. S. S. Comparação entre estimativas de taxas de produção primária no canal de São Sebastião e a influência das condições oceanográficas. 2019. 98f. Dissertação (Mestrado) - Instituto Oceanográfico, Universidade de São Paulo, São Paulo, 2019.

A importância de estudos sobre a produção primária (PP) marinha é consenso devido ao seu papel no ciclo do carbono global. Técnicas rápidas e não invasivas para medição de taxas de PP foram desenvolvidas nas últimas décadas para melhorar a resolução espacial e temporal das aquisições de dados, além de suprir as desvantagens e lacunas deixadas pelos métodos clássicos que envolvem a incubação de amostras. Os objetivos deste trabalho são: (1) comparar duas técnicas mais novas, a Bio-óptica (PPabs) e a Fluorescência Ativa Variável (PPFire), com o método clássico de evolução de oxigênio pelo metabolismo da comunidade planctônica que estima a PP bruta (PPB), (2) e determinar a influência de variáveis oceanográficas e como elas podem predizer a PP no canal de São Sebastião ao longo de diferentes períodos amostrais (verões de 2014, 2016 e 2018, inverno de 2014 e primavera de 2015). A PPB variou entre 47,55 e 341,94 $\mathrm{mg} \mathrm{C} \mathrm{m}^{-3} \mathrm{~d}^{-1}$, a PPabs entre 73,7 \pm 6,9 e 454,9 $\pm 25,8 \mathrm{mg} \mathrm{C} \mathrm{m}^{-3} \mathrm{~d}^{-1}$ e a PPFire entre 9,0 e $57,8 \mathrm{mg} \mathrm{C} \mathrm{m}^{-3} \mathrm{~d}^{-1}$ no verão de 2018. As relações entre os métodos foram significativas (PPB vs PPabs, $\mathrm{p}=0,007$, PPB vs PPFire, $\mathrm{p}=0,01$ e PPabs vs PPFire, $\mathrm{p}=0,01)$. A partir de uma regressão linear múltipla, vimos que a PPB $(\mathrm{p}=0,003)$ e PPFire $(\mathrm{p}<0,001)$ foram previstas pela temperatura e pela concentração da clorofila-a, já a PPabs $(\mathrm{p}=0,007)$ pelas duas variáveis adicionadas a salinidade. Esses resultados indicam que apesar dos métodos apresentarem magnitudes diferentes, informações adicionais sobre o ambiente são incorporadas por cada técnica. A PPB acrescenta informações quanto a comunidade planctônica como um todo, a PPabs sobre a composição pigmentar e de tamanhos de espécies e a PPFire sobre a fotofisiologia das células fitoplanctônicas. Quanto às condições oceanográficas, as relações com a temperatura e a salinidade indicam que os métodos são sensíveis a alteração de massas d'água, como a Água Central do Atlântico Sul (ACAS), bem como a entrada de aporte continental por plumas de rios, que são responsáveis pela disponibilidade de luz e nutrientes que afetam a PP no canal. Concluindo, os métodos são complementares e podem variar de diferentes formas conforme a dinâmica local, no entanto, são significativamente proporcionais uns aos outros, o que indica a robustez entre as medidas das duas técnicas mais novas aqui comparadas.

Palavras-chave: Metabolismo planctônico. Oceanografia bio-óptica. Fluorescência ativa variável. Fitoplâncton. 


\section{ABSTRACT}

OBATA, C. S. S. Comparing estimates of primary production rates in the São Sebastião channel and the oceanographic condition influence. 2019. 98f. Dissertação (Mestrado) Instituto Oceanográfico, Universidade de São Paulo, São Paulo, 2019.

There is a consensus of the importance of primary production (PP) studies due to its role on the global carbon cycle. Fast and non-invasive techniques to measure rates of PP were developed in the last few decades to improve temporal and spatial data acquisition, and to overcome disadvantages and gaps associated with classical methods using incubation of samples. The aim of this work are: (1) compare two newer techniques, Bio-optical (PPabs) and Active Variable Fluorescence (PPFire), to the classical method involving oxygen evolution by the planktonic community metabolism (PPB), and (2) determine the influence of oceanographic variables and investigate how they could predict PP in the São Sebastião channel. PPB varied between 47.55 and $341.94 \mathrm{mg} \mathrm{C} \mathrm{m}^{-3} \mathrm{~d}^{-1}$, PPabs between $73.7 \pm 6.9$ and $454.9 \pm 25.8 \mathrm{mg} \mathrm{C} \mathrm{m}^{-3}$ $\mathrm{d}^{-1}$ and PPFire between 9.0 and $57.8 \mathrm{mg} \mathrm{C} \mathrm{m}^{-3} \mathrm{~d}^{-1}$ in the summer of 2018. The relationships between methods were significant (PPB $v s$ PPabs, $\mathrm{p}=0.007$, PPB $v s$ PPFire, $\mathrm{p}=0.01$ and PPabs $v s$ PPFire, $\mathrm{p}=0.01)$. After a multiple linear regression test, we found that PPB $(\mathrm{p}=0.003)$ and PPFire ( $\mathrm{p}<0.001$ ) were predicted by temperature and chlorophyll-a concentration, however, PPabs ( $\mathrm{p}=0.007)$ was also predicted by salinity. These results indicate that despite the methods show different magnitudes, each one includes different information about the environment. The PPB adds overall information about the planktonic community, while the PPabs adds pigment composition and species size and the PPFire adds phytoplankton cell photophysiology. We found correlations with the different PPs and temperature and salinity indicating that the three methods are sensitive to water mass changes, as the South Atlantic Central Water (SACW) and the intrusion of river plumes in the channel, both responsible for light and nutrients availability. In conclusion, the three methods are complementary and could vary in different ways due to local dynamics. However, they are proportional to each other, showing strength to the use of the two newest techniques (PPabs and PPFire).

Keywords: Planktonic metabolism. Bio-optical oceanography. Active variable fluorescence. Phytoplankton. 
"Tenho a impressão de ter sido somente um garoto brincando e me divertindo na praia, encontrando, de vez em quando, um seixo mais liso ou uma concha mais bonita que o normal, enquanto que o grande oceano da verdade permanece todo desconhecido diante de mim"- 


\section{LISTA DE FIGURAS}

Figura 1. Mapa de localização da boia meteo-oceanográfica do Sistema de Monitoramento da Costa Brasileira (Boia-SP01, SIMCosta), localizada a cerca de 300 metros do Centro de Biologia Marinha da Universidade de São Paulo (CEBIMar/USP) e da estação meteorológica do CEBIMar, localizada na Ponta do Baleeiro, a 18 metros de altitude. 36

Figura 2. Procedimentos de titulação pelo método Winkler para determinação da concentração de oxigênio e conversão em Taxas Metabólicas. Sendo R1 é o primeiro reagente Hidróxido de Manganês $\left(\mathrm{MnSO}_{4}\right)$; R2 é o segundo reagente Iodeto de Potássio; R3, o terceiro reagente Ácido Sulfúrico $\left(\mathrm{HSO}_{4}\right) ;\left[\mathrm{O}_{2}\right]$ é a concentração de oxigênio; PPL a produção primária líquida; RC a respiração da comunidade, e; PPB a produtividade primária bruta. 40

Figura 3. Procedimento de leitura das amostras submetidas ao FIRe (Fluorescence Induction and Relaxation System) e ao processamento de dados pelo programa fireworx, que resultam nos parâmetros fotofisiológicos $\left(\mathrm{F}_{0}, \mathrm{~F}_{\mathrm{m}}, \sigma_{\mathrm{PSII}}\right.$ e $\left.\mathrm{F}_{\mathrm{v}} / \mathrm{F}_{\mathrm{m}}\right)$ necessários para calcular a produção primária de acordo com Giannini \& Ciotti (2016). Onde $F_{0}$ e $F_{m}$ as fluorescências (em URF) mínimas e máximas adaptadas ao escuro, $\mathrm{F}_{0}$ ' e $\mathrm{F}_{\mathrm{m}}$ ' sob luz modulada; $\tau$ (em segundos) o tempo de virada da transferência de elétrons; E a irradiância (em $\mu$ mol fótons $\mathrm{m}^{-2}$ ); ALS é a luz actínica; qP o "quenching” fotoquímico; NPQ o "quenching” fotoquímico; $\sigma_{P S I I}$ é a área efetiva de absorção de luz pelo fotossistema II (em $\AA^{2}$ fóton $\left.{ }^{-1}\right) ; F_{v} / F_{m}$ é a eficiência fotoquímica máxima (adimensional), e; F é a fluorescência (em URF). 42

Figura 4. Séries temporais da irradiância $\left(\mathrm{W} \mathrm{m}^{-2}\right)$ medida pela estação meteorológica do

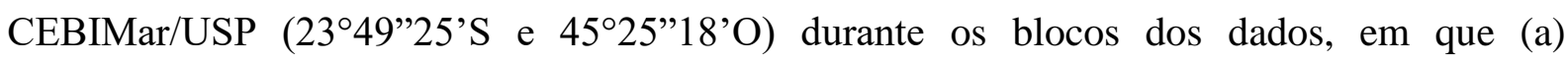
corresponde à B2.1 ou período entre outubro e dezembro de 2015, (b) B2.2 ou janeiro a março de 2016, e (c) B3 ou janeiro a março de 2018. Os triângulos indicam os dias em que foram realizados os experimentos de produção primária e coleta de outras variáveis. 48

Figura 5. Séries temporais da temperatura atmosférica $\left({ }^{\circ} \mathrm{C}\right)$ medida pela estação meteorológica do CEBIMar/USP (2349”25'S e 45²5”18'O) durante os blocos dos dados, em que (a) corresponde à B2.1 ou período entre outubro e dezembro de 2015, (b) B2.2 ou janeiro a março de 2016, e (c) B3 ou janeiro a março de 2018. Os triângulos indicam os dias em que foram realizados os experimentos de produção primária e coleta de outras variáveis... 49

Figura 6. Séries temporais da velocidade do vento $\left(\mathrm{km} \cdot \mathrm{h}^{-1}\right)$ medida pela estação

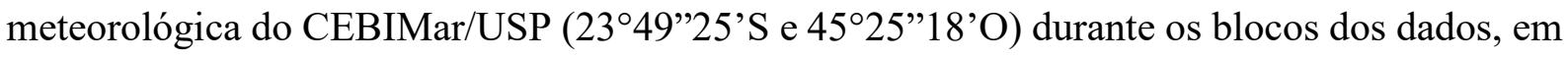
que (a) corresponde à B2.1 ou período entre outubro e dezembro de 2015, (b) B2.2 ou janeiro 
a março de 2016, e (c) B3 ou janeiro a março de 2018. Os triângulos indicam os dias em que foram realizados os experimentos de produção primária e coleta de outras variáveis... 50

Figura 7. Séries temporais de taxa instantânea de precipitação $(\mathrm{mm})$ medida pela estação meteorológica do CEBIMar/USP (2349”25’ S e 45²5”18' O) durante os blocos dos dados, em que (a) corresponde à B2.1 ou período entre outubro e dezembro de 2015, b) B2.2 ou janeiro a março de 2016, e (c) B3 ou janeiro a março de 2018. Os triângulos indicam os dias em que foram realizados os experimentos de produção primária e coleta de outras variáveis... 51

Figura 8. Variação dos valores registrados pela estação meteorológica do CEBIMar/USP

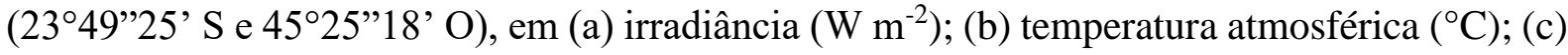
velocidade do vento $\left(\mathrm{km} \mathrm{h}^{-1}\right)$, e; (d) volume de chuva - note dados em escala logarítmica para melhor visualização (mm), nos blocos B2.1 (outubro a dezembro de 2015), B2.2 (janeiro a março de 2016) e B3 (janeiro a março de 2018).

Figura 9. Séries temporais da temperatura da água $\left({ }^{\circ} \mathrm{C}\right)$ medida por sensores instalados a 0,6 metros de profundidade na boia meteo-oceanográfica SP01 do projeto SIMCosta, em que (a) corresponde à B2.1 ou período entre outubro e dezembro de 2015, (b) B2.2 ou janeiro a março de 2016, e (c) B3 ou janeiro a março de 2018. Os triângulos indicam os dias em que foram realizadas as campanhas para medição da produção primária e coleta de outras variáveis. Lacunas de dados são referentes a períodos de manutenção dos sensores. 54

Figura 10. Séries temporais da salinidade medida por sensores instalados a 0,6 metros de profundidade na boia meteo-oceanográfica SP01 do projeto SIMCosta, em que (a) corresponde à B2.1 ou período entre outubro e dezembro de 2015, (b) B2.2 ou janeiro a março de 2016, e (c) B3 ou janeiro a março de 2018. Os triângulos indicam os dias em que foram realizadas as campanhas para medição da produção primária e coleta de outras variáveis. Lacunas de dados são referentes a períodos de manutenção dos sensores. Para melhor visualização das séries, limite mínimo de salinidade 25 foi empregado, no entanto, foi registrado 1 valor inferior em B3 $(\sim 16)$ no dia 15 de fevereiro. 55

Figura 11. Séries temporais da turbidez da água (NTU) medida por sensores instalados a 0,6 metros de profundidade na boia meteo-oceanográfica SP01 do projeto SIMCosta, em que (a) corresponde à B2.1 ou período entre outubro e dezembro de 2015, (b) B2.2 ou janeiro a março de 2016, e (c) B3 ou janeiro a março de 2018. Os triângulos indicam os dias em que foram realizadas as campanhas para medição da produção primária e coleta de outras variáveis. Lacunas de dados são referentes a períodos de manutenção dos sensores. Para melhor visualização das séries, limite máximo de 15 NTU foi empregado, no entanto, foram registrados 
25 valores em B2.1 (nos dias 13 e 18 de outubro e 6, 7, 8 12, 13, 14 e 21 de dezembro) e 1 valor superior em B3 (no dia 15 de fevereiro). 56

Figura 12. Séries temporais da fluorescência da clorofila-a (URF) medida por sensores instalados a 0,6 metros de profundidade na boia meteo-oceanográfica SP01 do projeto SIMCosta, em que (a) corresponde à B2.1 ou período entre outubro e dezembro de 2015, (b) B2.2 ou janeiro a março de 2016, e (c) B3 ou janeiro a março de 2018. Os triângulos indicam os dias em que foram realizadas as campanhas para medição da produção primária e coleta de outras variáveis. Lacunas de dados são referentes a períodos de manutenção dos sensores. Para melhor visualização das séries, limite máximo de 4 URF foi empregado, no entanto, foram registrados 4 valores superiores em B3, nos dias 1, 2, 4 e 21 de fevereiro. 57

Figura 13. Variação dos dados oceanográficos registrados pela boia meteo-oceanográfica do SIMCosta, em (a) temperatura da água $\left({ }^{\circ} \mathrm{C}\right)$; (b) salinidade; (c) fluorescência da clorofila-a (URF), e; (d) turbidez (NTU), nos blocos B2.1 (outubro a dezembro de 2015), B2.2 (janeiro a março de 2016) e B2 (janeiro a março de 2018). Valores inferior a 25 de salinidade ( $\mathrm{n}=6 \mathrm{em}$ B3), 15 NTU ( $n=25$ em B2.1 e $n=1$ em B3) e 4 URF ( $n=4$ em B3) foram ocultados para melhor visualização dos dados 58

Figura 14. Séries temporais da temperatura $\left({ }^{\circ} \mathrm{C}\right)$ na coluna d'água medido por um CTD (“conductivity, temperature, depth"), em que (a) corresponde à B2.1 ou período entre outubro e dezembro de 2015, (b) B2.2 ou janeiro a março de 2016, e (c) B3 ou janeiro a março de 2018. Os pontos vermelhos indicam os dias em que foram realizadas as campanhas para medição da produção primária e coleta de outras variáveis. As seções representam perfis verticais de CTD semanais no sitio de coleta (Ver sessão 4.5.1 para mais detalhes).

Figura 15. Séries temporais da salinidade na coluna d'água medido por um CTD (“conductivity, temperature, depth”), em que (a) corresponde à B2.1 ou período entre outubro e dezembro de 2015, (b) B2.2 ou janeiro a março de 2016, e (c) B3 ou janeiro a março de 2018. Os pontos vermelhos indicam os dias em que foram realizadas as campanhas para medição da produção primária e coleta de outras variáveis. As seções representam perfis verticais de CTD semanais no sitio de coleta (Ver sessão 4.5.1 para mais detalhes).

Figura 16. Séries temporais da turbidez (NTU - da sigla em inglês unidade nefelométrica de turbidez) na coluna d'água medido por um CTD (“conductivity, temperature, depth”), em que (a) corresponde à B2.1 ou período entre outubro e dezembro de 2015, (b) B2.2 ou janeiro a março de 2016, e (c) B3 ou janeiro a março de 2018. Os pontos vermelhos indicam os dias em que foram realizadas as campanhas para medição da produção primária e coleta de outras 
variáveis. As seções representam perfis verticais de CTD semanais no sitio de coleta (Ver sessão 4.5.1 para mais detalhes).

Figura 17. Séries temporais da fluorescência da clorofila-a (URF - unidade relativa de fluorescência) na coluna d'água medido por um CTD (“conductivity, temperature, depth”), em que (a) corresponde à B2.1 ou período entre outubro e dezembro de 2015, (b) B2.2 ou janeiro a março de 2016, e (c) B3 ou janeiro a março de 2018. Os pontos vermelhos indicam os dias em que foram realizadas as campanhas para medição da produção primária e coleta de outras variáveis. As seções representam perfis verticais de CTD semanais no sitio de coleta (Ver sessão 4.5.1 para mais detalhes).

Figura 18. Variação dos valores coletados in situ, em (a) concentração de clorofila-a (mg $\mathrm{m}^{-3}$ ); (b) profundidade de desaparecimento Disco de Secchi (m), nos blocos B2.1 (outubro a dezembro de 2015), B2.2 (janeiro a março de 2016) e B3 (janeiro a março de 2018). . 62

Figura 19. Relação entre a concentração de clorofila-a $\left(\mathrm{mg} \mathrm{m}^{-3}\right)$ e a profundidade de desaparecimento do disco de Secchi $(\mathrm{m})$, os coeficientes de determinação $\left(\mathrm{R}^{2}\right)$ são provenientes de ajustes lineares. Os pontos cinzas são referentes aos dados obtidos por Peres (2013) no canal de São Sebastião.

Figura 20. Variação da produtividade primária líquida da comunidade (PPL), da respiração da comunidade (RC) e da produção primária bruta (PPB) em $\mathrm{mg} \mathrm{C} \mathrm{m}^{-3} \mathrm{~d}^{-1} \mathrm{em} \mathrm{B} 3$ (janeiro a março de 2018).

Figura 21. Relação entre a respiração da comunidade (RC-pontos rosas) e (a) temperatura $\left({ }^{\circ} \mathrm{C}\right)$; (b) salinidade; (c) concentração da clorofila-a $\left(\mathrm{mg} \mathrm{m}^{-3}\right)$, e; (d) profundidade do disco de Secchi (metros) em B3 (janeiro a março de 2018). Os pontos pretos são as RC em B2.1 (pontos vazados, período correspondente a primavera de 2015) e B2.1 (pontos maciços, período correspondente ao verão de 2016) apresentados por Regaudie-de-Gioux et al. (2018). 64

Figura 22. Relação entre a produtividade primária líquida (PPL) da comunidade e: (a) temperatura $\left({ }^{\circ} \mathrm{C}\right)$; (b) salinidade; (c) concentração da clorofila-a $\left(\mathrm{mg} \mathrm{m}^{-3}\right)$, e; (d) profundidade do disco de Secchi (metros) em B3 (pontos rosas, correspondentes ao período de janeiro a março de 2018). Os triângulos rosas são referentes à produção primária bruta (PPB) em B3. Os pontos pretos são as PPL em B2.1 (pontos vazados, período correspondente à primavera de 2015) e B2.1 (pontos maciços, período correspondente ao verão de 2016) apresentados por Regaudiede-Gioux et al. (2018). Os $\mathrm{R}^{2}$ são resultantes de ajustes lineares e são estatisticamente significativos $(\mathrm{p}<0,05)$. 
Figura 23. Réplicas das curvas do coeficiente de absorção espectral da luz pelo fitoplâncton $\left(a_{\mathrm{ph}} \mathrm{em} \mathrm{m}^{-1}\right)$ das campanhas realizadas no verão de 2018.

Figura 24. Réplicas das curvas do coeficiente de absorção espectral da luz pelo fitoplâncton $\left(a_{\mathrm{ph}} \mathrm{em} \mathrm{m}^{-1}\right)$ normalizado pelo coeficiente médio calculado na faixa no visível do espectro eletromagnético $\left(\left\langle\mathrm{a}_{\mathrm{ph}}\right\rangle\right)$ das campanhas realizadas no verão de 2018.

Figura 25. Réplicas das curvas do coeficiente de absorção espectral da luz pelo fitoplâncton $\left(a_{\text {ph }}\right.$ em $\left.\mathrm{m}^{-1}\right)$ normalizado pela concentração de clorofila-a $\left(\mathrm{a}_{\mathrm{ph}} * \mathrm{em} \mathrm{mg}^{-1} \mathrm{~m}^{2}\right)$ das campanhas realizadas no verão de 2018 .

Figura 26. Comparação entre (a) concentração de clorofila-a ([chl] em $\mathrm{mg} \mathrm{m}^{-3}$ ) e o coeficiente de absorção espectral de luz pelo fitoplâncton $\left(a_{\mathrm{ph}}\right)$ em $676 \mathrm{~nm}\left(\mathrm{a}_{\mathrm{ph}}(676) \mathrm{em} \mathrm{m}^{-1}\right)$; (b) a [chl] e o aph em $440 \mathrm{~nm}\left(\mathrm{a}_{\mathrm{ph}}(440) \mathrm{em} \mathrm{m}^{-1}\right)$; (c) a [chl] e o aph em $443 \mathrm{~nm}\left(\mathrm{a}_{\mathrm{ph}}(443) \mathrm{em} \mathrm{m}^{-}\right.$ $\left.{ }^{1}\right)$, e; (d) $a_{p h}(443)$ e o coeficiente de absorção espectral de luz pelos detritos em $443 \mathrm{~nm}\left(\mathrm{a}_{\mathrm{d}}(443)\right.$ $\mathrm{em} \mathrm{m}^{-1}$ ), em B1.1, B1.2 e B3. As linhas tracejadas cinzas em (a) e (c) indicam as equações para os comprimentos de ondas obtidos por Bricaud et al. (1995) e Bricaud et al. (2004), respectivamente. A linha preta contínua indica a regressão linear para todos os blocos.68

Figura 27. Produção primária (em $\mathrm{mg} \mathrm{C} \mathrm{m}^{-3} \mathrm{~d}^{-1}$ ) pelo método bio-óptico (PPabs) em B3 (janeiro a março de 2018). Vale ressaltar que dos 15 experimentos realizados, apenas 10 foram considerados devido à perda de material.

Figura 28. Variação dos parâmetros fotofisiológicos, em (a) a eficiência fotoquímica máxima $\left(\mathrm{F}_{\mathrm{v}} / \mathrm{F}_{\mathrm{m}}\right.$ - admensional); (b) área efetiva de absorção de luz pelo fotossistema II ( $\sigma_{\mathrm{PSII}}-$ $\AA^{2}$ fóton $^{-1}$ ), nos blocos B2.1 (outubro a dezembro de 2015), B2.2 (janeiro a março de 2016) e B3 (janeiro a março de 2018). 70

Figura 29. Variação temporal das tréplicas de rendimento mínimo de fluorescência $\left(F_{0}\right.$ URF) durante B3 (janeiro a março de 2018). 71

Figura 30. Variação temporal das tréplicas de rendimento máximo de fluorescência $\left(\mathrm{F}_{\mathrm{m}}\right.$ URF) durante B3 (janeiro a março de 2018). 72

Figura 31. Variação temporal das tréplicas da área efetiva de absorção de luz pelo fotossistema II ( $\sigma_{\text {PSII }}-\AA^{2}$ fóton $^{-1}$ ) durante B3 (janeiro a março de 2018). 72

Figura 32. Variação temporal da soma dos resíduos quadráticos (SRQ) para os três modelos de curvas fotossíntese vs. irradiância (P-E), sendo EP, modelo de Eilers \& Peeters (1988); JP, Jassby \& Platt (1976), e; PHG, Platt et al. (1980) em B3 (janeiro a março de 2018).... 73

Figura 33. Produção primária ( $\mathrm{PP}$ em $\mathrm{mg} \mathrm{C} \mathrm{m}^{-3} \mathrm{~d}^{-1}$ ) pelo método de fluorescência ativa variável (PPFire) em B3 (janeiro a março de 2018). Vale ressaltar que as tréplicas dos 
parâmetros fotofisiológicos utilizados para calcular a PP foram utilizadas para estimar um único ajuste de curva, desta forma, não há desvio padrão de PP.

Figura 34. Exemplos de variabilidade do coeficiente de atenuação vertical da luz difusa $\left(\mathrm{K}_{\mathrm{d}}\right.$, $\mathrm{m}^{-1}$ ) durante dois períodos de 24 horas de incubação durante o verão de 2018. 74

Figura 35. Exemplos de variação das curvas P-E (produção primária vs. irradiância) antes e após a incubação em 16 de janeiro de 2018, em que os valores entre as réplicas parecem divergir; em 6 de fevereiro de 2018, em que apresenta pouca variação entre a PP por réplicas e entre os dias; e em 19 de março de 2018, que aparenta clara diferença entre os dias de coleta.

Figura 36. Relação entre estimativas de produção primária pelos métodos de metabolismo planctônico, pela produção primária bruta (PPB) e bio-óptico (PPabs). O $\mathrm{R}^{2}$ é proveniente de ajuste linear entre as produções com $p=0,007)$. 78

Figura 37. Relação entre estimativas de produção primária pelos métodos de metabolismo planctônico, pela produção primária bruta (PPB) e por fluorescência ativa variável (PPFire). O $\mathrm{R}^{2}$ é proveniente de ajuste linear entre as produções com $\left.\mathrm{p}=0,01\right)$. 78

Figura 38. Relação entre estimativas de produção primária pelos métodos de fluorescência ativa variável (PPFire) e bio-óptico (PPabs). O $\mathrm{R}^{2}$ é proveniente de ajuste linear entre as produções com $\mathrm{p}=0,01$ para todos os blocos, $\mathrm{p}=0,008, \mathrm{p}=0,02 \mathrm{e} \mathrm{p}=0,02$ para B1.1, B1.2 e B3, respectivamente). 79

Figura 39. Relação entre a produção primária bruta (PPB em $\left.\mathrm{mg} \mathrm{C} \mathrm{m}^{-3} \mathrm{~d}^{-1}\right)$ e (a) temperatura em ${ }^{\circ} \mathrm{C}$, (b) salinidade, (c) concentração de clorofila-a em $\mathrm{mg} \mathrm{m}^{-3} \mathrm{e}$ (d) profundidade do disco de Secchi em metros. As cores indicam os blocos de dados sendo B1.1 correspondente a janeiro a março de 2014; B1.2 de maio a agosto de 2014; B2.1 de outubro a dezembro de 2015; B2.2 de janeiro a março de 2016; B3 de janeiro a março de 2018 81

Figura 40. Relação entre a produção primária estimada pelo método bio-óptico (PPabs em $\mathrm{mg} \mathrm{C} \mathrm{m}{ }^{-3} \mathrm{~d}^{-1}$ ) e (a) temperatura em ${ }^{\circ} \mathrm{C}$, (b) salinidade, (c) concentração de clorofila-a em mg.m ${ }^{3}$ e (d) profundidade do disco de Secchi em metros. As cores indicam os blocos de dados sendo B1.1 correspondente a janeiro a março de 2014; B1.2 de maio a agosto de 2014; B2.1 de outubro a dezembro de 2015; B2.2 de janeiro a março de 2016; B3 de janeiro a março de 2018.82

Figura 41. Relação entre a produção primária estimada pelo método de fluorescência ativa variável (PPFire em $\mathrm{mg} \mathrm{C} \mathrm{m}^{-3} \mathrm{~d}^{-1}$ ) e (a) temperatura em ${ }^{\circ} \mathrm{C}$, (b) salinidade, (c) concentração de clorofila-a em $\mathrm{mg} \mathrm{m}^{-3}$ e (d) profundidade do disco de Secchi em metros. As cores indicam os blocos de dados sendo B1.1 correspondente a janeiro a março de 2014; B1.2 de maio a agosto 
de 2014; B2.1 de outubro a dezembro de 2015; B2.2 de janeiro a março de 2016; B3 de janeiro a março de 2018... 


\section{LISTA DE TABELAS}

Tabela 1. Valores de produção primária (PP) com diferentes métodos em diversas áreas costeiras sob a influência processos oceanográficos variados. Note que as unidades de PP não são as mesmas, uma vez que cada estudo optou por taxas diárias ou anuais de PP. 31

Tabela 2. Valores (mínimos, máximos, média e desvio padrão - DP) das variáveis obtidas

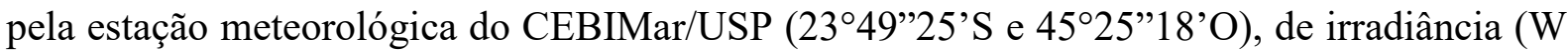
$\left.\mathrm{m}^{-2}\right)$, temperatura atmosférica $\left({ }^{\circ} \mathrm{C}\right)$, velocidade do vento $\left(\mathrm{km} \mathrm{h}^{-1}\right)$ e o volume de chuva $(\mathrm{mm})$ durante os 3 blocos de dados. Note que o volume de chuva representa taxas instantâneas.

Tabela 3. Valores (mínimos, máximos, médias e desvios padrão - DP) das variáveis obtidas pela boia meteo-oceanográfica do SIMCosta em 1 metro de profundidade, da temperatura $\left({ }^{\circ} \mathrm{C}\right)$, salinidade, turbidez (NTU) e a fluorescência da clorofila-a (URF) para cada bloco de dados (ver períodos correspondentes no texto e na Tabela 2).

Tabela 4. Valores (mínimos, máximos, média, desvio padrão - DP e o número de amostras) dos parâmetros fotofisiológicos eficiência fotoquímica máxima $\left(\mathrm{F}_{\mathrm{v}} / \mathrm{F}_{\mathrm{m}}\right.$ - adimensional $)$ e área efetiva de absorção de luz pelo fotossistema II $\left(\sigma_{P S I I}-\AA^{2}\right.$ fóton $\left.^{-1}\right)$. 70

Tabela 5. Valores (máximos, mínimos, médias e desvios padrões - DP) do coeficiente de atenuação vertical da luz difusa $\left(\mathrm{K}_{\mathrm{d}} \mathrm{em} \mathrm{m}^{-1}\right)$ durante o período de incubação de 24 horas em B3. Em 23 de janeiro, foi retirado um valor extremo de $0,83 \mathrm{~m}^{-1}$ devido a incoerência com os outros valores registrados.

Tabela 6. Média dos parâmetros fotofisiológicos fluorescência mínima ( $\left.F_{0}-U R F\right)$, área efetiva de absorção de luz do fotossistema II ( $\sigma$ PSII $-\AA^{2}$ fóton $\left.^{-1}\right)$, a eficiência fotoquímica máxima ( $F_{v} / F_{m}$ - adimensional) e a variação da fluorescência da clorofila-a (FLU em URF), da temperatura $\left(\mathrm{T} \mathrm{em}{ }^{\circ} \mathrm{C}\right)$ e profundidade do disco de Secchi (Sec em m) após incubação por 24 horas, durante experimento simultâneo de Taxas Metabólicas. Note que $\mathrm{T}_{0}$ é o tempo inicial, e $\mathrm{T}_{24}$ é a medida realizada após às 24 horas de incubação. Destaca-se que os experimentos ocorreram apenas no ano de 2018. 75

Tabela 7. Variação entre o início $\left(\mathrm{T}_{0}\right)$ e o final do período de incubação de 24 horas $\left(\mathrm{T}_{24}\right)$ da inclinação inicial da curva $\left(\alpha, \mathrm{mg} \mathrm{C}[\mathrm{chl}]^{-1} \mathrm{~h}^{-1}\right.$ mol quanta $\left.\mathrm{m}^{-2} \mathrm{~s}^{-1}\right)$ e a magnitude da irradiância de saturação $\left(E_{k}\right.$, mol quanta $\left.\mathrm{m}^{-2} \mathrm{~s}^{-1}\right)$. Destaca-se que os experimentos ocorreram apenas no ano de 2018. 76

Tabela 8. Modelos preditivos para cada método de produção primária, onde $\mathrm{T}$ é a temperatura, $\mathrm{S}$ a salinidade, $\mathrm{K}_{\mathrm{d}} \mathrm{o}$ coeficiente de atenuação vertical da luz difusa, [chl] a 
concentração de clorofila-a, para todos os blocos de análise sendo B1.1 correspondente a janeiro a março de 2014; B1.2 de maio a agosto de 2014; B2.1 de outubro a dezembro de 2015; B2.2 de janeiro a março de 2016; B3 de janeiro a março de 2018. Todos* refere-se aos períodos de primavera e verão, ou seja, B1.1 e B3 80 


\section{LISTA DE ABREVIATURAS E SIGLAS}

AC Água Costeira

ACAS Água Central do Atlântico Sul

AT Água Tropical

B1.1 Bloco de dados correspondente a janeiro a março de 2014 (verão)

B1.2 Bloco de dados correspondente a maio a agosto de 2014 (outono/inverno)

B2.1 Bloco de dados correspondente a outubro a dezembro de 2015 (primavera)

B2.2 Bloco de dados correspondente a janeiro a março de 2016 (verão)

B3 Bloco de dados correspondente a janeiro a março de 2018 (verão)

CB Corrente do Brasil

CDOM da sigla em inglês "Colored dissolved organic matter"

CEBIMar Centro de Biologia Marinha da Universidade de São Paulo

CSS Canal de São Sebastião

CTD da sigla em inglês "Conductivity, Temperature and, Salinity"

DBO Demanda Biológica de Oxigênio

EP modelo de P-E definido por Eileers \& Peeters (1988)

FIRe "Fluorescence Induction and Relaxation System"

GF/F da sigla em inglês "Glass Filter Fibers"

IOUSP Instituto Oceanográfico da Universidade de São Paulo

JP modelo de P-E definido por Jassby \& Platt (1976)

ODV da sigla em inglês "Ocean Data View"

PCSE Plataforma Continental Sudeste

PGH modelo de P-E definido por Platt et al. (1981) 
PP Produção Primária

PPB Produção Primária Bruta

PPL Produção Primária Líquida

P-E Modelo proveniente da relação entre a produção e a irradiância

RC Respiração da Comunidade

SIMCosta Sistema de Monitoramento da Costa Brasileira

TR Método de Transmitância e Reflectância

URF Unidade Relativa de Fluorescência 


\section{LISTA DE SÍMBOLOS}

[chl] Concentração de clorofila-a em $\mathrm{mg} \mathrm{m}^{-3}$

acDOM Coeficiente de absorção espectral pelo CDOM em $\mathrm{m}^{-1}$

$\mathrm{a}_{\mathrm{d}} \quad$ Coeficiente de absorção espectral pelos detritos em $\mathrm{m}^{-1}$

aNAP Coeficiente de absorção espectral pelo material particulado total $\mathrm{em} \mathrm{m}^{-1}$

$a_{\mathrm{ph}} \quad$ Coeficiente de absorção espectral pelo fitoplâncton em $\mathrm{m}^{-1}$

E Irradiância em $\mathrm{W} \mathrm{m}^{-2}$

$\mathrm{E}_{\mathrm{k}} \quad$ Magnitude da irradiância de saturação em mol quanta $\mathrm{m}^{-2} \mathrm{~s}^{-1}$

ETR Taxa de Transferência de Elétrons

$\mathrm{F}_{0} \quad$ Fluorescência mínima em URF

$F_{m} \quad$ Fluorescência máxima em URF

$\mathrm{K}_{\mathrm{c}} \quad$ Requerimento de elétrons para a fixação de carbono em mol e $\mathrm{e}^{-}[\mathrm{mol} \mathrm{C}]^{-1}$

$\mathrm{K}_{\mathrm{d}} \quad$ Coeficiente de atenuação vertical da luz difusa em $\mathrm{m}^{-1}$

$\alpha \quad$ Inclinação inicial da curva em $\mathrm{mg} \mathrm{C}[\mathrm{chl}]^{-1} \mathrm{~h}^{-1}$ mol quanta $\mathrm{m}^{-2} \mathrm{~s}^{-1}$

$\lambda \quad$ Comprimento de onda em $\mathrm{m}^{-1}$

бPSII área efetiva de absorção de luz pelo fotossistema II em $\AA^{2}$ fóton $^{-1}$ 


\section{SUMÁRIO}

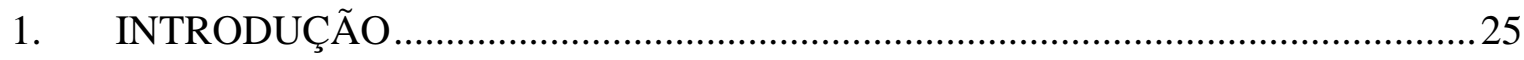

1.1. A dinâmica do fitoplâncton e produção primária em ambientes costeiros ..........25

1.2. Métodos e modelos de produção primária.........................................................28

1.3. Comparação entre métodos de produção primária ............................................29

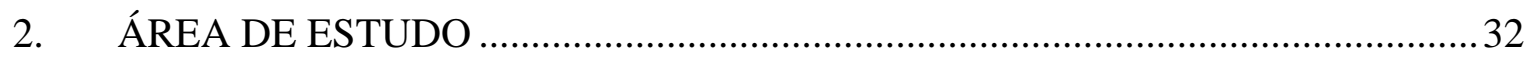

2.1. Oceanografia física no canal de São Sebastião ............................................... 32

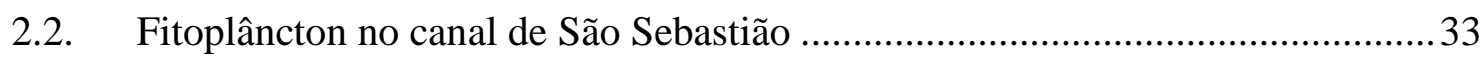

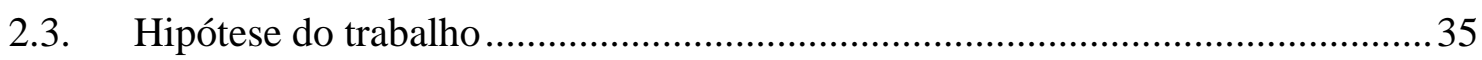

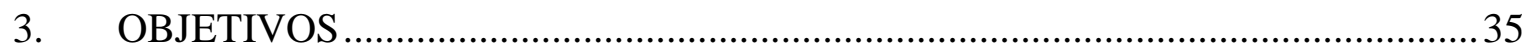

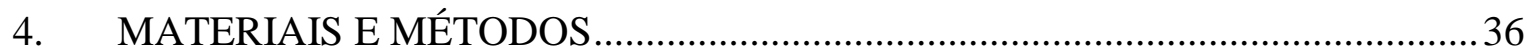

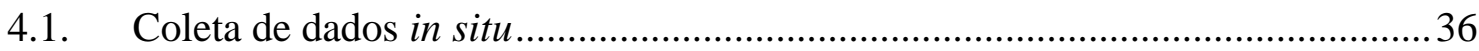

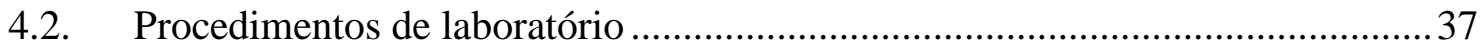

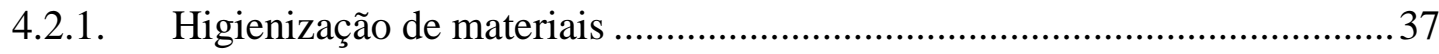

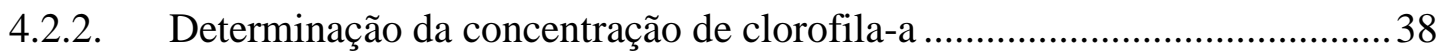

4.2.3. Determinação do coeficiente espectral de absorção de luz pelo fitoplâncton 38

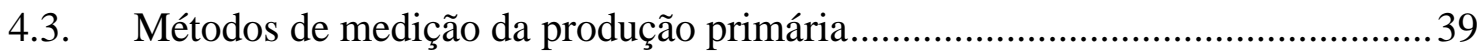

4.3.1. Método por Taxas Metabólicas .................................................................... 39

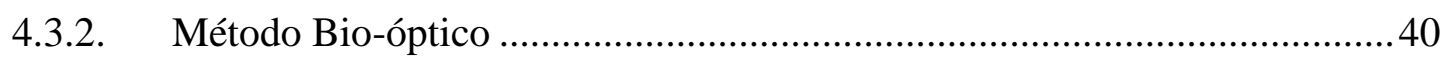

4.3.3. Método de Fluorescência Ativa Variável .................................................. 41

4.4. Resultados em outras bases de dados no canal de São Sebastião...................... 43

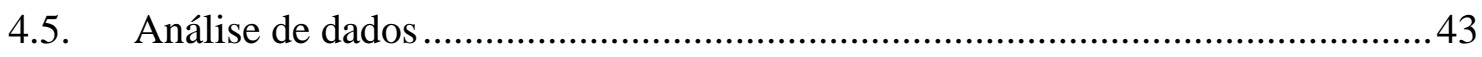

4.5.1. Processamento de dados obtidos pelo CTD .............................................. 43

4.5.2. Processamento e controle de qualidade dos dados oceanográficos medidos

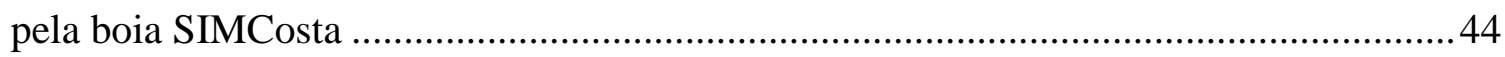


4.5.3. Determinação do coeficiente de atenuação vertical da luz difusa 44

4.5.4. Pré-processamento e controle de qualidade dos dados obtidos pelo FIRe.. 45

4.5.4.1. Teste de incubação dos parâmetros fotofisiológicos 45

4.5.5. Variáveis do modelo Bio-óptico ............................................................ 46

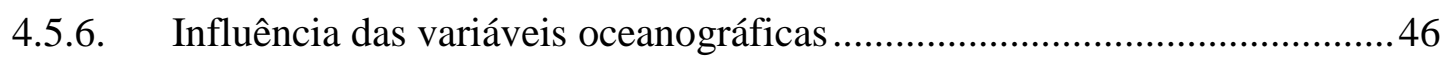

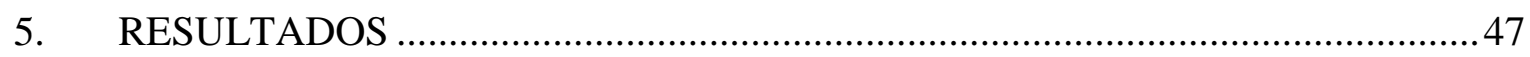

5.1. Variáveis ambientais ao longo do período experimental............................... 47

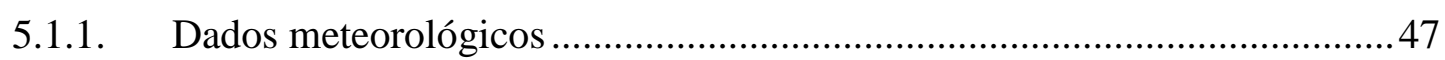

5.1.2. Série temporal dos dados oceanográficos da boia SIMCosta .....................53

5.1.3. Variáveis físico-químicas na coluna d'água.............................................59

5.1.4. Variação da concentração de clorofila-a in situ e a transparência da água. 61

5.2. O balanço metabólico da comunidade planctônica ...........................................63

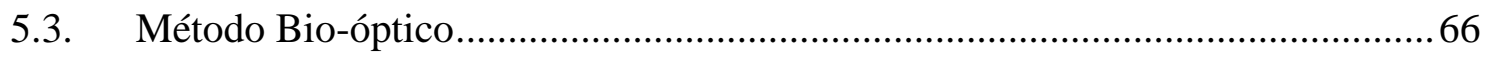

5.3.1. Coeficientes de absorção espectral de luz pelo fitoplâncton e dos detritos 66

5.3.2. Estimativas de produção primária pelo método bio-óptico......................... 69

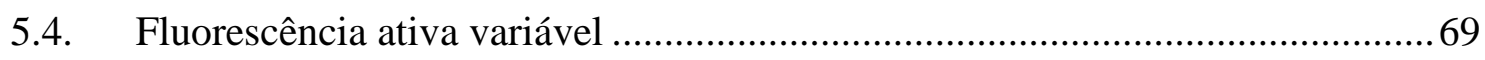

5.4.1. Parâmetros fotofisiológicos no canal de São Sebastião .............................69

5.4.2. Controle de qualidade dos parâmetros fotofisiológicos ............................. 71

5.4.3. Estimativas de produção primária por fluorescência .................................73

5.5. Comparação entre métodos de produção primária .......................................... 74

5.5.1. Alterações dos parâmetros fotofisiológicos em 24 horas............................ 75

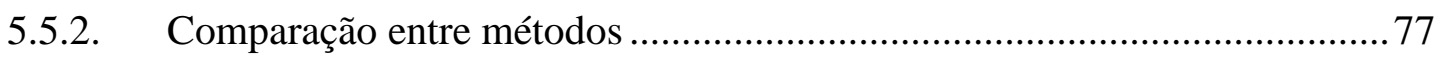

5.6. Forçantes e sua influência nas amplitudes dos métodos.....................................79

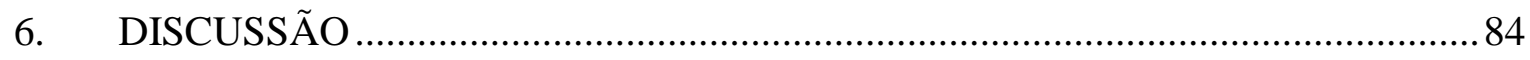

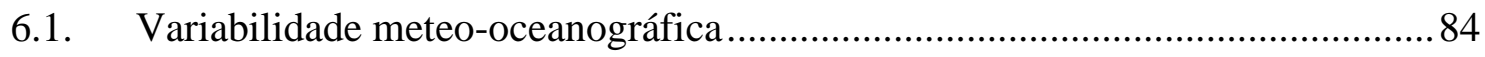

6.2. Estimativas de produção primária e suas forçantes ......................................... 86

6.2.1. O balanço metabólico da comunidade planctônica .................................... 86 


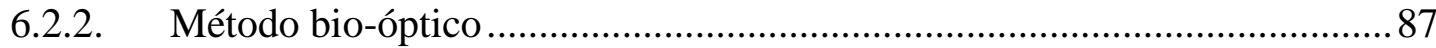

6.2.3. Método de fluorescência ativa variável.....................................................8 89

6.3. Comparação entre os métodos ..................................................................... 91

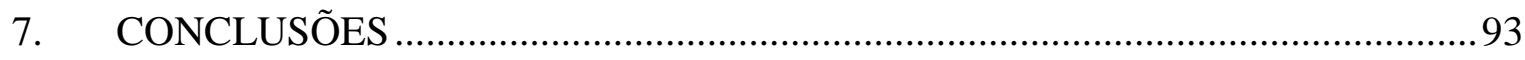

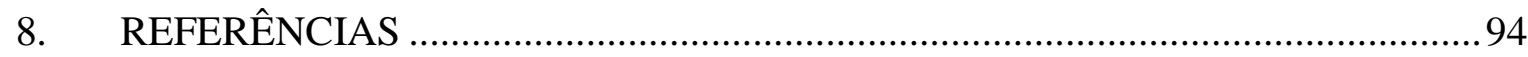




\section{INTRODUÇÃO}

\subsection{A dinâmica do fitoplâncton e produção primária em ambientes costeiros}

A produção primária (PP) é um dos principais processos ecológicos para a síntese bioquímica de compostos orgânicos, sendo uma via de conexão entre os fluxos de energia e os ciclos globais, regionais e locais de nutrientes e de elementos como o carbono e oxigênio (Falkowski et al., 1998). A PP global líquida (PPL), ou seja, a produção de carbono orgânico, descontada pela respiração da comunidade fitoplanctônica, é hoje estimada em 112,4 pentagramas por ano, e destes, quase metade, ou seja, 56 pentagramas por ano são provenientes dos oceanos (Ito, 2011; Buitenhuis et al., 2013). Assim o entendimento da PP marinha tem relevância na compreensão das mudanças das composições químicas atmosféricas e oceânicas, ao longo do passado geológico, e atuais, incluindo aquelas impostas por efeitos antropogênicos (Falkowski et al., 1998; Field et al, 1998).

A ocupação urbana desordenada em áreas costeiras, somada aos efeitos das mudanças climáticas, torna esperado, em algumas regiões, um aumento inicial da PP devido à elevação da temperatura da água e ao aporte costeiro de nutrientes causado pelo aumento da descarga continental (Rabalais et al., 2009; Paerl et al., 2014). Esta situação pode levar a eutrofização, hipóxia local e a proliferação de microalgas, algumas potencialmente tóxicas, consequentemente afetando serviços ecossistêmicos importantes como a balneabilidade e a exploração de estoques pesqueiros dessas regiões (Rabalais et al., 2009; Cloern, 2001). Desta forma, é essencial quantificar a PP marinha ao longo do tempo e espaço em águas costeiras uma vez que esta consiste na base para modelos de produção pesqueira (Brown et al., 2010; Cheung et al.,2011) e de eutrofização (Cloern, 2001).

Os corpos de água costeiros estão sujeitos a dissipação e fricção causadas por ondas e marés, ação de ventos sobre a superfície da água, além de fortes gradientes de densidade em resposta ao aquecimento por energia solar e descargas de rios da região adjacente (Simpson \& Sharples, 2012). Tais dinâmicas físicas resultam na variabilidade espacial e temporal da distribuição de organismos, especialmente o fitoplâncton devido a seu pequeno tamanho em geral, pois provocam a mistura horizontal e vertical de massas d'água ou a estratificação da coluna d'água, 
alterando a disponibilidade de nutrientes e a incidência luminosa (Piola et al., 2008; Atkinson et al., 2004).

Eventos de ressurgência costeira são responsáveis por aumentos locais ou regionais da PP, pois promovem o afastamento da água superficial mais quente e oligotrófica e o afloramento de massas d'água mais frias e ricas em nutriente na zona eufótica (ver revisão por Kampf \& Chapman, 2017). Esse processo é guiado pelo campo de ventos e favorecido em plataformas continentais estreitas (Tomczak \& Godfrey, 2002), e igualmente advectam a biomassa fitoplanctônica produzida sob sua influência.

Em escalas locais, a variabilidade da comunidade e da biomassa fitoplanctônica em ambientes costeiros pode depender da extensão de pluma dos rios, quando estas ocorrem. Plumas de rios são influenciadas pelo tamanho da bacia de drenagem, pelas taxas de pluviosidade sobre a mesma (Piola et al., 2008; Goes et al., 2014), além do regime de ventos (Möller Jr. et al., 2008), e transportam matéria orgânica, sedimentos e elementos nutritivos para o oceano adjacente, com destaque para o nitrogênio, o fósforo, o ferro e a sílica. Por outro lado, dependendo de sua extensão e da concentração de material particulado em suspensão, a PP em seu interior pode ser limitada pela atenuação da luz na coluna d'água (IOCCG, 2000). Mesmo em regiões costeiras onde rios de médio e grande porte estão ausentes, podem ser formadas plumas de aportes continentais difusos próximo à costa (van de Merwe et al., 2016; Gorman et al., 2017). É importante mencionar os efeitos das águas subterrâneas como fontes locais de nutrientes, como reportado por Sawyer et al. (2016), assim como em regiões onde aquíferos rochosos fraturados com paleocanais ocorrem (e.g., Bokuniewics et al., 2008; Russoniello et al., 2013).

A oscilação das marés ao longo da costa influencia a distribuição e a variabilidade da biomassa e grupos taxonômicos do fitoplâncton (Blauw, 2012). Mares costeiros sob influência de baixas amplitudes de marés tendem a possuir maior concentração de clorofila-a do que aqueles ambientes que possuem macromarés, devido à maior instabilidade provocada pela mistura vertical da água capaz de intensificar a ressuspensão de sedimentos e assim, mesmo com a disponibilidade de nutrientes, inibir o crescimento e acúmulo do fitoplâncton (e.g., Monbet, 1992). 
Processos advectivos, relacionados ou não com as marés, são, em geral, importantes na alteração da distribuição do fitoplâncton, como por exemplo a circulação por células de Langmuir e a advecção horizontal guiada pelos ventos (Denman \& Gargett, 1983). Assim, a advecção está relacionada ao movimento de material biológico causado pelo transporte vertical ou horizontal em diferentes escalas de tempo e espaço (Robinson, 1997), devendo ser considerados em estudos de cadeias alimentares marinhas. De fato, modelos preditivos para a produção e dinâmica biológica dos oceanos, consideram desde a biomassa e taxas de crescimento do fitoplâncton e zooplâncton, até a utilização de coeficientes de difusão turbulenta e outros termos advectivos (O’Brien \& Wroblewski, 1973), interações não lineares, difusão, transporte e locomoção de espécies (Malchow, 1996), ação de ventos, diferenças de temperatura e luz no ambiente marinho (Macías et al., 2012).

Além das alterações na dinâmica do fitoplâncton em resposta às mudanças naturais no ambiente, uma gama de fatores influentes e sinérgicos podem alterar o ambiente costeiro com a ação antrópica. Descargas de efluentes domésticos, industriais e agrícolas, assim como o desmatamento na região de entorno das bacias de drenagem, incrementam a entrada de sedimentos, material orgânico, poluentes e nutrientes nos oceanos costeiros (Cloern, 2001). O fitoplâncton, por sua vez, pode responder à essas alterações com acúmulos de biomassa, ou florações de algumas espécies (Anderson, 1989; Anderson et al., 2012). Neste contexto, alguns autores utilizam a concentração de clorofila-a do ambiente em índices desenhados para caracterizar o estado trófico da água no meio marinho e costeiro (Vollenweider et al., 1998; Smith et al., 1999; Penna et al., 2004).

Em suma, ambientes costeiros têm, em primeira ordem, hidrodinâmica intensa, e tanto a abundância total como a composição de espécies na comunidade de fitoplâncton variam no tempo e no espaço, o que complica a realização de estimativas de PP em escala local ou regional, ainda bastante escassas globalmente (Cloern et al., 2014). A maior parte dos estudos relacionados à PP se concentram na América do Norte e na Europa (ver Tabela 1), assim, existe uma grande lacuna de informações em outras regiões, como é o caso da costa brasileira (Lutz et al., 2018). Assim, é importante mencionar que o entendimento de como as metodologias de medição da PP disponíveis diferem nestes ecossistemas dinâmicos é ainda uma questão pouco explorada e requer muitos esforços de campo e atenção especial na interpretação dos resultados. 


\subsection{Métodos e modelos de produção primária}

Marra (2002) apontou que a medição da PP marinha é complexa devido à extensão e profundidade dos oceanos, à dimensão variada dos herbívoros, que inclui organismos do mesmo tamanho que as células fitoplanctônicas, à elevada taxa de reprodução dos organismos fotossintetizantes. O método clássico e padrão de determinação da PP nos oceanos, desenvolvido há décadas por Steemann-Nielsen (1952), consiste em quantificar a incorporação de ${ }^{14} \mathrm{C}$ na matéria orgânica durante a fotossíntese, diferenciando as frações particuladas e dissolvidas de carbono, em amostras que são inoculadas e incubadas por 24 horas ou ao longo de um período determinado de luz, e após este tempo, a concentração de ${ }^{14} \mathrm{C}$ incorporado pelos produtores primários é medida por técnicas de emissão radioativa. No entanto, dificuldades inerentes a este método, e principalmente a sua baixa resolução espaço-temporal, tornou necessário o desenvolvimento de métodos alternativos. Outras técnicas utilizam medidas de oxigênio dissolvido para estimar a PP bruta (PPB) pelo metabolismo da comunidade, sendo a produção e consumo relacionados às reações na presença de luz e no escuro (Gaarder \& Gran, 1927), ou ainda medidas da produção de ${ }^{18} \mathrm{O}$ durante a fotossíntese (Bender et al., 1987), após incubações com isótopos estáveis desse elemento. Assim, os problemas relacionados à incubação permanecem, e consequentemente, sua baixa resolução espaço-temporal (Kolber \& Falkowski, 1993).

Modelos utilizando a concentração de clorofila-a total da comunidade de fitoplâncton para estimar as suas taxas de fixação de carbono foi uma das primeiras abordagens utilizadas para a estimativa da PP em maior resolução com o potencial de desenvolvimento de algoritmos para uso em dados de cor do oceano a bordo de sensores remotos (Eppley et al., 1985), e assim, estimar a PP oceânica globalmente (Barber \& Hilting, 2002). No entanto, apesar da importância central da concentração de clorofila-a e seu papel nos fotossistemas, os modelos que a utilizam como descritor do fitoplâncton não estimam corretamente a variabilidade da produção primária (Campbell et al., 2002). Isso se deve as mudanças fisiológicas dos organismos e a regulação da concentração de pigmentos intracelulares em resposta às diferenças nas taxas de crescimento de cada espécie (MacIntyre et al., 2002). Com o passar dos anos, aos modelos foram incluídas variáveis que explicam variações nas taxas do crescimento do fitoplâncton, como a temperatura, irradiância solar e a concentração de nutrientes no sistema (Cloern et al., 1995; Carr et al., 2006). Marra et al. (2007) propõem que a PP marinha estaria mais relacionada com o coeficiente 
de absorção de luz por todos os pigmentos do fitoplâncton do que a concentração da clorofilaa em si, já que contêm informações taxonômicas e fisiológicas (Bricaud et al., 2004). Essa abordagem, dita bio-óptica, tem igual potencial de aplicação em sensoriamento remoto e instrumentações in situ. Em águas costeiras, a complexidade óptica causada pela presença de materiais particulados em suspensão ou dissolvidos na água, pode levar a superestimação da clorofila-a através de técnicas aplicadas aos sensores remotos. Neste contexto, Barnes et al. (2014) considera a abordagem proposta por Marra et al. (2007), incluindo a absorção de luz por outros materiais, que não somente o fitoplâncton.

A busca por alternativas para medidas de PP tem sido crescente nos últimos anos (Suggett et al., 2010). Dentre as técnicas promissoras estão as que utilizam medidas da fluorescência variável ativa da clorofila-a para a quantificação da PP, uma vez que são consideradas não invasivas e rápidas em comparação aos experimentos clássicos baseados em concentrações de $\mathrm{O}_{2}$ e $\mathrm{CO}_{2}$ e que necessitam de incubações (Kolber \& Falkowski, 1993).

\subsection{Comparação entre métodos de produção primária}

Apesar de ser a técnica mais difundida entre os pesquisadores e ser mais sensível em ambientes oligotróficos, as medidas de PP por incorporação de ${ }^{14} \mathrm{C}$ apresentam muitas incertezas relacionadas à incubação, uma vez que esta causa efeitos de confinamento para pequenos volumes ("bottle effect"), além de apresentar elevados custos e riscos inerentes a radiação envolvida no processo (Regaudie-de-Gioux et al., 2014). Esse último quesito não se aplica aos métodos utilizando a concentração de oxigênio, fluorescência ativa da clorofila-a e o coeficiente espectral de absorção de luz do fitoplâncton.

As técnicas utilizando as variações da concentração de oxigênio dissolvido na água, que representam as taxas metabólicas dos organismos, estimam tanto a PP líquida quanto a bruta, já que também calculam a respiração da comunidade (Gaarder \& Gran, 1927). Além disso, após o aprimoramento das análises de $\mathrm{O}_{2}$ de precisão pelo método Winkler (Carpenter, 1965), essas técnicas possuem ótima resolução em ambientes com baixa biomassa fitoplanctônica e são, de fácil interpretação. No entanto, ocorre o mesmo efeito de confinamento da técnica com ${ }^{14} \mathrm{C}$, além de assumir que a respiração da comunidade durante a fase clara e escura do experimento 
são iguais (ver detalhes na sessão de métodos), quando na realidade há diminuição da taxa fotossintetizante e aumento da respiração sob regimes de luz elevados de formas variadas dependendo da espécie (Harris \& Lott, 1973, Falkowski \& Owen, 1978, Weger et al., 1989). Esta situação leva à fotoinibição, sendo que esta depende da profundidade em que a célula se encontra, o horário do dia, da região, estação do ano e o grupo taxonômico do fitoplâncton (Platt et al., 1981, Platt et al., 2017).

Identificados estes problemas, surgiu-se a necessidade de encontrar novos métodos que possam englobar o estado fisiológico da célula, uma vez que este altera a assimilação de carbono durante a fotossíntese (Morris, 1980). É também conhecido que a fixação de carbono pelo fitoplâncton é alterada em ambientes limitados por nutrientes e relacionada à taxa de crescimento do grupo (Halsey et al., 2010).

Taxas de fotossíntese estimadas por fluorescência ativa da clorofila-a são medidas instantâneas, hoje disponíveis tanto para instrumentos de laboratório como in situ, e desta forma aumentam consideravelmente a resolução temporal (em escalas de segundos) entre medidas, permitindo assim uma melhor resolução espacial (Kolber \& Falkowski, 1993, Maxwell \& Johnson, 2000). Por outro lado, ainda há dúvidas em relação à variação dos parâmetros fotofisiológicos frente a mudanças nas condições ambientais dos oceanos, e por ser instantânea, dificulta a acuidade na conversão de unidade para escalas de tempo de dias ou ainda maiores (Regaudie-deGioux et al., 2014).

Métodos bio-ópticos têm a vantagem de poder caracterizar o comportamento espectral da coluna d’água em relação à sua composição, diferenciando os detritos dos pigmentos do fitoplâncton (Marra et al., 2007; Barnes et al., 2014). O método também é instantâneo, ou seja, melhora a resolução espacial, mas dificulta a precisão temporal em escalas de dias ou maiores, como no método que utiliza a fluorescência da clorofila-a. Entretanto, desvantagens são observadas em relação à estimativa de coeficientes de absorção utilizados nesta técnica, devido ao processo de filtração em filtros de fibra de vidro que podem superestimar o caminho ótico das amostras (Roesler et al., 2017).

Apesar de haver alguns poucos estudos que comparem diferentes metodologias, nada se sabe como estes são influenciados pelas condições ambientais e a própria estrutura da comunidade (Regaudie-de-Gioux et al., 2014). Além disso, ainda não há comparações entre métodos 
de PP por fluorescência ativa da clorofila-a (PPFire) e a absorção do fitoplâncton (PPabs). É importante ressaltar que essas comparações são essenciais para compreender informações já obtidas em variadas regiões do mundo sob diferentes processos oceanográficos (Tabela 1).

Tabela 1. Valores de produção primária (PP) com diferentes métodos em diversas áreas costeiras sob a influência processos oceanográficos variados. Note que as unidades de PP não são as mesmas, uma vez que cada estudo optou por taxas diárias ou anuais de PP.

\begin{tabular}{|c|c|c|c|c|}
\hline Autor & $\begin{array}{c}\text { Principal processo } \\
\text { oceanográfico }\end{array}$ & Local & Método & $\mathbf{P P}$ \\
\hline Flemer, 1970 & $\begin{array}{c}\text { Drenagem continental e } \\
\text { marés }\end{array}$ & $\begin{array}{c}\text { Baia de Chesapeake } \\
\text { (EUA) }\end{array}$ & $\mathrm{O}_{2}$ & $\begin{array}{c}780-1310 \mathrm{mgCm}^{-} \\
{ }^{2} \mathrm{~d}^{-1}\end{array}$ \\
\hline Wafar et al., 1983 & Marés & $\begin{array}{c}\text { Baia de Morlaix } \\
\text { (França) }\end{array}$ & ${ }^{14} \mathrm{C}$ & $1-107 \mathrm{mgCm}^{-3} \mathrm{~d}^{-1}$ \\
\hline Zoppini et al., 1995 & Drenagem continental & $\begin{array}{c}\text { Mar Adriático } \\
\text { (Itália) }\end{array}$ & ${ }^{14} \mathrm{C}$ & $260 \mathrm{gCm}^{-2} \mathrm{ano}^{-1}$ \\
\hline $\begin{array}{l}\text { Rivera-Monroy et al., } \\
1998\end{array}$ & $\begin{array}{c}\text { Drenagem continental e } \\
\text { marés }\end{array}$ & $\begin{array}{c}\text { Laguna de Términos } \\
\text { (México) }\end{array}$ & $\mathrm{O}_{2}$ & $\begin{array}{c}285-478 \mathrm{gCm}- \\
\text { 2ano-1 }\end{array}$ \\
\hline Lohrenz et al., 1999 & Drenagem continental & $\begin{array}{c}\text { Delta do Mississipi } \\
\text { (EUA) }\end{array}$ & ${ }^{14} \mathrm{C}$ & $>10000 \underset{1}{\mathrm{mgCm}^{-2} \mathrm{~d}}$ \\
\hline Figueiras et al., 2002 & Ressurgência & $\begin{array}{c}\text { Baixas Rías } \\
\text { (Espanha) }\end{array}$ & ${ }^{14} \mathrm{C}$ & $\begin{array}{l}\text { média } 1400 \\
\mathrm{mgCm}^{-2} \mathrm{~d}^{-1}\end{array}$ \\
\hline Gazeau et al., 2005 & Drenagem continental & $\begin{array}{l}\text { Estuário de Schedlt } \\
\text { (França/Bélgica) }\end{array}$ & $\mathrm{O}_{2}$ & $\begin{array}{c}\sim 264-444 \mathrm{mg} \mathrm{C} \\
\mathrm{m}^{-2} \mathrm{~d}^{-1}\end{array}$ \\
\hline $\begin{array}{c}\text { Estévez-Blanco et } \\
\text { al., } 2006\end{array}$ & Ressurgência & $\begin{array}{c}\text { Baixas Rías } \\
\text { (Espanha) }\end{array}$ & $\begin{array}{l}{ }^{14} \mathrm{C}+ \\
\text { Fluorescência }\end{array}$ & $\begin{array}{l}\text { média } 1300 \pm 200 \\
\mathrm{gCm}^{-2} \mathrm{~d}^{-1}\end{array}$ \\
\hline Debes et al., 2008 & Marés e mistura vertical & Ilhas Faroe & Fluorescência & $\begin{array}{c}\text { máximo } 2900 \\
\mathrm{mgCm}^{-2} \mathrm{~d}^{-1}\end{array}$ \\
\hline Glé et al., 2008 & $\begin{array}{c}\text { Drenagem continental e } \\
\text { marés }\end{array}$ & $\begin{array}{l}\text { Baia de Arcachon } \\
\text { (França) }\end{array}$ & ${ }^{14} \mathrm{C}$ & $103 \mathrm{gCm}^{-2} \mathrm{ano}^{-1}$ \\
\hline Barnes et al., 2015 & $\begin{array}{c}\text { Drenagem continental e } \\
\text { marés }\end{array}$ & $\begin{array}{l}\text { Canal Oeste Inglês } \\
\text { (Reino Unido) }\end{array}$ & Bio-óptico & $\begin{array}{c}15,1 \mathrm{gCm}^{-3} \mathrm{ano}^{-} \\
{ }^{1} \text { (superfície) - } 112 \\
\mathrm{gCm}^{-2} \mathrm{ano}^{-1} \\
\text { (integrada) }\end{array}$ \\
\hline Robinson et al., 2017 & $\begin{array}{l}\text { Drenagem continental, } \\
\text { monções }\end{array}$ & $\begin{array}{c}\text { Yongala, Queensland } \\
\text { (Austrália) }\end{array}$ & Bio-óptico & $<\sim 230 \mathrm{mgCm}^{-3} \mathrm{~d}^{-1}$ \\
\hline
\end{tabular}




\section{2. ÁREA DE ESTUDO}

\subsection{Oceanografia física no canal de São Sebastião}

Localizado no litoral norte do estado de São Paulo, o canal de São Sebastião (CSS) está posicionado entre o município de mesmo nome e Ilhabela. O canal tem como dimensões: 22,2 $\mathrm{km}$ de comprimento e largura variada, possuindo aproximadamente 6,7 e $2 \mathrm{~km}$, nas partes norte, sul e central, respectivamente. A batimetria do CSS é caracterizada por áreas rasas mais próximas ao continente e um abrupto aumento da profundidade no chamado canal de navegação, onde sua profundidade máxima atinge $42 \mathrm{~m}$ na porção central CSS, nas proximidades do Porto de São Sebastião (DHN, 2013; DHN, 2016).

Sobre a Plataforma Continental Sudeste (PCSE), segundo Castro et al. (2006), estão presentes a Água Tropical (AT), a Água Central do Atlântico Sul (ACAS) e a Água Costeira (AC). A AT é advinda da Corrente do Brasil (CB) e é caracterizada por alta temperatura e salinidade, além de ser considerada oligotrófica (Aidar et al. 1993; Ciotti et al. 1995; Gianesella, 2000). A ACAS, por sua vez possui menor temperatura e tem elevada concentração de nutrientes. Resultado da mistura das massas d'água de origem oceânica e águas de origem continental, a AC possui então índices termohalinos variáveis, mas em geral com salinidade reduzida, diferente das outras massas que são caracterizadas por índices constantes durante o ano (Emílsson, 1961; Castro, 2014). A estrutura termohalina da coluna d'água possui uma variabilidade sazonal e interanual bem marcada, cujo verão é caracterizado por forte estratificação e intrusões episódicas da ACAS sobre a plataforma continental e a AC mais quente e com maior salinidade. Por outro lado, no inverno a coluna d'água tende a estar bem misturada e a há um enfraquecimento da mistura entre ACAS e AC, devido ao recuo da primeira em direção ao oceano (Castro, 2014).

Na maior parte do ano o CSS é dominado pela AC, principalmente no outono e inverno, quando a coluna d'água é homogênea com menor temperatura e salinidade e pouca variação da temperatura vertical. Durante a primavera e verão, todavia, a estratificação da coluna d'água nas áreas que possuem maior profundidade é resultado do aumento da salinidade e gradiente de temperatura. Na superfície ainda há a presença da AC, mas pode ocorrer a intrusão da ACAS junto ao fundo em resposta a intensificação de ventos de quadrante norte/nordeste durante esta 
época do ano, situação relatada em outras regiões da PCSE, com avanço desta massa sobre a plataforma interna (Campos et al., 2013; Dottori et al., 2015).

A AC é resultado da mistura de águas de origem oceânica com a descarga continental de rios e córregos na plataforma continental, conferindo à massa d'água menor salinidade (Castro et al., 2006). Ao norte da região de estudo, ao redor de Ilha Grande - Rio de Janeiro, sabe-se que frentes salinas caracterizam parte da hidrografia da região (Miranda et al., 1977). Desta forma, embora não haja estudos específicos sobre a frequência, volume e tempo de residência de plumas de baixas salinidades no CSS e de regiões próximas, como a Baia de Caraguatatuba, não é possível desconsiderar sua importância sobre a área.

Silva et al. (2005), em estudo realizado no canal, constatou que a intrusão da ACAS na região, culminada com a diferença da pressão entre as partes sul e norte do CSS, são responsáveis por intensificar as correntes de fundo em direção ao norte, sobretudo no verão. Por outro lado, as correntes superficiais são reflexo da circulação dos ventos em larga escala. Sendo os ventos de nordeste mais frequentes, essas correntes se propagam em direção ao sul, com enfraquecimento no outono e as máximas velocidades encontradas no verão. O tempo de residência da água no canal foi estimado em aproximadamente 1 a 8 dias, sendo resultado da intensificação ou enfraquecimento das correntes de acordo com sua variabilidade sazonal (Paixão, 2008).

\subsection{Fitoplâncton no canal de São Sebastião}

Uma série de estudos relacionados à PP, ao fitoplâncton e suas interações com o ambiente foram conduzidos no CSS e na Baía do Araçá em consequência de pesquisas iniciais conduzidas pela Universidade de São Paulo, principalmente pelos grupos de pesquisa do Instituto Oceanográfico (IO/USP) e mais recentemente do Centro de Biologia Marinha (CEBIMar). Gaeta et al. (1990), obteve valores de PP integrada até a profundidade da Zona Eufótica na ordem de 16,8 $\mathrm{mg} \mathrm{C} \mathrm{m} \mathrm{m}^{-2} \mathrm{~h}^{-1}$ na estação de coleta localizada nas proximidades do CEBIMar, concluindo que a PP estava diretamente relacionada com os nutrientes nitrato, silicato e amônia, bem como a biomassa de fitoflagelados. Por outro lado, a PP correlacionou-se negativamente à salinidade, à anomalia de densidade em relação à temperatura, e ao nitrito. 
Giasenella et al. (1999) apresentaram uma avaliação ambiental na região antes da construção de um emissário submarino na baia do Araçá. Um dos principais resultados foi a classificação do canal como meso-oligotrófico com o predomínio de fitoflagelados, seguidos de diatomáceas e dinoflagelados. No entanto, a comunidade fitoplanctônica como um todo apresentou alta diversidade.

Peres (2013), conduziu um estudo ao longo do CSS na entrada da Baia do Araçá sobre as classes de tamanho do fitoplâncton em respostas as massas d'água. Seus resultados indicaram que durante o verão a entrada da ACAS no sistema foi responsável pelo sutil aumento do microfitoplâncton em virtude do incremento de nitrato pela massa d'água. Por outro lado, durante o inverno, em geral, baixas concentrações de nutrientes foram observadas indicando alto consumo destes, e somente o silicato foi registrado em grande abundancia. A classe de tamanho mais frequente nesta época do ano foi a do nanofitoplâncton (2 a $20 \mu \mathrm{m}$ ), possivelmente relacionado à mistura de massas d'água e o aporte continental constante de nutrientes, embora de baixa concentração.

Recentemente, Tocci (2016) mostrou que no CSS e baia do Araçá há predominância de diatomáceas e que existe uma relação entre a pluviosidade local e a ocorrência de cianobactérias diazotróficas. A autora observou que a ocorrência das espécies Trichodesmium spp. e Richelia intracellularis foram relacionadas proporcionalmente com o aumento da pluviosidade na região. Além disso, foi relatada importância da interação das águas da baía com o canal, principalmente em relação à temperatura e ao fosfato, como também aos ventos de sudeste que são capazes de advectar as células.

Giannini \& Ciotti (2016) mediram a fluorescência ativa do fitoplâncton no CSS e através da técnica de Fluorescência Ativa Variável estimaram a PP. Entre seus resultados observaram que a PP foi máxima (2,59 $\mathrm{mg} \mathrm{C} \mathrm{mg} \mathrm{Chl}^{-1} \mathrm{~h}^{-1}$, aproximadamente igual a 4,85 $\mathrm{mg} \mathrm{C} \mathrm{m}^{-2} \mathrm{~h}^{-1}$ ) em comunidades dominadas por ultra e microfitoplâncton $(2-5 \mu \mathrm{m}$ e $>20 \mu \mathrm{m}$, respectivamente), e mínima (2,25 mg C mg Chl ${ }^{-1} \mathrm{~h}^{-1}$, aproximadamente igual a 4,85 $\left.\mathrm{mg} \mathrm{C} \mathrm{m}^{-2} \mathrm{~h}^{-1}\right)$ em comunidades dominadas apenas por microfitoplâncton. Em outro estudo, a PP líquida no CSS foi quantificada, e segundo Regaudie-de-Gioux et al. (2017), ela é influenciada pela intrusão da ACAS sobre a região durante a primavera e o verão, aumentando em até 3 vezes neste período. Utilizando a técnica de Taxas Metabólicas por $\mathrm{O}_{2}$, os autores encontraram média global da PP 
líquida integrada equivalente a $31,0 \pm 10,5 \mu \mathrm{mol} \mathrm{O}_{2} \mathrm{~m}^{-2} \mathrm{~d}^{-1}\left(371,1 \pm 125,7 \mathrm{mg} \mathrm{C} \mathrm{m}^{-2} \mathrm{~h}^{-1}\right)$, com a dominância de comunidades autotróficas quando há input de nutrientes pela ACAS.

\subsection{Hipótese do trabalho}

Considerando a forte hidrodinâmica atuante no canal de São Sebastião e a variabilidade do fitoplâncton em relação à primeira, descritos nas sessões anteriores, nós esperamos que as principais forçantes oceanográficas locais exerçam efeitos similares, mas em diferentes magnitudes, nas metodologias instantâneas (PPabs e PPFire) utilizadas para medir a produção primária do fitoplâncton, em relação a metodologia tradicional baseada no metabolismo aquático da comunidade (PPB).

\section{OBJETIVOS}

Os objetivos gerais do presente trabalho são definidos a seguir:

i. Estimar a PP no canal de São Sebastião $\left(\mathrm{mg} \mathrm{C} \mathrm{m}^{-3} \mathrm{~d}^{-1}\right)$ por métodos não invasivos (Bioótico e Fluorescência Ativa Variável) e comparar suas magnitudes, em diferentes períodos, com aquela obtida pelo método clássico de Metabolismo de Comunidade Planctônica, bem como entre eles.

ii. Determinar a influência de quatro forçantes relevantes, temperatura, salinidade, concentração de clorofila-a e coeficiente de atenuação vertical da luz difusa, nas taxas de PP obtidas pelos diferentes métodos.

iii. Explorar a sinergia das quatro forçantes na previsibilidade da PP no canal de São Sebastião. 


\section{MATERIAIS E MÉTODOS}

\subsection{Coleta de dados in situ}

As coletas ocorreram no período matutino, por volta das 8 e 9 horas, entre os dias 4 de janeiro a 20 de março de 2018 em um único ponto do canal de canal de São de Sebastião. O ponto situava-se próximo a boia meteo-oceanográfica do Sistema de Monitoramento da Costa Brasileira (SIMCosta - SP01, http://www.simcosta.furg.br) - latitude 2349'50”S e longitude 45²5’19’'W, a aproximadamente 300 metros do Centro de Biologia Marinha da Universidade de São Paulo (CEBIMar/USP) (Figura 1). O procedimento de coleta consistiu em lançamentos triplicados com uma garrafa de Van Dorn a aproximadamente 1 metro de profundidade. Nos primeiro e terceiro lançamentos foram coletadas alíquotas para os cálculos do coeficiente espectral de absorção de luz pelo fitoplâncton e concentração da clorofila-a, métodos que serão descritos nas sessões seguintes. No segundo lançamento, além destas alíquotas, frascos DBO (Demanda Biológica de Oxigênio, com cerca de $100 \mathrm{ml}$ ) para o experimento de taxas metabólicas foram preenchidos delicadamente com tubo de silicone, evitando a entrada de bolhas, e assim foram posicionados em uma estrutura de incubação, por 24 horas, em local próximo ao local de coleta protegido do tráfego de embarcações (Figura 1).

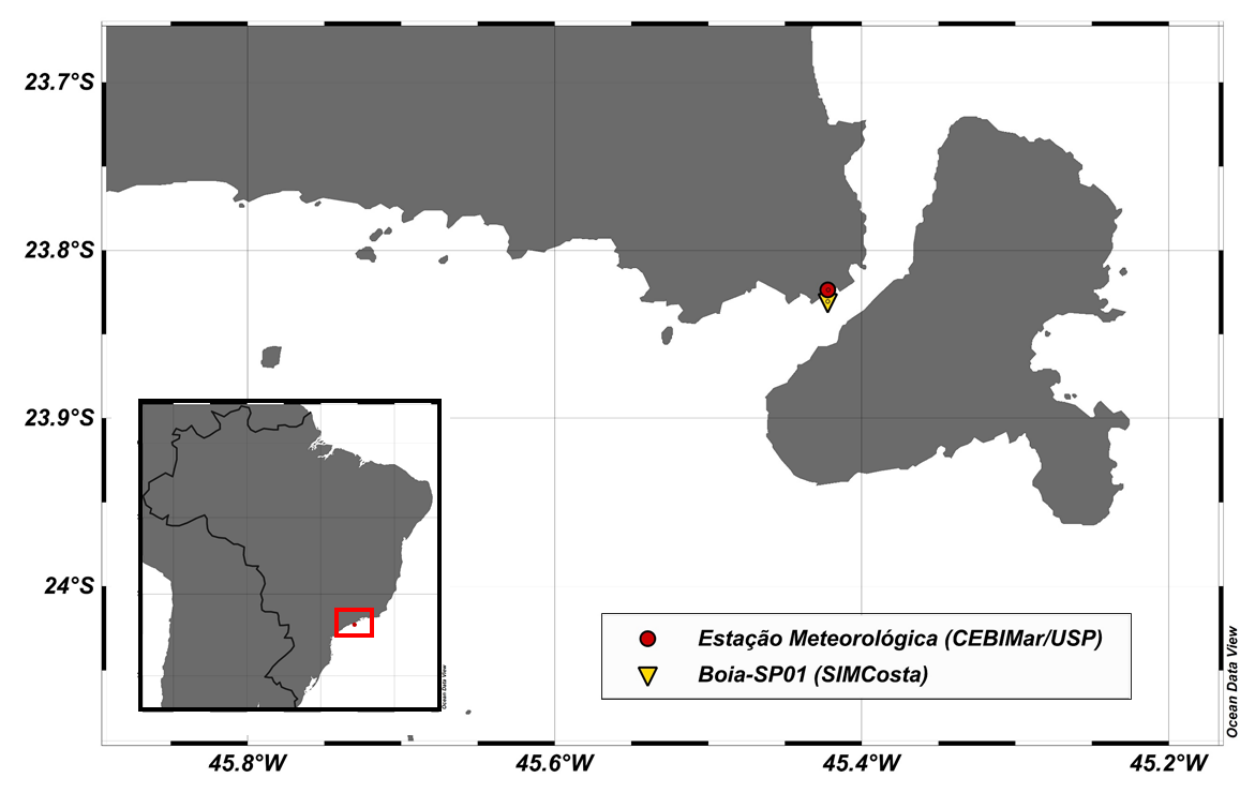

Figura 1. Mapa de localização da boia meteo-oceanográfica do Sistema de Monitoramento da Costa Brasileira (Boia-SP01, SIMCosta), localizada a cerca de 300 metros do Centro de Biologia Marinha da Universidade de São Paulo (CEBIMar/USP) e da estação meteorológica do CEBIMar, localizada na Ponta do Baleeiro, a 18 metros de altitude. 
Além do procedimento de coleta de água, foram realizados perfis verticais com um sensor CTD (“conductivity, temperature, depth" - AAQ, RINKO 127), para medir a temperatura, salinidade, e que continha sensores acessórios para medir turbidez e fluorescência da clorofila-a na coluna d'água. Na falta deste equipamento, um outro CTD (YSI Castaway) foi utilizado, medindo apenas temperatura e salinidade em função da profundidade. Além disso, um disco de Secchi foi utilizado para estimar o coeficiente de atenuação vertical da luz difusa $\left(\mathrm{K}_{\mathrm{d}}\right)$. Com objetivo de identificar possíveis variações das condições oceanográficas durante o período de incubação das amostras, tanto perfilagem com CTD quanto utilização do disco de Secchi, foram repetidas no sitio ao final do experimento.

A fim de encontrar possíveis forçantes atmosféricas e oceanográficas na variabilidade de produção primária ao longo do período de análise foram adquiridos dados meteorológicos como a irradiância solar, a taxa de chuva, temperatura atmosférica e a intensidade e velocidade de ventos. Estes dados foram obtidos pela Estação Meteorológica (Estação Davis - Precision Weather Station, Vantage Pro 2, dados disponíveis em http://cebimar.usp.br), localizada no

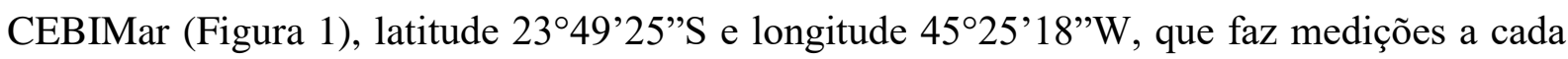
10 minutos. Outra fonte de dados complementares para todo o período foi a boia meteooceanográfica do SIMCosta, fornecendo a temperatura, salinidade, fluorescência da clorofilaa, oxigênio dissolvido e turbidez na superfície em aquisições realizadas a cada 1 hora. Devido a frequência de observações destes dois equipamentos, estação meteorológica e boia, todas as variáveis foram monitoradas durante todo o período de incubação das amostras (ver sessão 4.3.1).

\subsection{Procedimentos de laboratório}

\subsubsection{Higienização de materiais}

Antes das coletas, para eliminar resíduos orgânicos e inorgânicos, todo o material foi higienizado com banho em Extran 5\% por 24 horas, seguidos por enxague com Milli-Q, banho em ácido clorídrico ( $\mathrm{HCl} 10 \%)$, por 24 horas quando vidraria ou aproximadamente 12 horas para materiais plásticos, e novamente enxague em Milli-Q. Os materiais secaram a temperatura ambiente, em local com umidade controlada. 


\subsubsection{Determinação da concentração de clorofila-a}

Imediatamente após as coletas, em laboratório, foi realizada filtração das amostras em filltros de fibra de vidro GF/F (Whatman) com $25 \mathrm{~mm}$ de diâmetro e poro nominal de $0,7 \mu \mathrm{m}$. Para a análise da concentração de clorofila-a, $250 \mathrm{ml}$ foram filtrados. Assim, os filtros foram imediatamente extraídos com uma solução de acetona $90 \%$ e óxido de dimetil sulfato (DMSO) 6:4 em volume, como proposto por Shoaf \& Lium (1976). Os frascos foram mantidos durante 24 horas em um freezer $\left(-22^{\circ} \mathrm{C}\right)$ ao abrigo da luz, para em seguida a fluorescência dos extratos, em temperatura ambiente, ser lida em um fluorímetro de bancada (Turner Designs, modelo Trilogy) equipado com o "kit" para o método sem acidificação proposto por Welschmeyer (1994).

\subsubsection{Determinação do coeficiente espectral de absorção de luz pelo fitoplâncton}

Para a determinação do coeficiente espectral de absorção de luz pelo fitoplâncton $\left(\mathrm{a}_{\mathrm{ph}}\right)$ foram filtrados, em geral, $500 \mathrm{ml}$, ou um volume necessário para a saturação dos filtros. Os filtros foram então armazenados em tubos criogênicos em nitrogênio líquido, para leitura posterior em laboratório. A leitura destes filtros foi feita em espectrofotômetro equipado com esfera integradora acoplada e feixe duplo (Perkin Elmer Lambda 35), conforme o método "Transmitance Reflectance (TR) descrito por Tassan \& Ferrari (1995) entre os comprimentos de onda 390 e $800 \mathrm{~nm}$, com resolução de $1 \mathrm{~nm}$. Como descrito no método (Tassan \& Ferrari, 2002), duas leituras são feitas, em absorptância, com o filtro posicionado na frente (T) e atrás (R) da abertura da esfera integradora. Após este procedimento, os pigmentos do fitoplâncton foram removidos com cerca de 6 gotas de uma solução de hipoclorito de sódio P.A. a 0,5\% (Tassan et al., 2000), assim foi obtido a parcela de detritos após uma segunda leitura nos modos T e R. Os coeficientes de absorção da luz pelo material particulado total $\left(\mathrm{a}_{\mathrm{t}} \mathrm{em} \mathrm{m}^{-1}\right)$ e pelos detritos $\left(\mathrm{a}_{\mathrm{d}} \mathrm{em} \mathrm{m}^{-1}\right)$ são calculados (Roesler et al., 2017), e a diferença entre ela obtêm-se então, o espectro de absorção de luz do fitoplâncton $\left(\mathrm{em} \mathrm{m}^{-1}\right)$ que foi corrigido pela área de filtração e o volume filtrado da amostra, e espalhamento durante as medidas. 


\subsection{Métodos de medição da produção primária}

\subsubsection{Método por Taxas Metabólicas}

A produção primária bruta (PPB) é medida a partir da produção primária líquida (PPL) da comunidade planctônica e suas taxas de respiração $(\mathrm{RC})$, registradas por meio de mudanças nas concentrações de $\mathrm{O}_{2}$ dissolvido (Equação 1, Gaarder \& Gran, 1927). Os experimentos consistiram em períodos de incubação por 24 horas de amostras mantidas em 5 frascos de vidro para demanda biológica de oxigênio (DBO) transparentes, para medir a PPL, e 5 escuros, para medir a RC. Além disso, foi necessário obter as concentrações iniciais de $\mathrm{O}_{2}$ dissolvido a partir de 5 frascos para DBO, que foram analisados imediatamente após a coleta (Figura 2). Para isto, foi utilizado o método descrito por Oudot et al. (1988) em que a determinação de $\mathrm{O}_{2}$ é feita por titulação Winkler - (Metrohm, 848 Titrino plus) com eletrodo pontenciométrico e detecção automatizada dando uma precisão de $0,1 \%$ nas concentrações (Equação 1):

$$
P P B=P P L+R C\left[m g O_{2} m^{-3} d^{-1}\right]
$$

onde PPB é a produção primária bruta PPL, produção primária líquida, e RC, taxa de respiração da comunidade, todas em $\mathrm{mg} \mathrm{O}_{2} \mathrm{~m}^{-3} \mathrm{~d}^{-1}$. Para a descrição em unidades de carbono este valor foi multiplicado por um fator de conversão igual a 374,128 (Masterman \& Redding, 2007). 


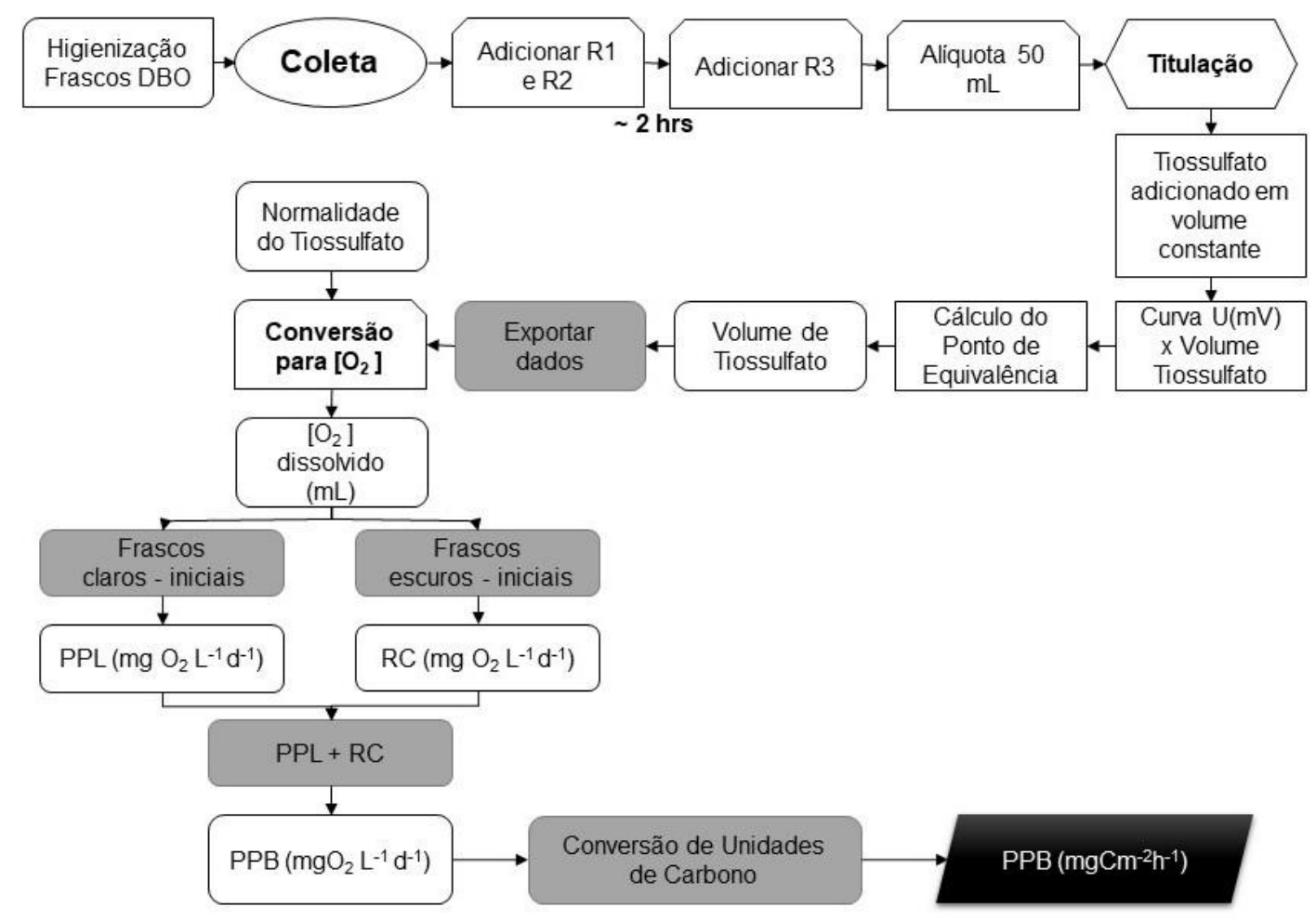

Figura 2. Procedimentos de titulação pelo método Winkler para determinação da concentração de oxigênio e conversão em Taxas Metabólicas. Sendo R1 é o primeiro reagente Hidróxido de Manganês $\left(\mathrm{MnSO}_{4}\right) ; \mathbf{R 2}$ é o segundo reagente Iodeto de Potássio; R3, o terceiro reagente Ácido Sulfúrico $\left(\mathrm{HSO}_{4}\right)$; $\left[\mathrm{O}_{2}\right]$ é a concentração de oxigênio; PPL a produção primária líquida; RC a respiração da comunidade, e; PPB a produtividade primária bruta.

\subsubsection{Método Bio-óptico}

O método bio-ótico descrito por Marra et al. (2007), foi desenvolvido para a superfície marinha aplicada a sensores remotos e tem por princípio que a PP (descrita em mols $\mathrm{C} \mathrm{m}^{-3} \mathrm{~d}^{-1}$ ) nos oceanos estaria mais relacionada e de forma linear a coeficientes de absorção de pigmentos fitoplanctônicos do que a clorofila-a, uma vez que esta última não é afetada por mudanças de temperatura, irradiância e nutrientes. Visando definir ajustes estatísticos para este modelo, Barnes et al. (2014) propuseram uma série de equações (ver "Table 1" em Barnes et al., 2014), através da relação entre os coeficientes de absorção da luz $\left(\mathrm{m}^{-1}\right)$ e a irradiância incidente $(\mu \mathrm{mol}$ quanta $\left.\mathrm{m}^{-2} \mathrm{~s}^{-1}\right)$, levando em consideração diferentes comprimentos de ondas absorvidos por fitoplâncton $\left(\mathrm{a}_{\mathrm{ph}}\right)$, materiais particulados $\left(\mathrm{a}_{\mathrm{NAP}}\right)$ e pela matéria orgânica dissolvida colorida (acDOM - em que CDOM provêm da sigla em inglês "colored dissolved organic matter"), 
tamanhos diversos da comunidade fitoplanctônica (microfitoplâncton e nanofitoplâncton + picofitoplâncton), e a complexidade óptica de água costeiras.

\subsubsection{Método de Fluorescência Ativa Variável}

As variáveis necessárias para a aplicação do modelo foram derivadas das amostras de água coletadas e armazenadas in situ, nas quais, logo após ao desembarque foram submetidas a análise no "Fluorescence Induction and Relaxation System" (FIRe - Satlantic Inc.). O FIRe é um equipamento que mede a intensidade da fluorescência em relação ao tempo (Figura 3), no qual, após um período de ajuste a uma luz "led" azul (actínica) de baixa intensidade, um pulso de luz saturante atinge a amostra, com o objetivo de fechar momentaneamente os fotossistemas da célula. $\mathrm{O}$ procedimento consistiu então na medida da fluorescência durante a exposição à luz fraca actínica, resultando na fluorescência inicial $\left(\mathrm{F}_{\mathrm{o}}\right)$. Após o pulso luminoso, foi construído uma curva de fluorescência versus tempo, e assim dois parâmetros foram derivados: a fluorescência máxima $\left(\mathrm{F}_{\mathrm{m}}\right)$ e a área efetiva de absorção de luz pelo fotossistema II ( $\left.\sigma_{\mathrm{PSII}}\right)$. A fluorescência variável foi computada pela diferença entre $F_{m}$ e $F_{o}$ e normalizada por $F_{m}$. Estes parâmetros foram inseridos ao modelo para o cálculo de PP em conjunto com a concentração de clorofila-a.

Para a aplicação do modelo de PP utilizando a fluorescência variável ativa foi necessário obter a taxa de transferência de elétrons (ETR) a partir de medidas do $\sigma_{\text {PSII }}$ em um gradiente de luz, dividido em 6 intensidades, 0, 100, 200, 300, 400 e $600 \mu \mathrm{mol}$ fótons $\mathrm{m}^{-2} \mathrm{~h}^{-1}$. O ETR é uma propriedade de emissão da energia pelos fotossistemas das células fitoplanctônicas (Kolber \& Falkowski, 1993) sendo a empregada no modelo referente apenas a transferência de elétrons nos fotossistemas II, chamada então de ETRPSII, (Equação 2):

$$
\text { ETRPSII }=\sigma_{P S I I} * q p * F_{v} F_{m} * E_{P A R}
$$

onde GPSII é a área efetiva de absorção de luz pelo fotossistema II; qp é o "quenching fotoquímico"; $F_{v}$ a fluorescência variável; $F_{m}$, fluorescência máxima, e; EPAR, a irradiância. Lembrando que qp é definido como "resultado do uso de energia de excitação dentro do fotossistema II (PSII) para conduzir o transporte de elétrons entre os centros de reação do PSII e o aceptor primário QA (molécula de quinona)" (Baker, 2008). Ou seja, ocorre uma reação de oxi-redução 
da QA, podendo reduzir o sinal de fluorescência devido a competição entre os dois processos (Kalaji et al., 2017).

A partir deste valor foi possível então estimar as taxas de incorporação de carbono pelo fitoplâncton (Pc, mg C mg Chl-1 ${ }^{-1}$ ) (Equação 3, Giannini \& Ciotti, 2016) para os comprimentos escolhidos no gradiente de luz.

$$
P C=E T R P S I I * \emptyset e * P Q^{-1}
$$

onde $\emptyset$ e, é a razão de elétrons transferidos por molécula de $\mathrm{O}_{2}$ produzida durante a fotossíntese ( $\mathrm{mol} \mathrm{O}_{2}$ (mol elétron $)^{-1}$ ), e PQ, o coeficiente fotossintético, que é a razão entre o $\mathrm{O}_{2}$ produzido e o $\mathrm{CO}_{2}$ fixado $\left(\mathrm{mol} \mathrm{O}_{2}(\mathrm{~mol} \mathrm{C})^{-1}\right)$. Note que valores estão normalizados pela concentração de clorofila-a e a fim de comparar com as demais metodologias, estes valores foram multiplicados novamente por essa concentração para a unidade de PP em $\mathrm{mg} \mathrm{C} \mathrm{m}^{-2} \mathrm{~h}^{-1}$.

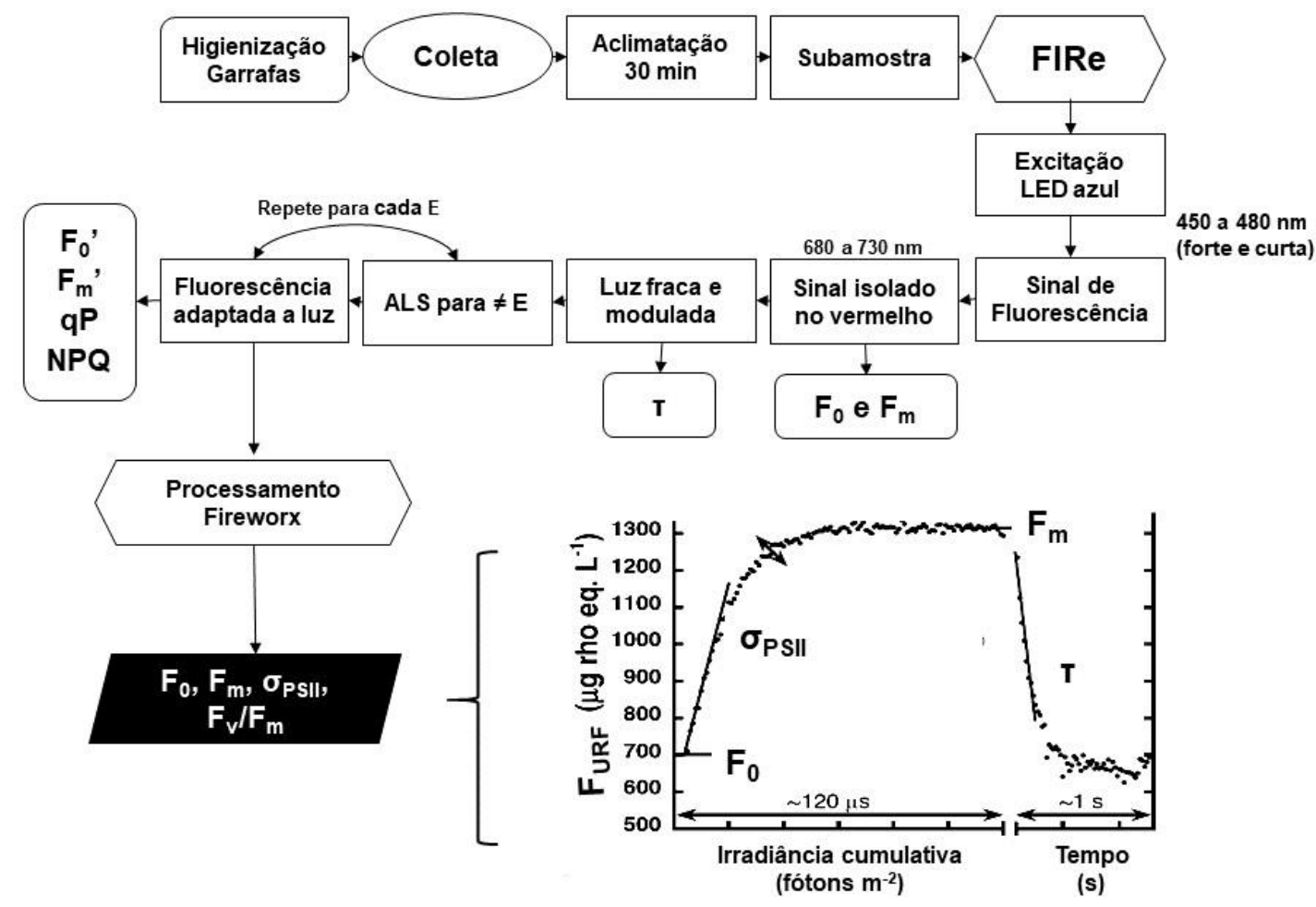

Figura 3. Procedimento de leitura das amostras submetidas ao FIRe (Fluorescence Induction and Relaxation System) e ao processamento de dados pelo programa fireworx, que resultam nos parâmetros fotofisiológicos $\left(F_{0}, F_{m}\right.$, $\sigma_{P S I I}$ e $\left.F_{v} / F_{m}\right)$ necessários para calcular a produção primária de acordo com Giannini \& Ciotti (2016). Onde $F_{0}$ e $F_{m}$ as fluorescências (em URF) mínimas e máximas adaptadas ao escuro, $F_{0}$ ' e $F_{m}$ ' sob luz modulada; $\tau$ (em segundos) o tempo de virada da transferência de elétrons; $E$ a irradiância (em $\mu \mathrm{mol}$ fótons $\mathrm{m}^{-2}$ ); ALS é a luz actínica; qP o "quenching" fotoquímico; NPQ o "quenching" fotoquímico; $\sigma$ PSI é a área efetiva de absorção de luz pelo fotossistema II $\left(\mathrm{em}^{2}\right.$ fóton $\left.^{-1}\right) ; F_{\mathrm{v}} / F_{\mathrm{m}}$ é a eficiência fotoquímica máxima (adimensional), e; F é a fluorescência (em URF). 


\subsection{Resultados em outras bases de dados no canal de São Sebastião}

Na primavera e verão de 2015/2016, experimentos similares aos descritos acima foram realizados nas proximidades de boia de SIMCosta pela equipe do CEBIMar (Laboratório Aquarela), cujos dados foram recentemente publicados (Regaudie-de-Gioux et al., 2017). Dados físico-químicos e de PP, tanto por taxas de metabolismo como por fluorescência ativa variável, foram coletados em 19 dias entre outubro de 2015 a fevereiro de 2016 e assim foram adicionados à base de dados da presente pesquisa. Note que informações sobre a PP pelo método bioóptico não foram obtidas durante este experimento, porém este também estimou o metabolismo aquático integrado na coluna d’água, a concentração de nutrientes (nitrato, nitrito, silicato e fosfato), a absorção do CDOM e a abundância bacteriana.

Outra base de dados adicionada ao presente trabalho foi gerada por estudos pela equipe do CEBIMar na baia do Araçá e no mesmo ponto amostral do presente trabalho no CSS. Em experimentos realizados entre setembro de 2013 a agosto de 2014, foram estimados (1) os parâmetros fotofisiológicos, (2) concentração da clorofila-a em diferentes classes de tamanho, (3) a concentração de nutrientes inorgânicos e (4) os coeficientes espectrais de absorção de luz pelo fitoplâncton e por detritos. No entanto, de (1) a (4) foram utilizados em Giannini \& Ciotti (2016), assim (4) ficou disponível para o cálculo da PP pelo método biótico e que poderá ser comparada a PP utilizando o método de fluorescência ativa variável da clorofila-a através de (1).

\subsection{Análise de dados}

\subsubsection{Processamento de dados obtidos pelo CTD}

O procedimento de limpeza dos dados obtidos pelo CTD consistiu primeiramente na remoção dos valores de subida do equipamento, seguida de binagem por $0,3 \mathrm{~m}$ de resolução. Além disso, um controle de qualidade foi aplicado considerando a média mais ou menos 1,5 do desvio padrão. Para a realização da série temporal dos perfis de temperatura $\left({ }^{\circ} \mathrm{C}\right)$, salinidade, turbidez 
(NTU - unidade nefelométrica de turbidez) e fluorescência da clorofila-a (URF - unidade relativa de fluorescência), foi utilizado o software Ocean Data View (ODV versão 5.1.0). Para a interpolação dos dados, foi utilizado o método de média ponderada entre os valores observados.

\subsubsection{Processamento e controle de qualidade dos dados oceanográficos medidos pela boia SIMCosta}

Os sensores acoplados à boia do SIMCosta foram programados para registrar 20 segundos de medidas, em cada hora, em uma frequência de $1 \mathrm{~Hz}$. Uma filtragem inicial manual foi realizada para a retirada de valores extremos das variáveis devido a redundância de registros feita pelo datalogger do equipamento. Para computar a média horária das variáveis temperatura, salinidade, fluorescência da clorofila-a e turbidez, foram removidos dados espúrios, consistindo daqueles dois desvios padrões, positivos ou negativos, da média. Valores muito próximos ao limite de detecção de cada sensor, de acordo com a especificação do fabricante e configuração, foram também removidos manualmente.

\subsubsection{Determinação do coeficiente de atenuação vertical da luz difusa}

Para o cálculo da produção integrada ao longo de 24 horas pelo método de Fluorescência Ativa Variável, é necessário obter o coeficiente de atenuação vertical de luz difusa ( $\left.\mathrm{K}_{\mathrm{d}}\right)$ na profundidade de coleta, uma vez que com esta variável estima-se a irradiação fotossinteticamente ativa (EPAR, equação 4 - Morel, 1988) que é entrada do modelo de curvas P-E (ver sessão 4.5.4). Sendo $K_{d}$ definido por $1 / 7$ da profundidade do disco de Secchi no momento da coleta. Para estimar o coeficiente no período de 24 horas, foi feito um modelo baseado no $\mathrm{K}_{\mathrm{d}}$ e a turbidez da Boia do SIMCosta, para estimar o primeiro nos outros horários. No entanto, para a série de dados de 2013 e 2014, em que não foi realizada a medida do disco de Secchi, aproximações foram feitas pela turbidez medida pelo CTD quando realizadas ou pela concentração da clorofila-a no CSS em outros períodos amostrais, dados apresentados por Peres (2013). No primeiro caso, a mediana de $\mathrm{K}_{\mathrm{d}}$ por mês foi utilizada.

$$
E_{P A R}=E \times 0,45 \times 4,57 \times e^{-K_{d} \times P}
$$


onde E é a irradiância em W.m $\mathrm{m}^{-2} ; 0,45$ corresponde a faixa do espectro de luz da fotossíntese (Kirk, 1994); 4,57 o fator de conversão entre W. $\mathrm{m}^{-2}$ para $\mu$ mol fótons $\mathrm{m}^{-2} \mathrm{~s}^{-1}$ (Thimijan \& Heins, 1983) e; P a profundidade de coleta da amostra.

\subsubsection{Pré-processamento e controle de qualidade dos dados obtidos pelo FIRe}

Devido à limitação de precisão do equipamento FIRe para baixas concentrações de clorofila-a e para pequenos tamanhos de células, foi necessário aplicar um controle de qualidade nas tréplicas de aquisição dos parâmetros fotofisiológicos $\mathrm{F}_{\mathrm{o}}, \mathrm{F}_{\mathrm{m}}$ e $\sigma_{\mathrm{PSII}}$, antes de calcular a PP (ver sessão 4.3.3). Para esta finalidade, primeiramente foram removidos manualmente valores negativos, resultado de ruído eletrônico do aparelho, aplicando-se o método baseado em quartis para a remoção de dados espúrios (Equações 5 a 6).

$$
\begin{array}{cc}
\text { Limite Superior } & Q 3+(1.5 * I Q R) \\
\text { Limite Inferior } & Q 1-(1.5 * I Q R) \\
I Q R=Q 3-Q 1
\end{array}
$$

onde Q3 é o terceiro quartil, Q1 o primeiro quartil e IQR é o intervalo interquartil.

Após este processamento, as tréplicas $\left(\mathrm{F}_{\mathrm{o}}, \mathrm{F}_{\mathrm{m}}\right.$ e $\left.\sigma_{\mathrm{PSII}}\right)$ foram testadas por ANOVA bi-fatorial sem repetição, com a finalidade de uni-las e aplicá-las aos modelos de ajuste da estimativa de PP, obtida pelo método de fluorescência variável, em função da irradiância. Os parâmetros fotossintéticos incluem a inclinação inicial da curva $\left(\alpha, \mathrm{mg} \mathrm{C} \mathrm{Chl}{ }^{-1} \mathrm{~h}^{-1}\right.$ mol quanta $\left.\mathrm{m}^{-2} \mathrm{~s}^{-1}\right)$ e a magnitude da irradiância de saturação (Ek, mol quanta $\left.\mathrm{m}^{-2} \mathrm{~s}^{-1}\right)$, ou curvas P-E. Os modelos P-E descritos por Jassby \& Platt (1976), Platt et al. (1981) e Eilers \& Peeters (1988), que aqui serão chamados de modelos JP, PGH e EP foram testados par a par (Teste-t student), a partir do valor de PP. Em seguida ao teste, um dos ajustes foi escolhido para estimar a PP integrada ao longo de um período de 24 horas, ou seja, com a finalidade de comparar estes valores por aqueles obtidos pelo método de Taxas Metabólicas $\left(\mathrm{mg} \mathrm{C} \mathrm{m}^{-2} \mathrm{~d}^{-1}\right)$.

\subsubsection{Teste de incubação dos parâmetros fotofisiológicos}

Os parâmetros fotofisiológicos também foram medidos após o período de incubação em amostras confinadas simultaneamente ao experimento de taxas metabólicas. Desta forma, as 
variações entre início e final destes parâmetros e de variáveis oceanográficas foram registradas. A diferença entre a produção primária calculada pelo método de Fluorescência Ativa Variável também foi analisada por comparação par a par (Teste-t Student).

\subsubsection{Variáveis do modelo Bio-óptico}

Com a finalidade de identificar a relação entre os coeficientes de absorção espectral de luz pelo fitoplâncton $\left(a_{\mathrm{ph}}\right)$ e detritos $\left(\mathrm{a}_{\mathrm{d}}\right)$ em diferentes comprimentos de onda $(\lambda)$ e a concentração de clorofila-a, foram realizadas regressões lineares, bem como o coeficiente de determinação $\left(\mathrm{R}^{2}\right)$ e a probabilidade de significância (valor-p).

\subsubsection{Influência das variáveis oceanográficas}

A princípio cada método de produção primária foi relacionado linearmente com as variáveis oceanográficas: temperatura, salinidade, concentração de clorofila-a e a profundidade do disco de Secchi, em que em todos foram estimados o coeficiente de determinação $\left(\mathrm{R}^{2}\right)$ e a probabilidade de significância (valor-p). Em seguida, identificou-se as variáveis que explicam os métodos por remoção e adição de previsores, diminuindo erros e por fim ajudar a ajustar o melhor modelo por regressão múltipla. Para esta etapa, foi necessário utilizar o método de análise de regressão por passos "de trás para a frente", ou seja, removendo variável a variável até ajuste mais forte ser alcançado, método este recomendado para conjunto de dados com mais números amostrais do que variáveis preditivas (Kassambara, 2018). 


\section{RESULTADOS}

Os dados compreendem 5 séries distintas, sendo então o Bloco 1.1 composto por janeiro a fevereiro de 2014, o Bloco 1.2 por maio a agosto de 2014, o Bloco 2.1 por outubro a dezembro de 2015, o Bloco 2.2 por janeiro a março de 2016 e, o Bloco 3 por janeiro a março de 2018 . Uma vez que as variáveis ambientais em B1.1 e B1.2 já foram apresentadas em Giannini \& Ciotti (2016), as subseções seguintes apresentarão apenas as variáveis nos outros blocos descritos anteriormente.

\subsection{Variáveis ambientais ao longo do período experimental}

\subsubsection{Dados meteorológicos}

Durante os três últimos blocos de dados (Tabela 2, Figuras 4 a 7), pode-se identificar que tanto B2.2, quanto B3 apresentaram média de irradiância, considerando dia e noite, semelhantes $\left(193 \pm 289 \mathrm{~W} \mathrm{~m}^{-2}\right.$ e $199 \pm 292 \mathrm{~W} \mathrm{~m}^{-2}$, respectivamente - Figura $\left.8 \mathrm{a}\right)$, e o mesmo foi registrado para a temperatura atmosférica, com médias de $26,7 \pm 3,5^{\circ} \mathrm{C}$ e $26,4 \pm 3,1^{\circ} \mathrm{C}$, respectivamente (Figura 8 b). Durante B2.1 foi observado os maiores registros de velocidade do vento $(14,0 \pm$ $9,3 \mathrm{~km} \mathrm{~h}^{-1}$, Figura 8c). Destaca-se que B3, apresentou comparativamente a menor velocidade de ventos, porém maior o volume de chuva (média 0,06 $\pm 0.50 \mathrm{~mm}$, Figura 8c).

Tabela 2. Valores (mínimos, máximos, média e desvio padrão - DP) das variáveis obtidas pela estação meteorológica do CEBIMar/USP (2349"25'S e $4^{\circ} 25^{\prime}$ '18'O), de irradiância (W $\left.\mathbf{m}^{-2}\right)$, temperatura atmosférica $\left({ }^{\circ} \mathrm{C}\right)$, velocidade do vento $\left(\mathrm{km} \mathrm{h}^{-1}\right)$ e o volume de chuva $(\mathrm{mm})$ durante os 3 blocos de dados. Note que o volume de chuva representa taxas instantâneas.

\begin{tabular}{ccccccc}
\hline Variável & Bloco & Período & Mínimo & Máximo & Média & DP \\
\hline \multirow{2}{*}{ Irradiância $\left(\mathbf{W ~ m ~}^{-\mathbf{2}}\right)$} & $\mathbf{2 . 1}$ & Out-Dez 2015 & 0 & 1180 & 169 & 259 \\
& $\mathbf{2 . 2}$ & Jan-Fev 2016 & 0 & 1203 & 193 & 289 \\
& $\mathbf{3}$ & Jan-Mar 2018 & 0 & 1243 & 199 & 292 \\
\hline Temperatura atmosférica $\left({ }^{\circ} \mathbf{C}\right)$ & $\mathbf{2 . 1}$ & Out-Dez 2015 & 18,4 & 39,4 & 24,9 & 3,4 \\
& $\mathbf{2 . 2}$ & Jan-Fev 2016 & 19,9 & 41,2 & 26,7 & 3,5 \\
Velocidade do vento $\left(\mathbf{k m ~ h}^{\mathbf{- 1}}\right)$ & $\mathbf{3}$ & Jan-Mar 2018 & 20,4 & 37,6 & 26,4 & 3,1 \\
\hline & $\mathbf{2 . 1}$ & Out-Dez 2015 & 0,0 & 59,5 & 14,0 & 9,3 \\
Chuva $(\mathbf{m m})$ & Jan-Fev 2016 & 0,0 & 46,7 & 10,9 & 7,5 \\
& $\mathbf{3}$ & Jan-Mar 2018 & 0,0 & 41,8 & 9,5 & 6,2 \\
\hline & $\mathbf{2 . 2}$ & Out-Dez 2015 & 0,00 & 13,20 & 0,02 & 0,21 \\
& $\mathbf{3}$ & Jan-Fev 2016 & 0,00 & 13,20 & 0,03 & 0,31 \\
& & & 0,00 & 17,60 & 0,06 & 0,50 \\
\hline
\end{tabular}




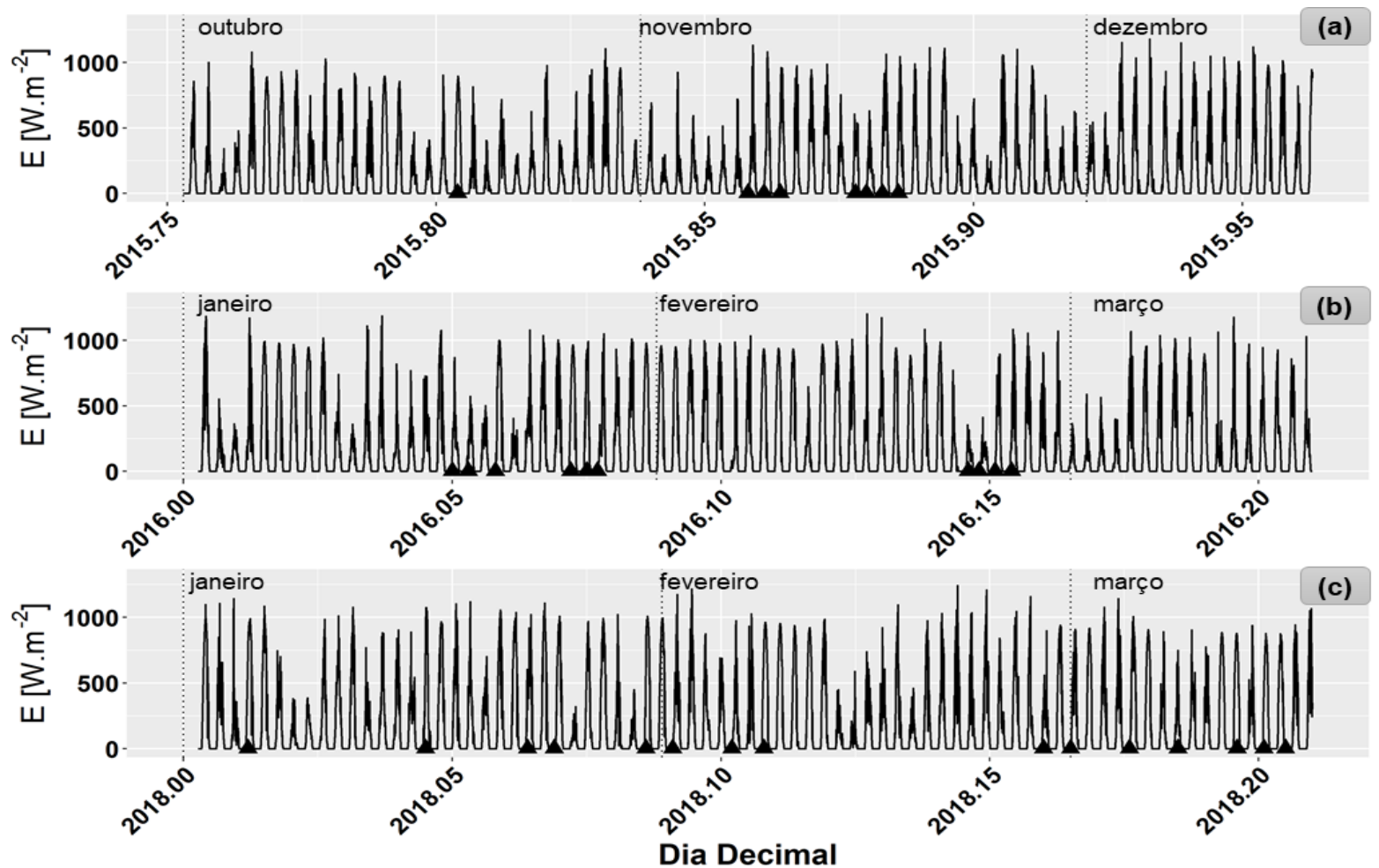

Figura 4. Séries temporais da irradiância $\left(\mathrm{W} \mathrm{m}^{-2}\right)$ medida pela estação meteorológica do CEBIMar/USP $\left(23^{\circ} 49^{\prime \prime} 25\right.$ 'S e $\left.45^{\circ} 25^{\prime \prime} 18^{\prime} O\right)$ durante os blocos dos dados, em que (a) corresponde à B2.1 ou período entre outubro e dezembro de 2015, (b) B2.2 ou janeiro a março de 2016, e (c) B3 ou janeiro a março de 2018. Os triângulos indicam os dias em que foram realizados os experimentos de produção primária e coleta de outras variáveis. 


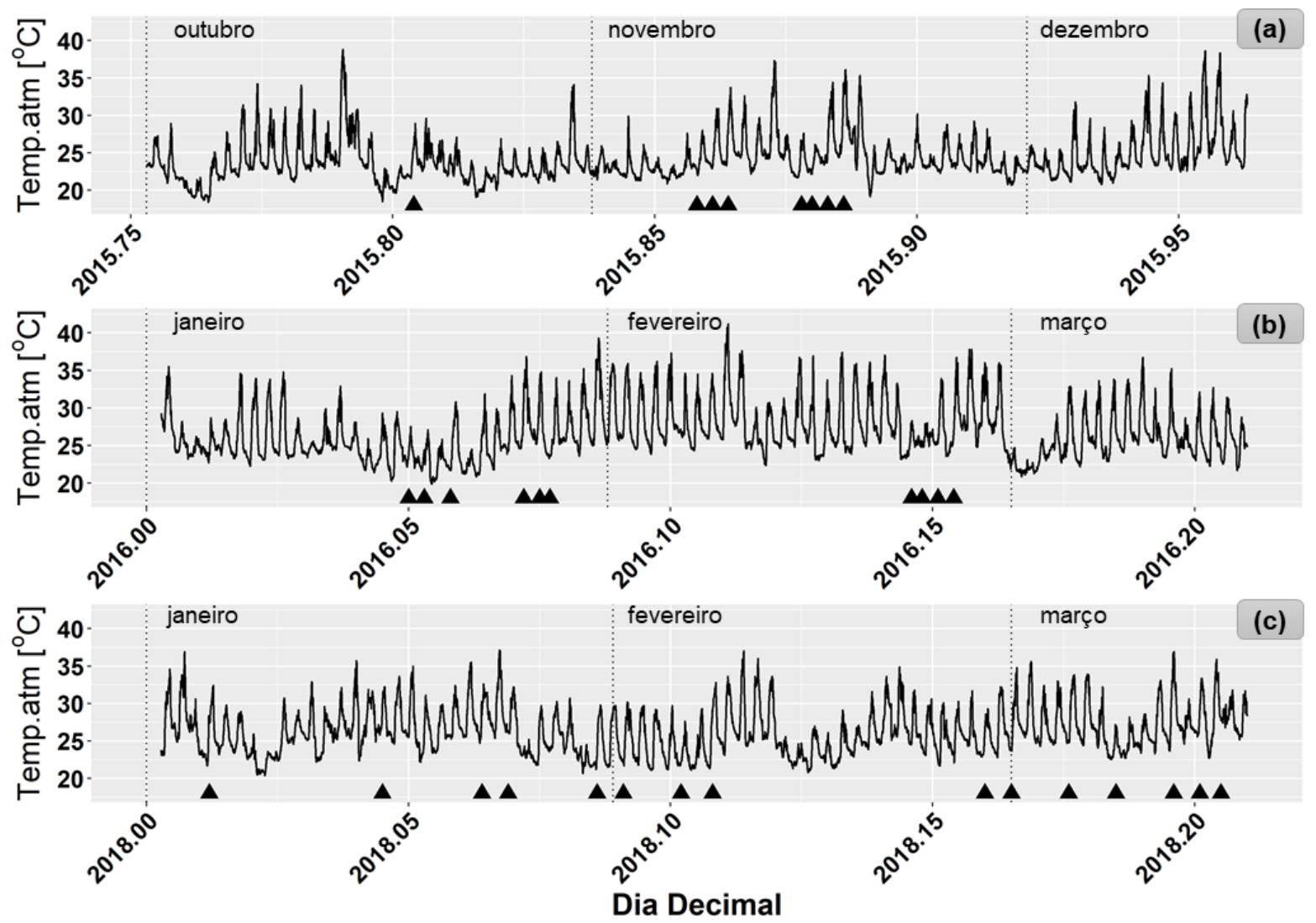

Figura 5. Séries temporais da temperatura atmosférica $\left({ }^{\circ} \mathrm{C}\right)$ medida pela estação meteorológica do CEBIMar/USP (23 ${ }^{\circ} 49^{\prime \prime 25}$ 'S e $4^{\circ} 25^{\prime}$ '18'O) durante os blocos dos dados, em que (a) corresponde à B2.1 ou período entre outubro e dezembro de 2015, (b) B2.2 ou janeiro a março de 2016, e (c) B3 ou janeiro a março de 2018. Os triângulos indicam os dias em que foram realizados os experimentos de produção primária e coleta de outras variáveis. 


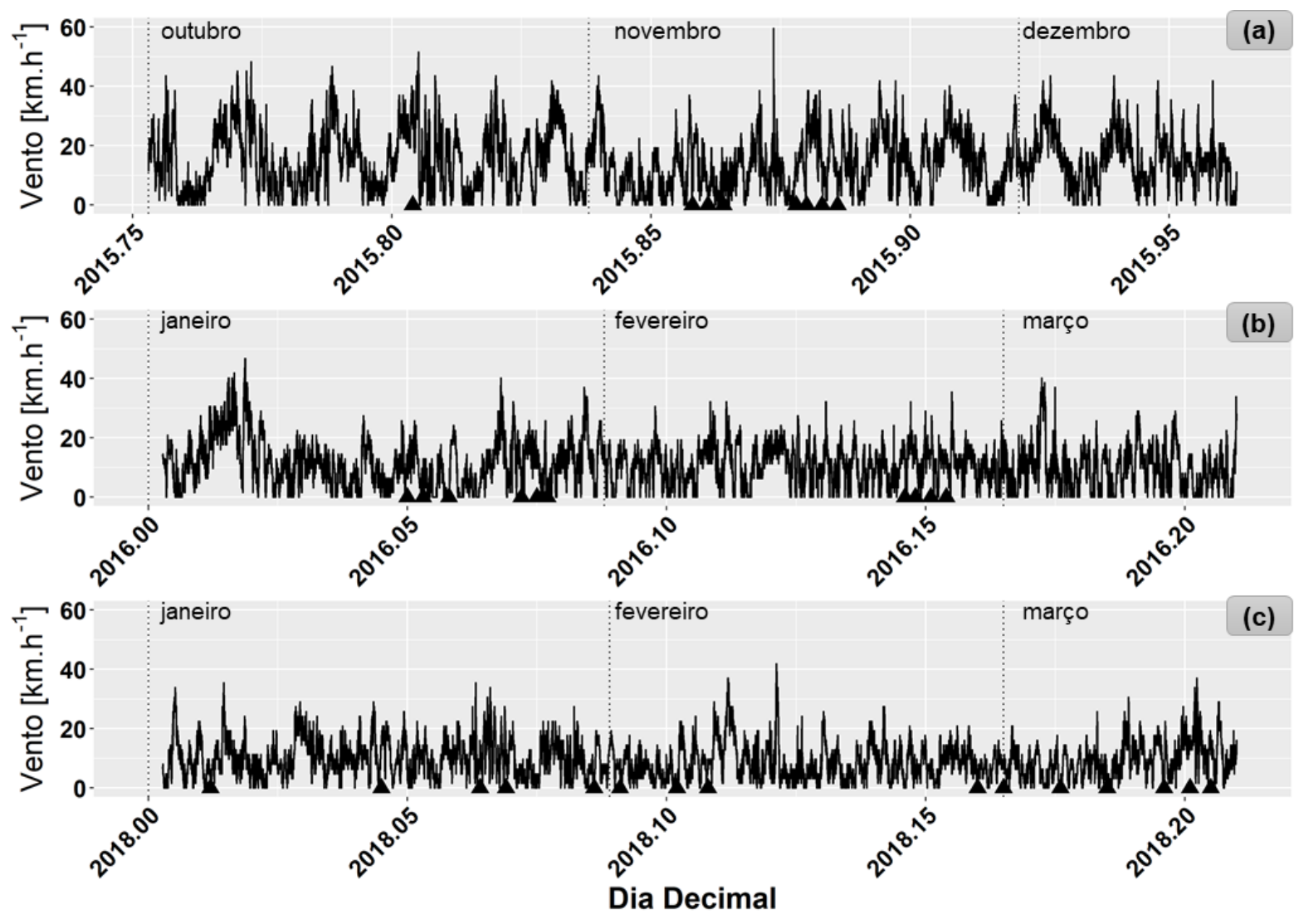

Figura 6. Séries temporais da velocidade do vento $\left(\mathrm{km} \cdot \mathrm{h}^{-1}\right)$ medida pela estação meteorológica do CEBIMar/USP $\left(23^{\circ} 49^{\prime}{ }^{\prime} 25^{\prime} S\right.$ e $4^{\circ} 25^{\prime}$ '18'O) durante os blocos dos dados, em que (a) corresponde à B2.1 ou período entre outubro e dezembro de 2015, (b) B2.2 ou janeiro a março de 2016, e (c) B3 ou janeiro a março de 2018. Os triângulos indicam os dias em que foram realizados os experimentos de produção primária e coleta de outras variáveis. 


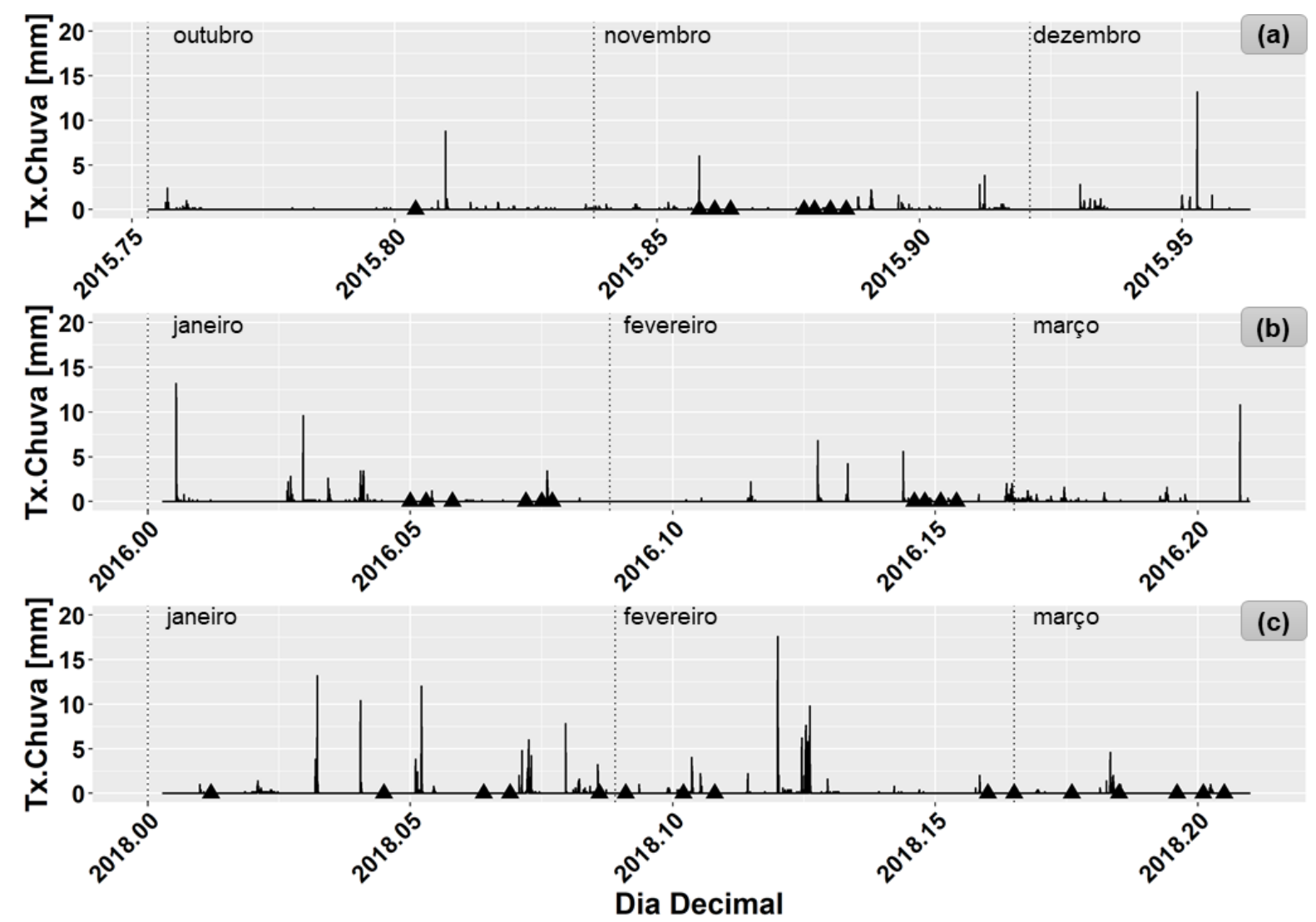

Figura 7. Séries temporais de taxa instantânea de precipitação $(\mathrm{mm})$ medida pela estação meteorológica do CEBIMar/USP (2349" 25 ' S e 45 ${ }^{\circ} 25^{\prime}$ '18' O) durante os blocos dos dados, em que (a) corresponde à B2.1 ou período entre outubro e dezembro de 2015, b) B2.2 ou janeiro a março de 2016, e (c) B3 ou janeiro a março de 2018. Os triângulos indicam os dias em que foram realizados os experimentos de produção primária e coleta de outras variáveis. 

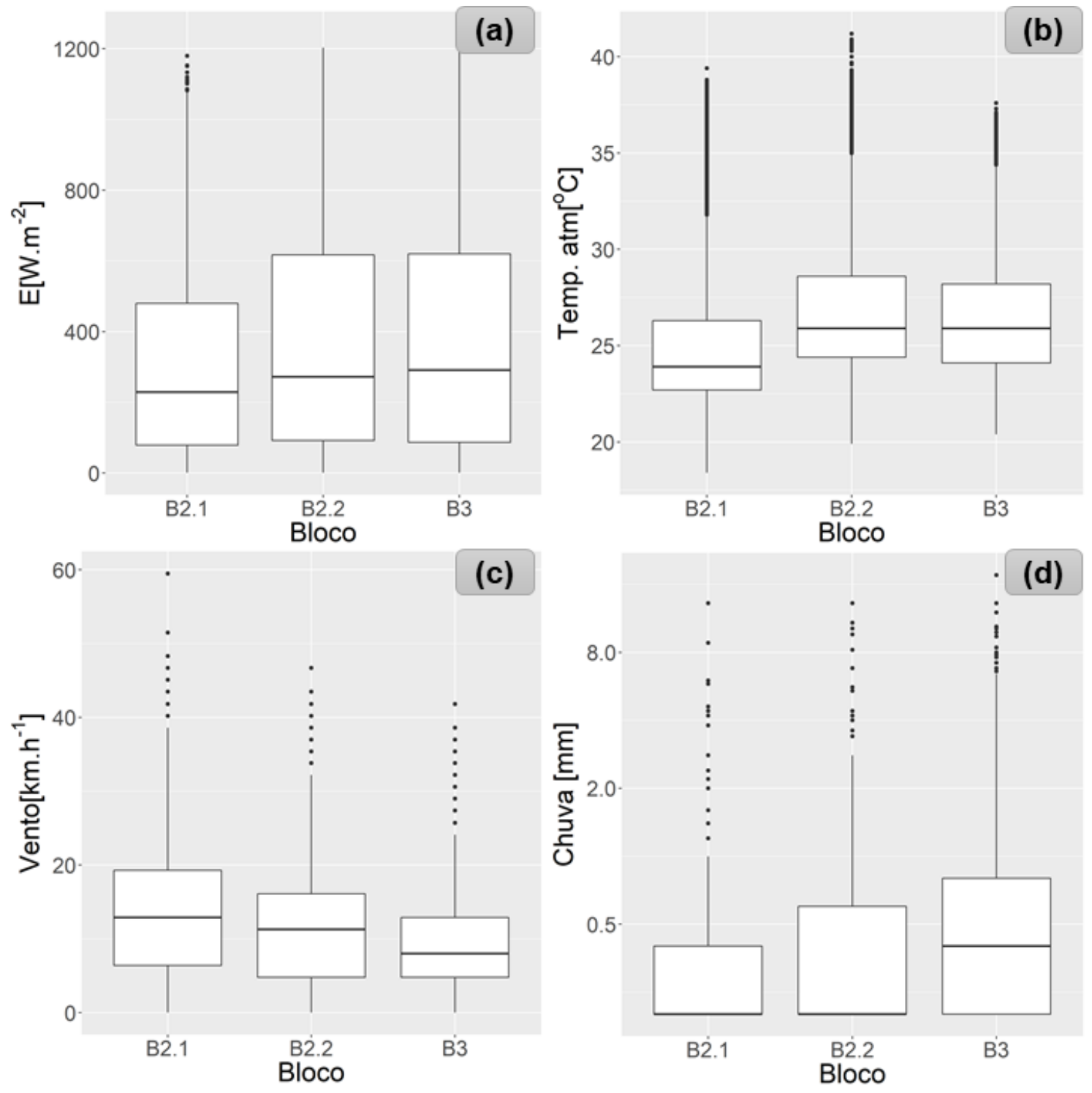

Figura 8. Variação dos valores registrados pela estação meteorológica do CEBIMar/USP $\left(23^{\circ} 44^{\prime}\right.$ '25' S e $45^{\circ} 25^{\prime}$ ' 18' O), em (a) irradiância $\left(W^{-2}\right)$; (b) temperatura atmosférica $\left({ }^{\circ} \mathrm{C}\right)$; (c) velocidade do vento $\left(\mathrm{km} \mathrm{h}^{-}\right.$ 1), e; (d) volume de chuva - note dados em escala logarítmica para melhor visualização $(\mathrm{mm})$, nos blocos B2.1 (outubro a dezembro de 2015), B2.2 (janeiro a março de 2016) e B3 (janeiro a março de 2018).

Os valores médios e desvio para todo o período de B1.1 e B1.2, respectivamente, foram de irradiância de $286 \pm 369 \mathrm{~W} \mathrm{~m}^{-2}$ e $138 \pm 225 \mathrm{~W} \mathrm{~m}^{-2}$, temperatura atmosférica de $28,9 \pm 3,7^{\circ} \mathrm{C}$ e $21,9 \pm 2,9^{\circ} \mathrm{C}$, velocidade do vento $13,8 \pm 7,9 \mathrm{~km} \mathrm{~h}^{-1}$ e $13,9 \pm 9,0 \mathrm{~km} \mathrm{~h}^{-1}$, e por fim a chuva instantânea de 0,03 $\pm 0,43 \mathrm{~mm}$ e $0,01 \pm 0,13 \mathrm{~mm}$. É importante ressaltar, que estes dados são provenientes da mesma base de dados da estação meteorológica utilizada nos outros blocos, e não foram descritos como os outros por estarem descritos parcialmente em Giannini \& Ciotti (2016) e Ciotti et al. (2018). 


\subsubsection{Série temporal dos dados oceanográficos da boia SIMCosta}

As figuras 9 a 12 apresentam as séries temporais dos dados oceanográficos coletados por sensores instalados na boia SP01 do projeto SIMCosta próximo a superfície (0,6 metros). Note que em alguns períodos não existem dados devido a manutenção dos equipamentos ou plataforma. Durante B2.2, observou-se a maior variação da temperatura da água (média 26,8 \pm $1,9^{\circ} \mathrm{C}$ ), enquanto durante B2.1, registrou-se temperaturas mais baixas (Figura 13a, Tabela 3). Em B2.2 a média de salinidade foi a menor $(33,9 \pm 0,5)$, no entanto em B3 houve a maior amplitude de valores observados, entre 16,9 e 35,4 (Figura 13b, Tabela 3). A turbidez (Figura 13c, Tabela 3) apresentou a maior média (3,5 $\pm 3,0 \mathrm{NTU})$, mas também a maior variação (entre 0,3 a 23,3 NTU), em B2.1. Observou-se que a fluorescência da clorofila-a (Figura 13, Tabela 3) média em B2.1 foi a maior, no entanto, foi em B3 que houve o máximo registrado de 6,3 mg $\mathrm{m}^{-3}$.

Tabela 3. Valores (mínimos, máximos, médias e desvios padrão - DP) das variáveis obtidas pela boia meteooceanográfica do SIMCosta em 1 metro de profundidade, da temperatura $\left({ }^{\circ} \mathrm{C}\right)$, salinidade, turbidez (NTU) e a fluorescência da clorofila-a (URF) para cada bloco de dados (ver períodos correspondentes no texto e na Tabela 2).

\begin{tabular}{cccccc}
\hline Variável & Bloco & Mínimo & Máximo & Média & DP \\
\hline \multirow{3}{*}{ Temperatura $\left({ }^{\circ} \mathbf{C}\right)$} & $\mathbf{2 . 1}$ & 22,1 & 28,3 & 24,5 & 0,9 \\
& $\mathbf{2 . 2}$ & 23,0 & 30,3 & 26,8 & 1,9 \\
& $\mathbf{3}$ & 24,5 & 30,0 & 27,6 & 0,8 \\
\hline \multirow{3}{*}{ Salinidade } & $\mathbf{2 . 1}$ & 32,2 & 35,1 & 33,9 & 0,5 \\
& $\mathbf{2 . 2}$ & 32,1 & 35,1 & 34,3 & 0,5 \\
& $\mathbf{3}$ & 16,9 & 35,4 & 34,0 & 1,2 \\
\hline \multirow{3}{*}{ Turbidez (NTU) } & $\mathbf{2 . 1}$ & 0,3 & 23,3 & 3,5 & 3,0 \\
& $\mathbf{2 . 2}$ & 0,1 & 4,2 & 1,1 & 0,8 \\
& $\mathbf{3}$ & 0,1 & 15,1 & 1,0 & 1,0 \\
\hline \multirow{2}{*}{ Fluorescência da clorofila- } & $\mathbf{2 . 1}$ & 0,2 & 3,0 & 1,0 & 0,5 \\
a (URF) & $\mathbf{2 . 2}$ & 0,2 & 2,4 & 0,7 & 0,3 \\
& $\mathbf{3}$ & 0,1 & 6,3 & 0,7 & 0,4 \\
\hline
\end{tabular}




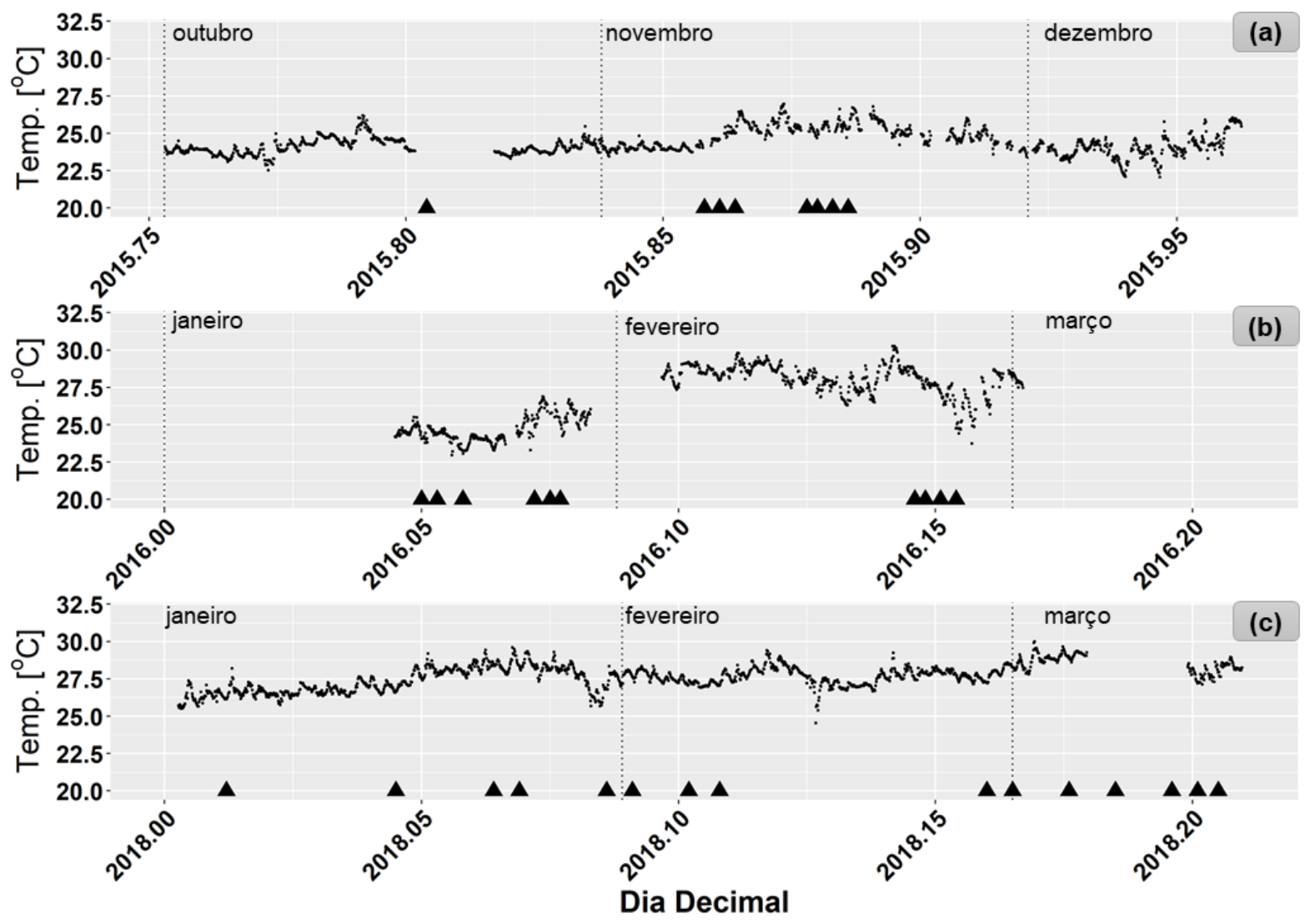

Figura 9. Séries temporais da temperatura da água $\left({ }^{\circ} \mathrm{C}\right)$ medida por sensores instalados a 0,6 metros de profundidade na boia meteo-oceanográfica SP01 do projeto SIMCosta, em que (a) corresponde à B2.1 ou período entre outubro e dezembro de 2015, (b) B2.2 ou janeiro a março de 2016, e (c) B3 ou janeiro a março de 2018. Os triângulos indicam os dias em que foram realizadas as campanhas para medição da produção primária e coleta de outras variáveis. Lacunas de dados são referentes a períodos de manutenção dos sensores. 


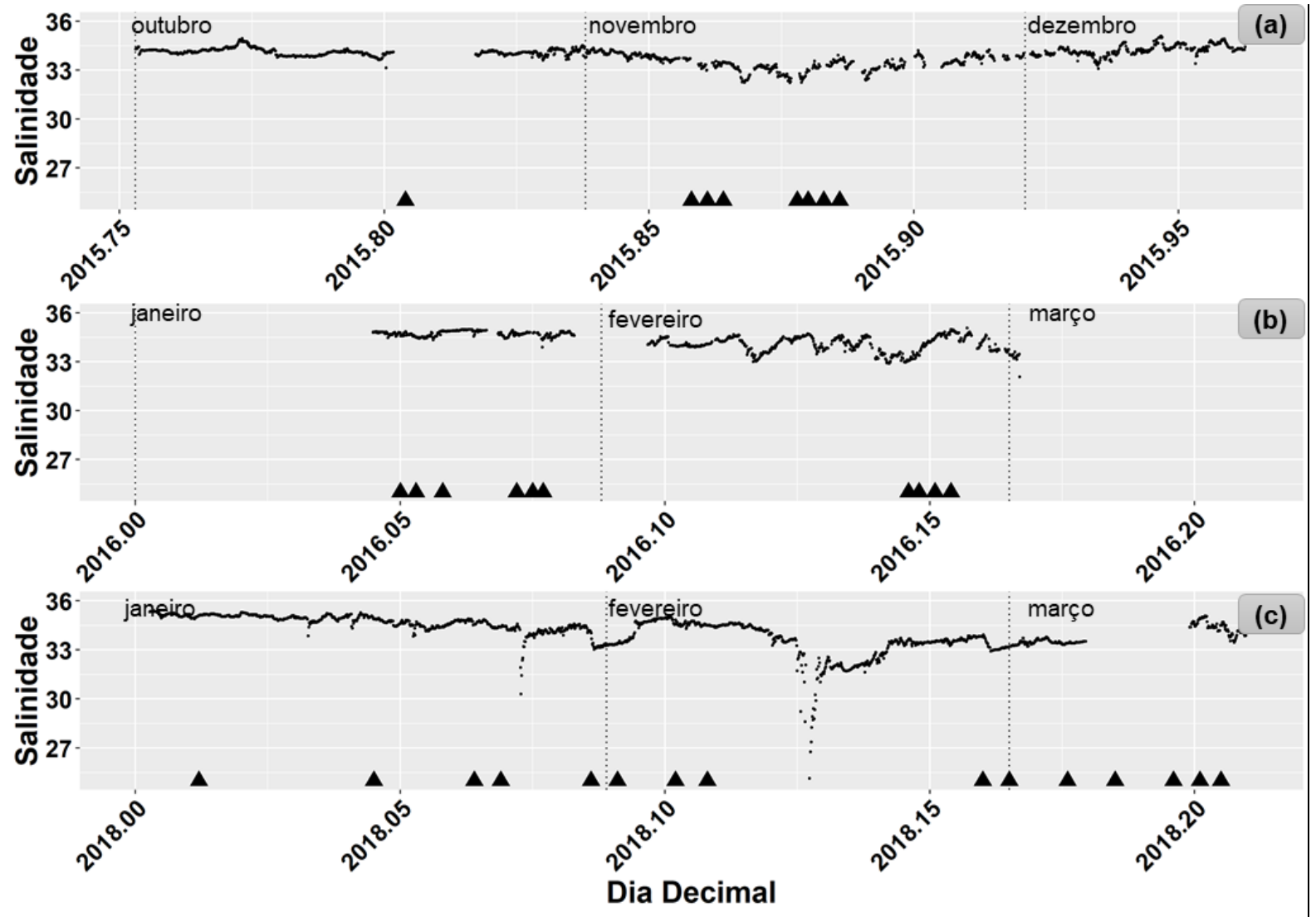

Figura 10. Séries temporais da salinidade medida por sensores instalados a 0,6 metros de profundidade na boia meteo-oceanográfica SP01 do projeto SIMCosta, em que (a) corresponde à B2.1 ou período entre outubro e dezembro de 2015, (b) B2.2 ou janeiro a março de 2016, e (c) B3 ou janeiro a março de 2018. Os triângulos indicam os dias em que foram realizadas as campanhas para medição da produção primária e coleta de outras variáveis. Lacunas de dados são referentes a períodos de manutenção dos sensores. Para melhor visualização das séries, limite mínimo de salinidade 25 foi empregado, no entanto, foi registrado 1 valor inferior em B3 ( 16) no dia 15 de fevereiro. 


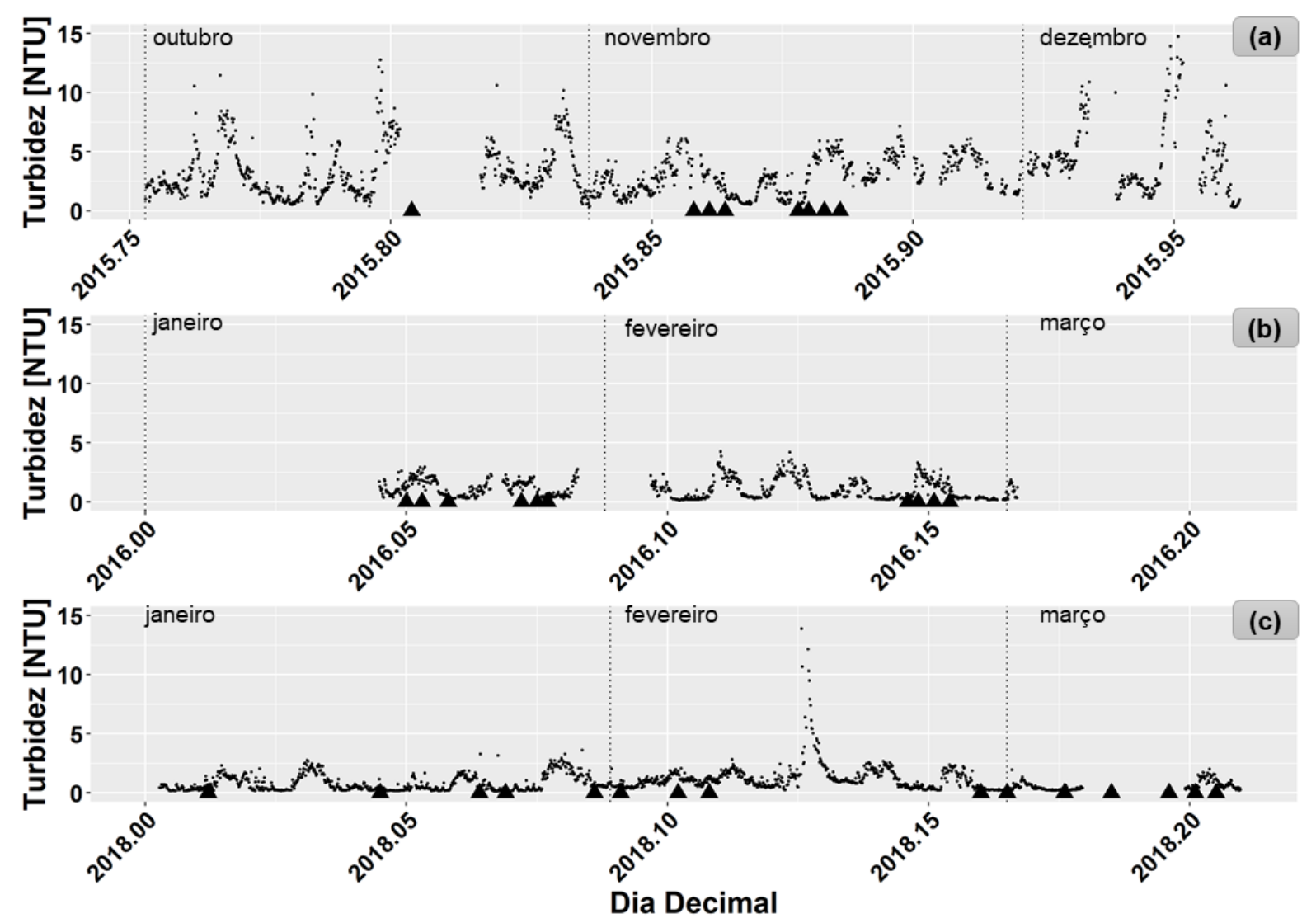

Figura 11. Séries temporais da turbidez da água (NTU) medida por sensores instalados a 0,6 metros de profundidade na boia meteo-oceanográfica SP01 do projeto SIMCosta, em que (a) corresponde à B2.1 ou período entre outubro e dezembro de 2015, (b) B2.2 ou janeiro a março de 2016, e (c) B3 ou janeiro a março de 2018. Os triângulos indicam os dias em que foram realizadas as campanhas para medição da produção primária e coleta de outras variáveis. Lacunas de dados são referentes a períodos de manutenção dos sensores. Para melhor visualização das séries, limite máximo de 15 NTU foi empregado, no entanto, foram registrados 25 valores em B2.1 (nos dias 13 e 18 de outubro e 6, 7, 8 12, 13, 14 e 21 de dezembro) e 1 valor superior em B3 (no dia 15 de fevereiro). 


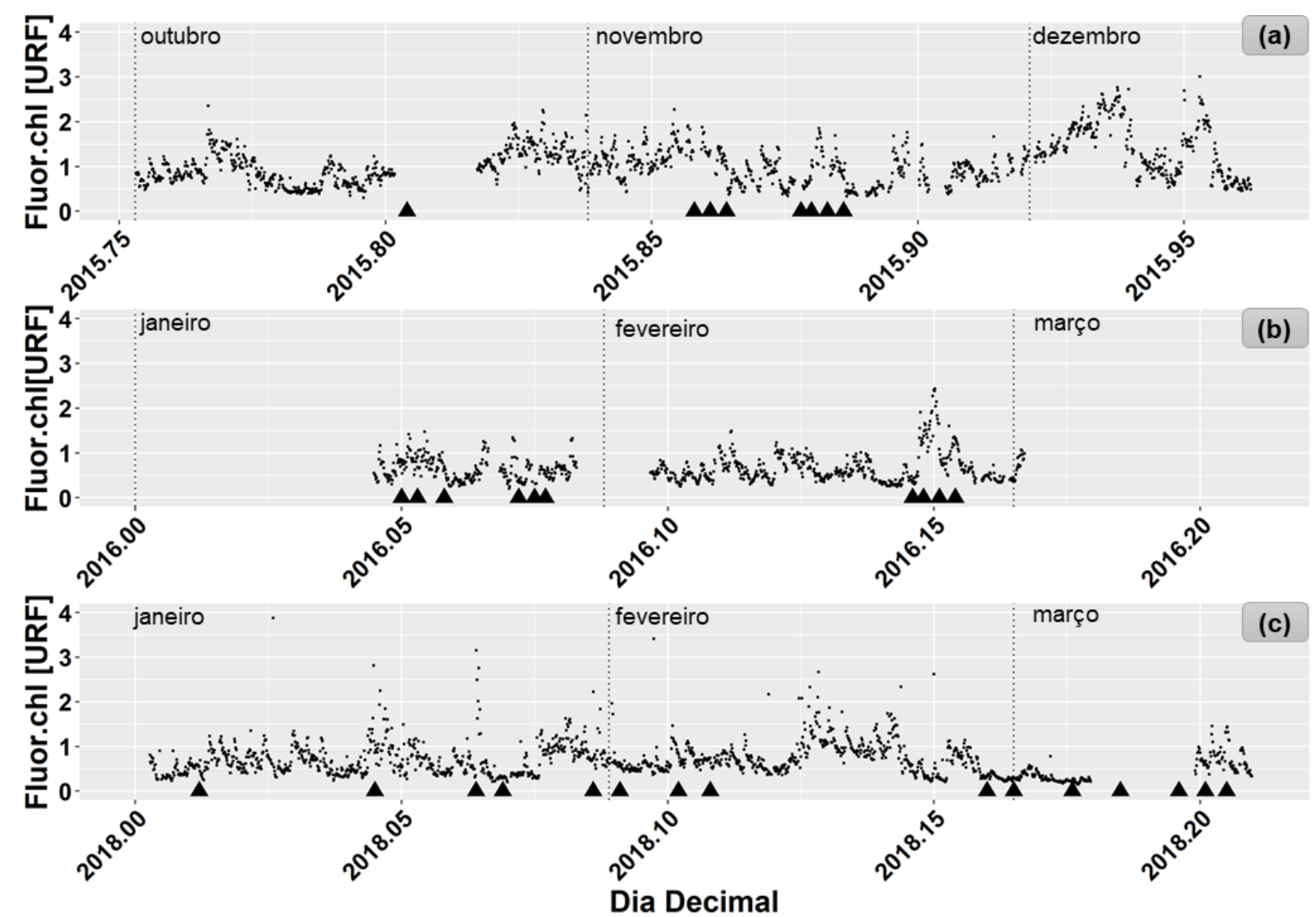

Figura 12. Séries temporais da fluorescência da clorofila-a (URF) medida por sensores instalados a 0,6 metros de profundidade na boia meteo-oceanográfica SP01 do projeto SIMCosta, em que (a) corresponde à B2.1 ou período entre outubro e dezembro de 2015, (b) B2.2 ou janeiro a março de 2016, e (c) B3 ou janeiro a março de 2018. Os triângulos indicam os dias em que foram realizadas as campanhas para medição da produção primária e coleta de outras variáveis. Lacunas de dados são referentes a períodos de manutenção dos sensores. Para melhor visualização das séries, limite máximo de 4 URF foi empregado, no entanto, foram registrados 4 valores superiores em $B 3$, nos dias 1, 2, 4 e 21 de fevereiro. 

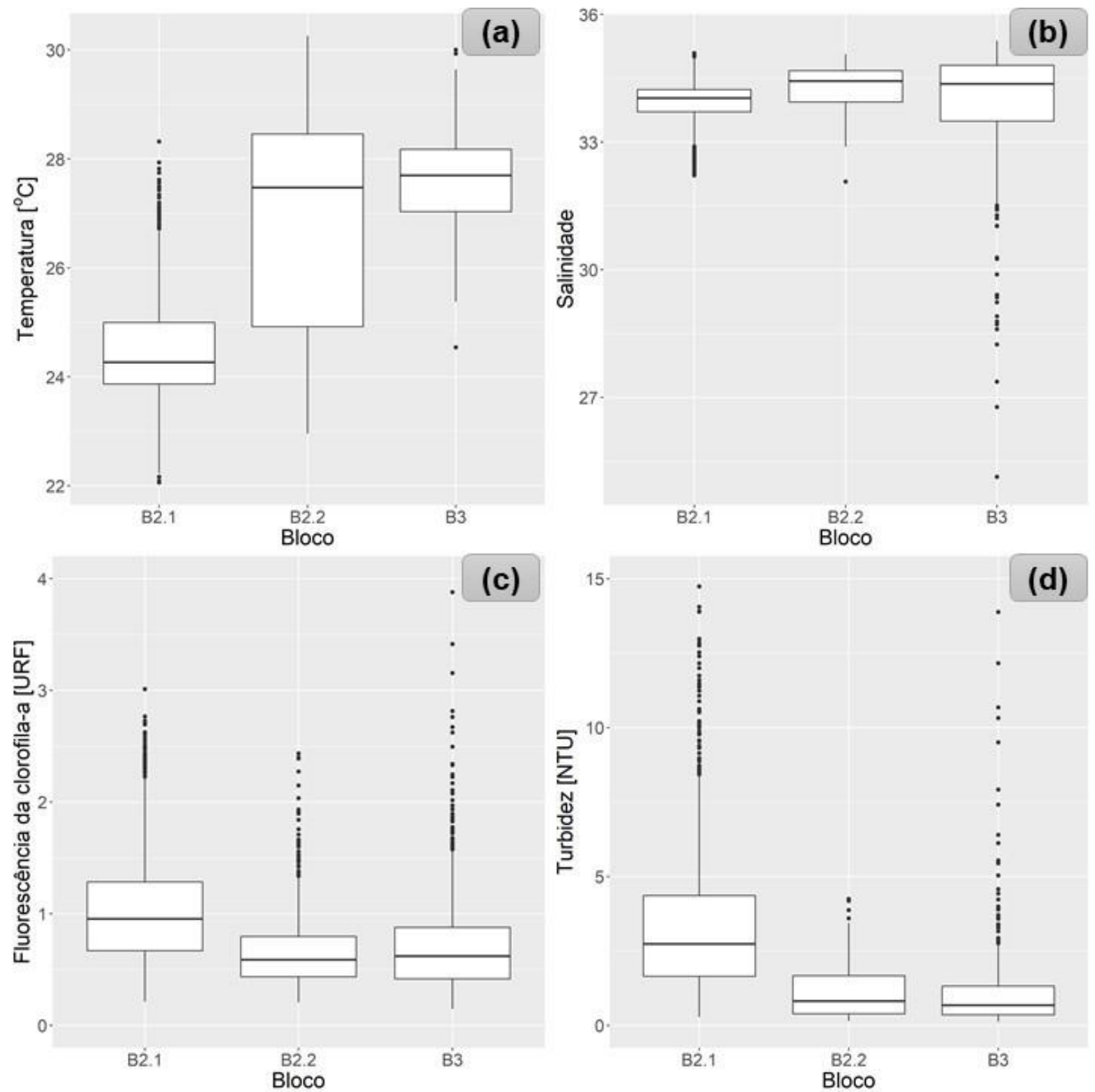

Figura 13. Variação dos dados oceanográficos registrados pela boia meteo-oceanográfica do SIMCosta, em (a) temperatura da água $\left({ }^{\circ} \mathrm{C}\right)$; (b) salinidade; (c) fluorescência da clorofila-a (URF), e; (d) turbidez (NTU), nos blocos B2.1 (outubro a dezembro de 2015), B2.2 (janeiro a março de 2016) e B2 (janeiro a março de 2018). Valores inferior a 25 de salinidade ( $n=6 \mathrm{em} \mathrm{B3}), 15$ NTU $(n=25 \mathrm{em} \mathrm{B2.1}$ e $n=1$ em B3) e 4 URF (n=4 em B3) foram ocultados para melhor visualização dos dados.

Note que esses dados não estavam disponíveis durante B1.1 e B1.2, uma vez que a boia meteo-oceanográfica foi instalada em 2015. No entanto, Giannini \& Ciotti (2016) mostram dados de temperatura e salinidade superficial nos dias de coleta (temperatura $28,0 \pm 1,0^{\circ} \mathrm{C}$ e 22,8 $\pm 1,2^{\circ} \mathrm{C}$, salinidade $34,7 \pm 0,3$ e $\left.34,5 \pm 0,26\right)$. 


\subsubsection{Variáveis físico-químicas na coluna d'água}

Durante B2.1 a temperatura da água se manteve relativamente homogênea verticalmente, sendo a estratificação evidente em dezembro de 2015 (Figura 14a), após o período de coletas. Destaca-se que a salinidade nos dias de coleta também não variou da superfície ao fundo, se mantendo abaixo de 34 por quase todo o período (Figura 15a). Por sua vez, destacam-se em B2.1 máximos de turbidez e de fluorescência da clorofila-a (Figuras 16a e 17a), ocorrendo no primeiro dia de coleta. Durante B2.2, identificou-se alternância de períodos com estratificação e homogeneidade vertical (Figura 12b), com mínimos de turbidez (Figura 16b) e máximos de clorofila-a (Figura 15b) ocorrendo na região de baixas temperaturas. B3 foi caracterizado por temperatura alta e homogênea em todo o período e profundidades (Figura 14c), no entanto, com grandes variações de salinidade (Figura 15c). Observa-se também que a turbidez neste bloco (Figura 16c), em geral foi baixa, com leve aumento em direção ao fundo. Por fim, a fluorescência da clorofila-a em B3 (Figura 17c), foi a menor em relação aos outros períodos.
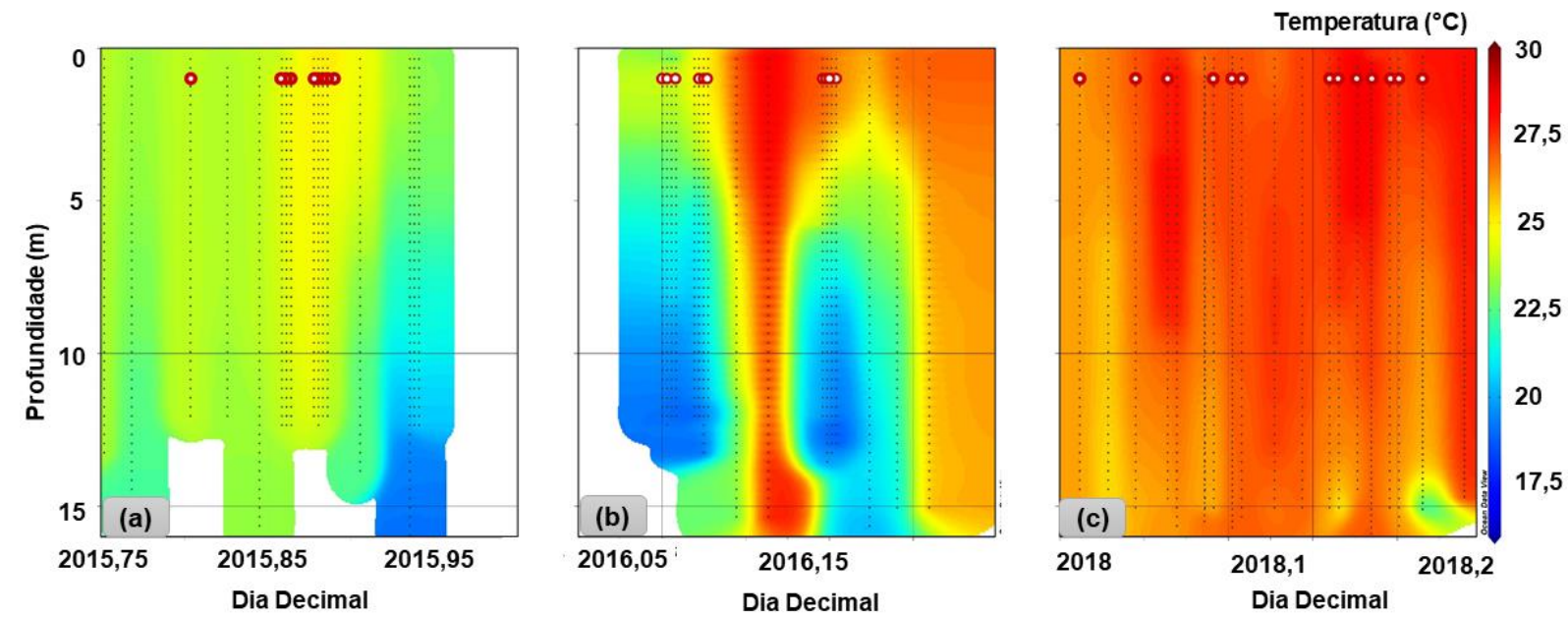

Figura 14. Séries temporais da temperatura $\left({ }^{\circ} \mathrm{C}\right)$ na coluna d'água medido por um CTD (“conductivity, temperature, depth"), em que (a) corresponde à B2.1 ou período entre outubro e dezembro de 2015, (b) B2.2 ou janeiro a março de 2016, e (c) B3 ou janeiro a março de 2018. Os pontos vermelhos indicam os dias em que foram realizadas as campanhas para medição da produção primária e coleta de outras variáveis. As seções representam perfis verticais de CTD semanais no sitio de coleta (Ver sessão 4.5.1 para mais detalhes). 

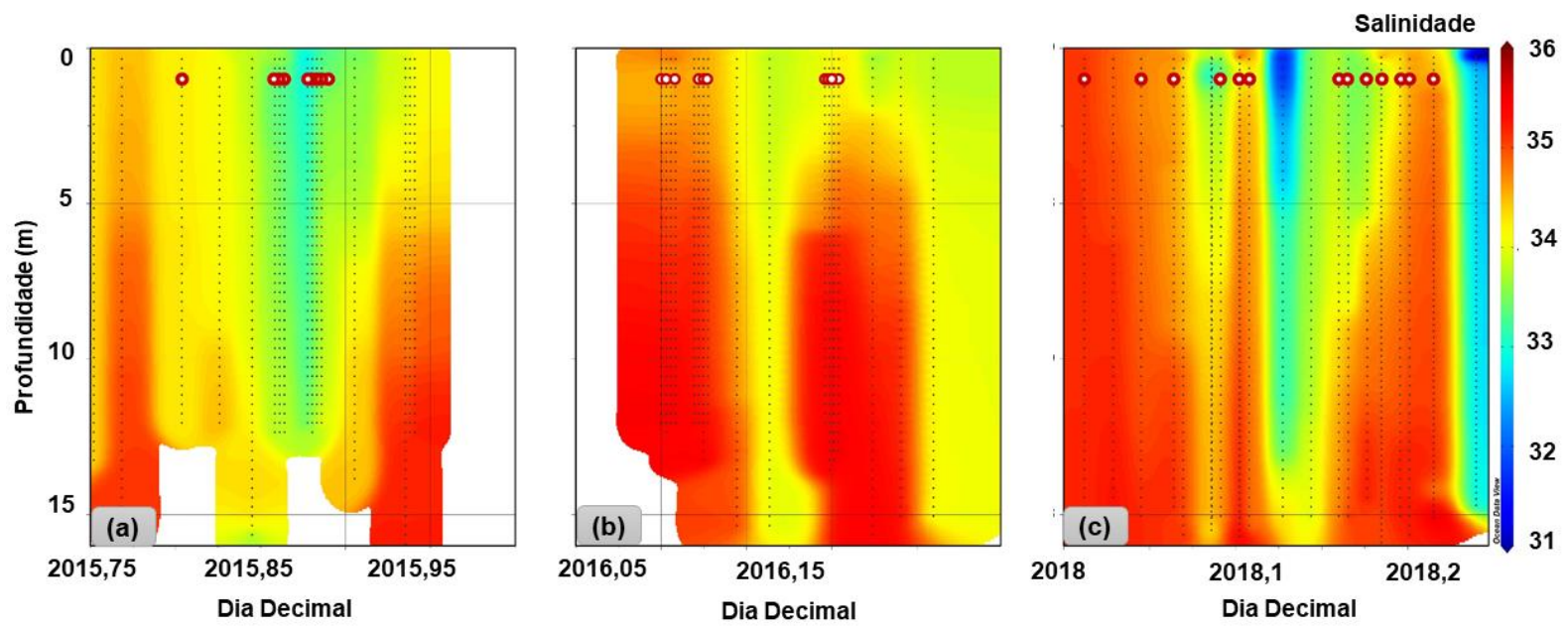

Figura 15. Séries temporais da salinidade na coluna d'água medido por um CTD ("conductivity, temperature, depth"), em que (a) corresponde à B2.1 ou período entre outubro e dezembro de 2015, (b) B2.2 ou janeiro a março de 2016, e (c) $\mathrm{B3}$ ou janeiro a março de 2018. Os pontos vermelhos indicam os dias em que foram realizadas as campanhas para medição da produção primária e coleta de outras variáveis. As seções representam perfis verticais de CTD semanais no sitio de coleta (Ver sessão 4.5.1 para mais detalhes).
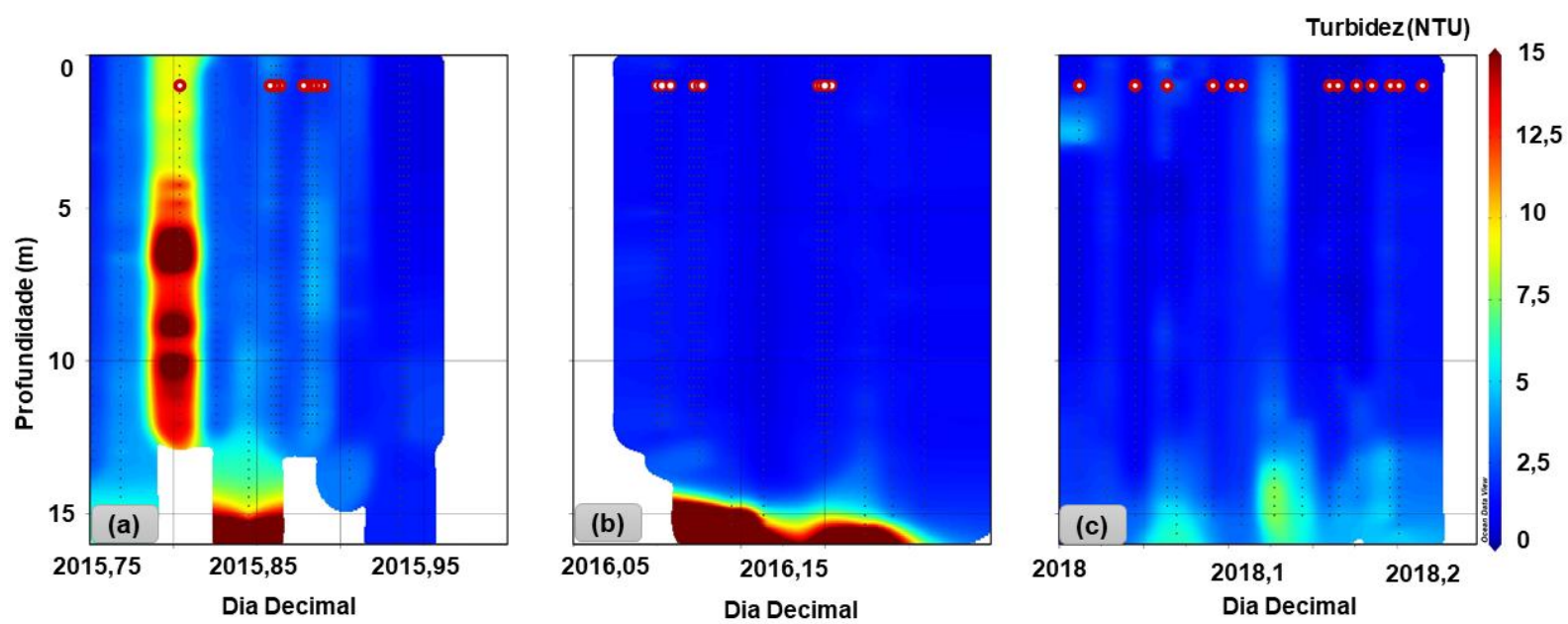

Figura 16. Séries temporais da turbidez (NTU - da sigla em inglês unidade nefelométrica de turbidez) na coluna d'água medido por um CTD ("conductivity, temperature, depth"), em que (a) corresponde à B2.1 ou período entre outubro e dezembro de 2015, (b) B2.2 ou janeiro a março de 2016, e (c) B3 ou janeiro a março de 2018. Os pontos vermelhos indicam os dias em que foram realizadas as campanhas para medição da produção primária e coleta de outras variáveis. As seções representam perfis verticais de CTD semanais no sitio de coleta (Ver sessão 4.5.1 para mais detalhes). 

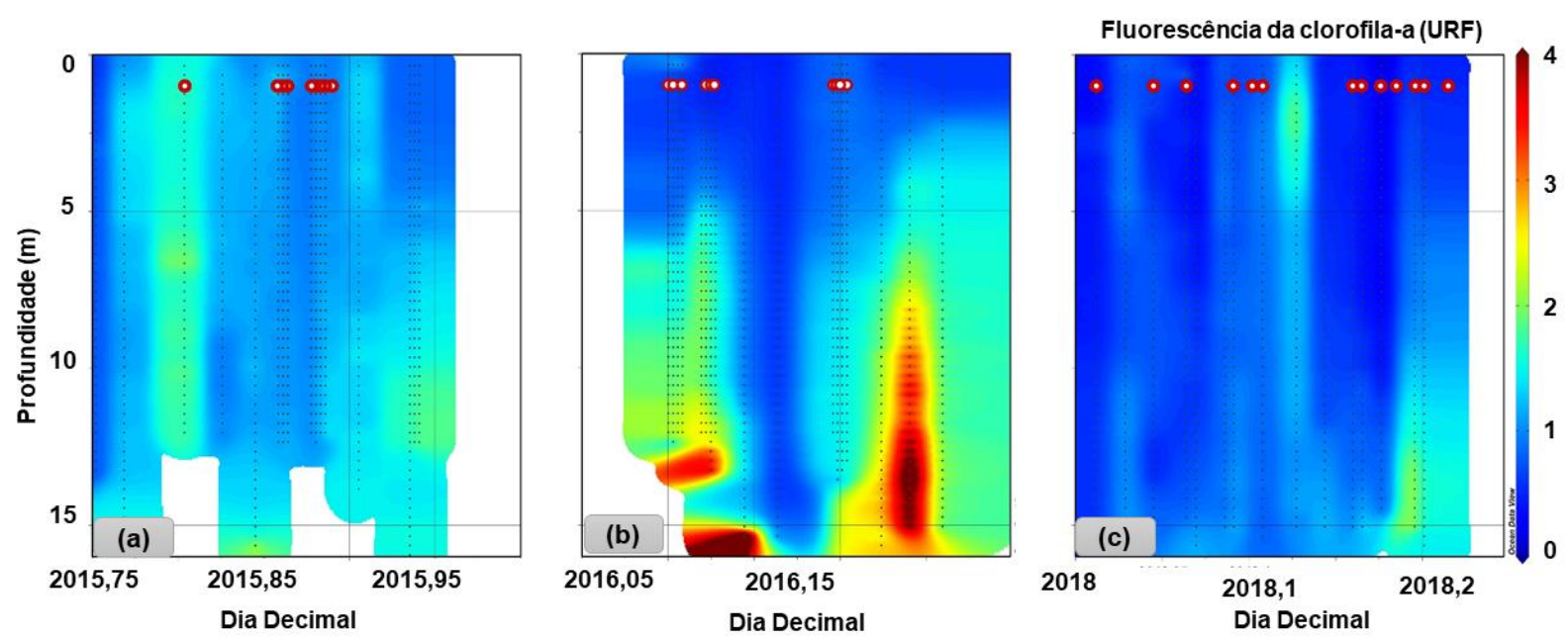

Figura 17. Séries temporais da fluorescência da clorofila-a (URF - unidade relativa de fluorescência) na coluna d'água medido por um CTD (“conductivity, temperature, depth"), em que (a) corresponde à B2.1 ou período entre outubro e dezembro de 2015, (b) B2.2 ou janeiro a março de 2016, e (c) B3 ou janeiro a março de 2018. Os pontos vermelhos indicam os dias em que foram realizadas as campanhas para medição da produção primária e coleta de outras variáveis. As seções representam perfis verticais de CTD semanais no sitio de coleta (Ver sessão 4.5.1 para mais detalhes).

Segundo Ciotti et al. (2018, ver material suplementar), durante B1.1 os perfis de CTD identificaram estratificação da coluna d'água principalmente em fevereiro de 2013, com temperaturas variando aproximadamente entre $20^{\circ} \mathrm{C}$ e $30^{\circ} \mathrm{C}$ e salinidade entre 34 e 36 . Por outro lado, as autoras mostram que em B2.2, os perfis mostram homogeneidade vertical, com diminuição da temperatura ao longo do período e salinidade variada.

\subsubsection{Variação da concentração de clorofila-a in situ e a transparência da água}

A concentração da clorofila-a ([chl], Figura 18a) variou entre 1,48 e 3,86 mg.m ${ }^{-3}, 0,66$ e 2,76 $\mathrm{mg} \mathrm{m}^{-3}$, e 0,33 e 4,03 $\mathrm{mg} \mathrm{m}^{-3}$ nos Blocos 2.1, 2.2 e 3, respectivamente, sendo a maior variação observada durante o Bloco 3 , sendo as médias, $2,13 \pm 0,78 \mathrm{mg} \mathrm{m}^{-3}, 1,49 \pm 0,52 \mathrm{mg} \mathrm{m}^{-}$ 3, 1,16 $\pm 0,91 \mathrm{mg} \mathrm{m}^{-3}$, respectivamente. É evidente o decréscimo da [chl] quando os 3 Blocos são comparados, e a correspondência inversa, e esperada, na profundidade de desaparecimento do disco de Secchi (Figura 18b), mas essa última mostrou grande variação, oscilando entre 1,1 a 7,0 m (média 2,6 $\pm 1,9 \mathrm{~m}$ ), 2,3 a 8,0 m (média $5,0 \pm 2,3 \mathrm{~m}$ ) e 2,2 a $11,0 \mathrm{~m}(6,6 \pm 2,8 \mathrm{~m}$ ), respectivamente. Estes valores indicam águas mais transparentes, e, portanto, uma maior penetração da luz na coluna d'água durante todo o Bloco 3, que foi semelhante a observada durante o Bloco 2.2, mas, no entanto, claramente superior ao Bloco 2. 
A Figura 19 apresenta a relação entre as duas variáveis nos blocos, podendo observar que são inversamente proporcionais umas às outras $\left(\mathrm{R}^{2}=0,44 \mathrm{e} \mathrm{p}=0\right)$. Entre os blocos essa relação só é significativa em $\mathrm{B} 3\left(\mathrm{R}^{2}=0,61\right.$ e p=0,001).
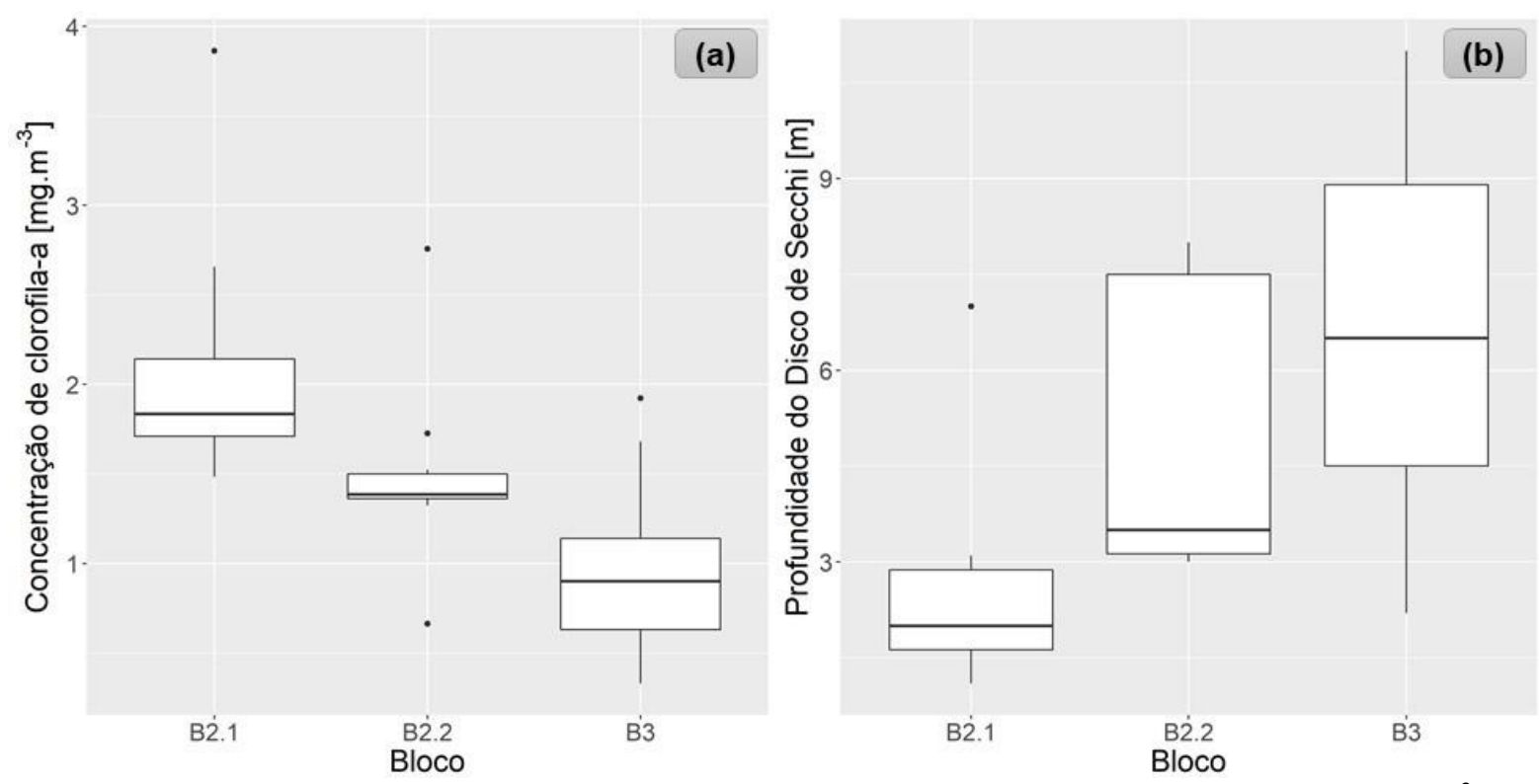

Figura 18. Variação dos valores coletados in situ, em (a) concentração de clorofila-a $\left(\mathrm{mg} \mathrm{m}^{-3}\right)$; (b) profundidade de desaparecimento Disco de Secchi (m), nos blocos B2.1 (outubro a dezembro de 2015), B2.2 (janeiro a março de 2016) e B3 (janeiro a março de 2018).

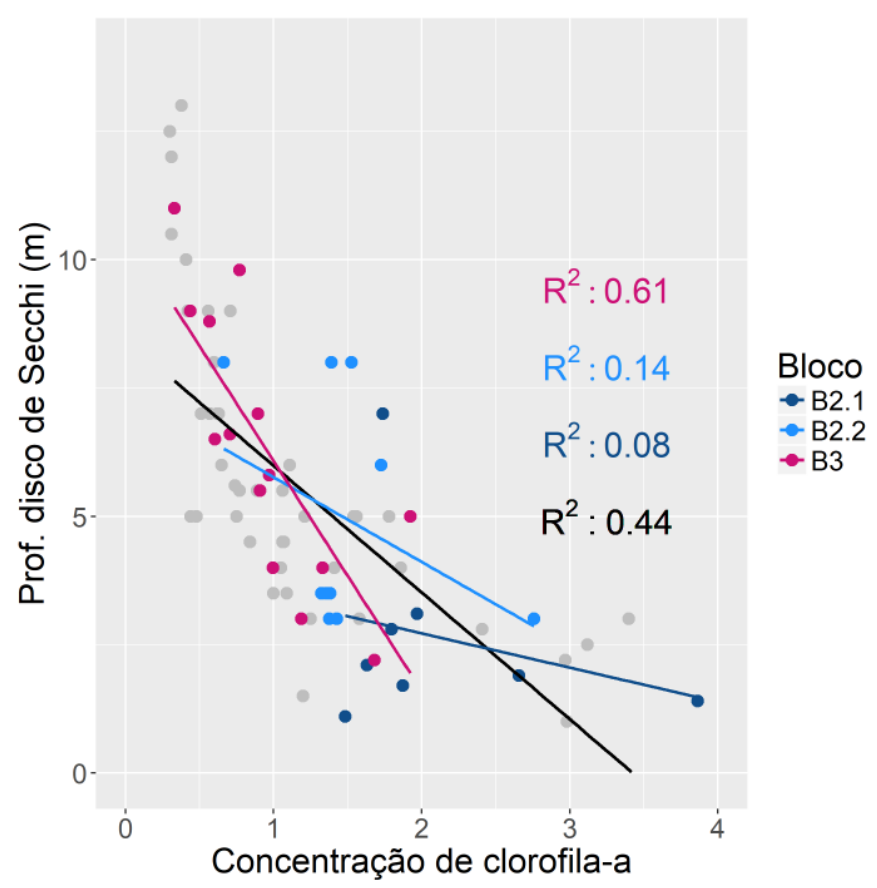

Figura 19. Relação entre a concentração de clorofila-a $\left(\mathrm{mg} \mathrm{m}^{-3}\right)$ e a profundidade de desaparecimento do disco de Secchi (m), os coeficientes de determinação $\left(R^{2}\right)$ são provenientes de ajustes lineares. Os pontos cinzas são referentes aos dados obtidos por Peres (2013) no canal de São Sebastião. 
Ciotti et al. (2018), mediram a [chl] na superfície durante os blocos B1. Separando os valores pelos blocos, obteve-se as médias 2,28 $\pm 1,02 \mathrm{mg} \mathrm{m}^{-3}$ em B1.1, enquanto em B1.2 de 2,17 $\pm 0,43 \mathrm{mg} \mathrm{m}^{-3}$, médias essas superiores aos 3 blocos seguintes. Como nestes primeiros blocos, não haviam informações quanto a profundidade do disco de Secchi (mais detalhes na seção 4.5.3). Em B1.1, foi necessário estimá-la através da [chl] (Equação 8) da relação obtida por dados de Peres (2013), resultando na média de 3,4 \pm 1,5 m. Já em B1.2, foi utilizada a relação linear obtida pela turbidez medida pelo CTD (Equação 9), sendo a média para o período de 2,9 $\pm 1,2 \mathrm{~m}$, semelhante a B2.1.

$$
\begin{aligned}
& \text { Prof. disco de Secchi }=4,8782 \times[\text { chl }]^{-0,632} \\
& \frac{1 / 7}{\text { Prof.disco de Secch } i}=0,2074 \times \text { Turbidez }+0,154
\end{aligned}
$$

\subsection{O balanço metabólico da comunidade planctônica}

A produção primária líquida (PPL), a respiração da comunidade $(\mathrm{RC})$ e a produção primária bruta (PPB), variaram entre $-6,20$ e 206,44 $\mathrm{mg} \mathrm{C} \mathrm{m}^{-3} \mathrm{~d}^{-1}, 6,92$ e $183,90 \mathrm{mg} \mathrm{C} \mathrm{m}^{-3} \mathrm{~d}^{-1}, 47,55$ e $341,94 \mathrm{mg} \mathrm{C} \mathrm{m}^{-3} \mathrm{~d}^{-1}$, respectivamente (Figura 20). A RC não foi relacionada a nenhuma das variáveis durante B3 (Figura 21). A PPL foi forte e inversamente relacionada a temperatura $\left(\mathrm{R}^{2}\right.$ $=0,67$ e $\mathrm{p}=0,0002$, Figura 22a) e positivamente com a concentração de clorofila-a $\left(R^{2}=0,57\right.$ e p=0,001, Figura 22c), não havendo relação com as outras das variáveis (Figura 22b e d).

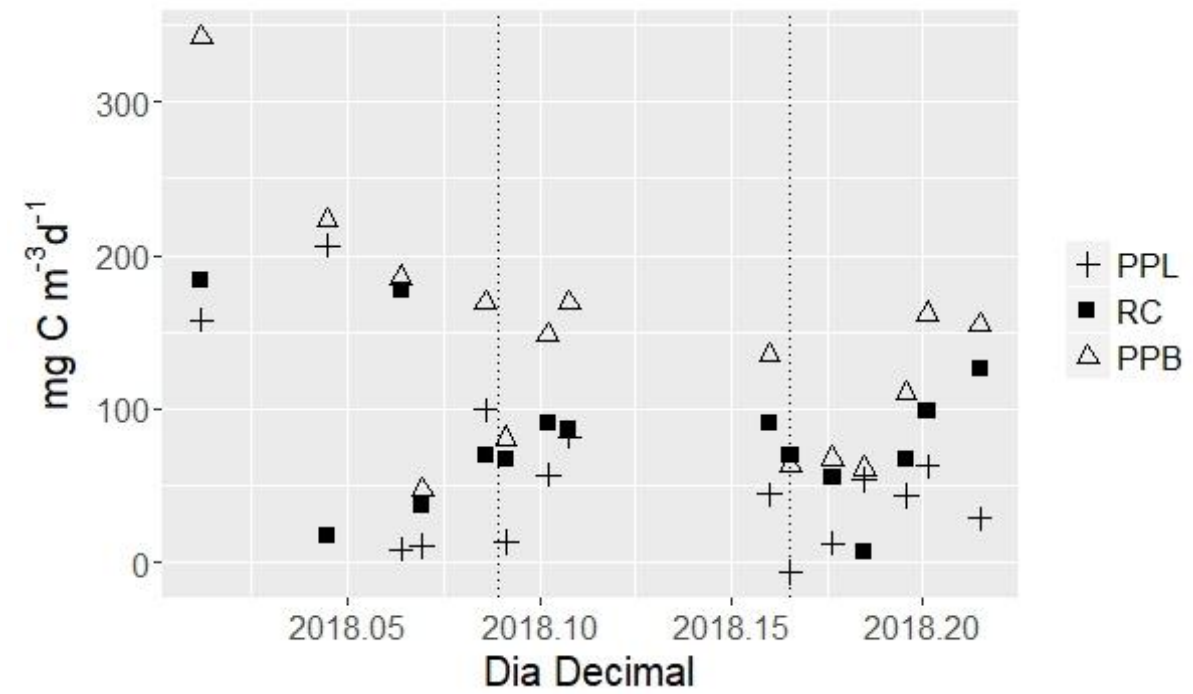

Figura 20. Variação da produtividade primária líquida da comunidade (PPL), da respiração da comunidade (RC) e da produção primária bruta (PPB) $\mathrm{em} \mathrm{mg} \mathrm{C} \mathrm{m}^{-3} \mathrm{~d}^{-1} \mathrm{em} \mathrm{B3}$ (janeiro a março de 2018). 

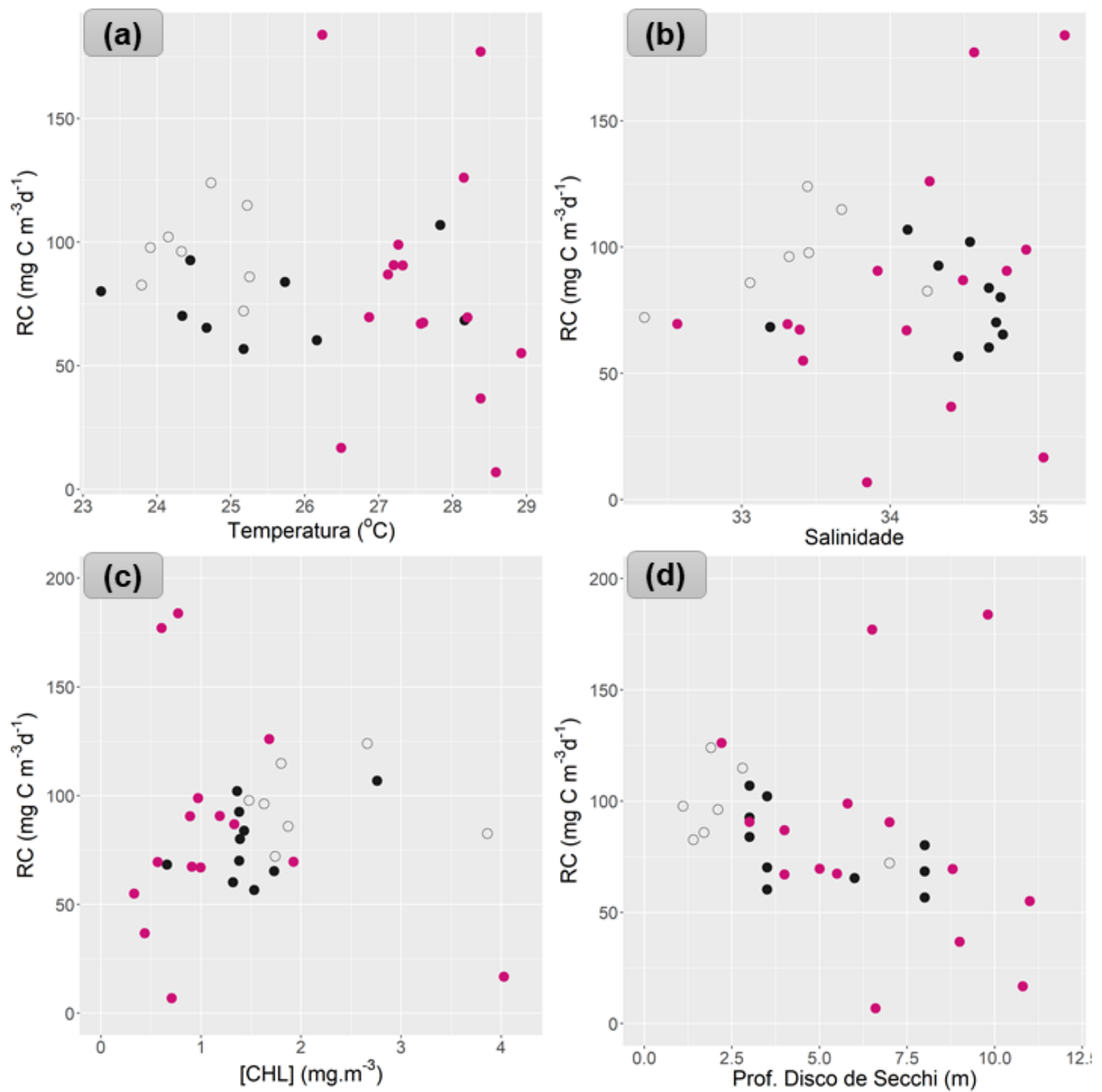

Figura 21. Relação entre a respiração da comunidade $\left(\mathrm{RC}\right.$ - pontos rosas) e (a) temperatura $\left({ }^{\circ} \mathrm{C}\right)$; $(\mathrm{b})$ salinidade; (c) concentração da clorofila-a $\left(\mathrm{mg} \mathrm{m}^{-3}\right)$, e; (d) profundidade do disco de Secchi (metros) em B3 (janeiro a março de 2018). Os pontos pretos são as RC em B2.1 (pontos vazados, período correspondente a primavera de 2015) e B2.1 (pontos maciços, período correspondente ao verão de 2016) apresentados por Regaudie-de-Gioux et al. (2018). 

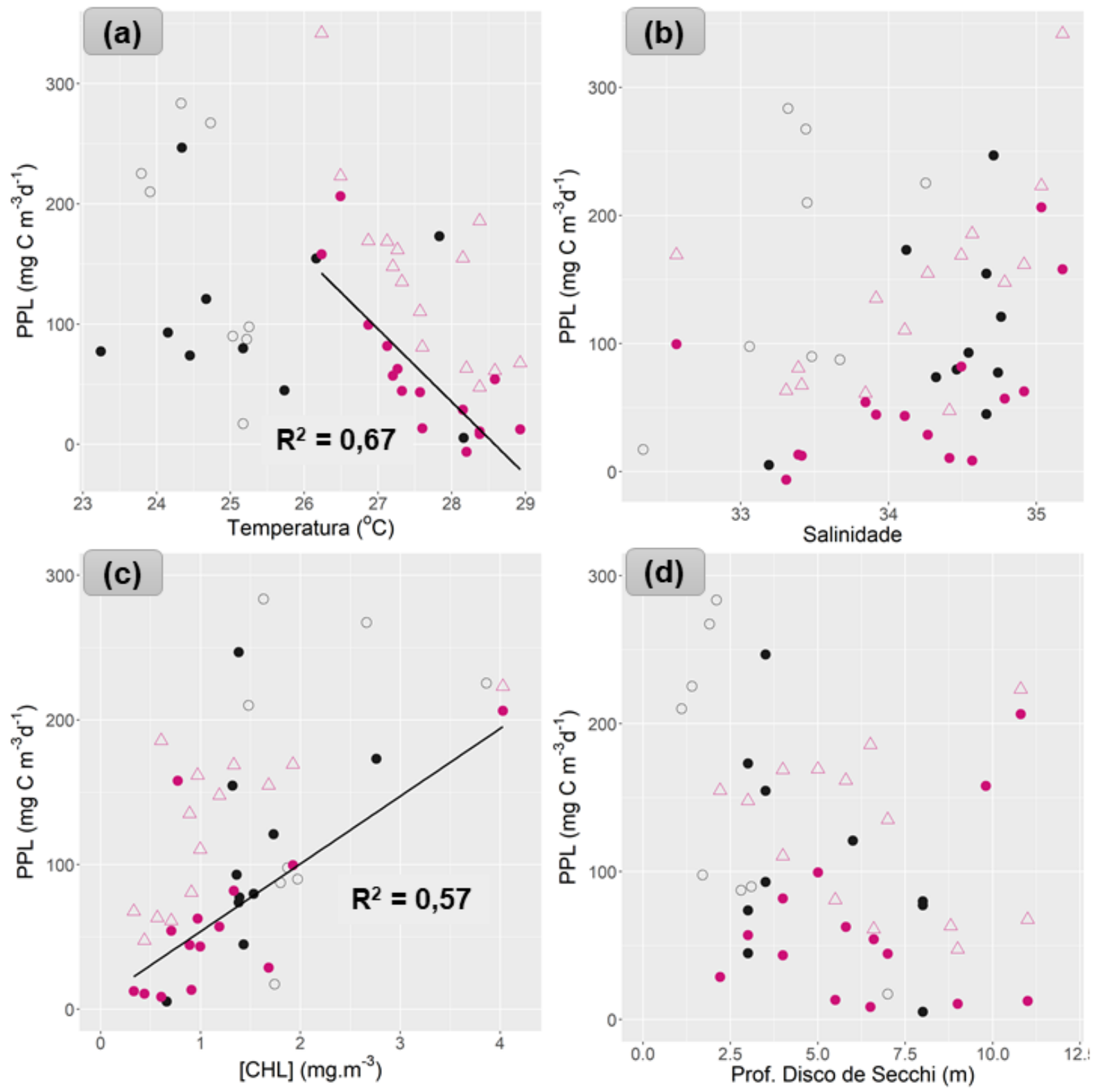

Figura 22. Relação entre a produtividade primária líquida $\left(\right.$ PPL) da comunidade e: $\left(\right.$ a) temperatura $\left({ }^{\circ} \mathrm{C}\right)$; (b) salinidade; (c) concentração da clorofila-a $\left(\mathrm{mg} \mathrm{m}^{-3}\right)$, e; (d) profundidade do disco de Secchi (metros) em B3 (pontos rosas, correspondentes ao período de janeiro a março de 2018). Os triângulos rosas são referentes à produção primária bruta (PPB) em B3. Os pontos pretos são as PPL em B2.1 (pontos vazados, período correspondente à primavera de 2015) e B2.1 (pontos maciços, período correspondente ao verão de 2016) apresentados por Regaudie-de-Gioux et al. (2018). $O s R^{2}$ são resultantes de ajustes lineares e são estatisticamente significativos $(\mathbf{p}<\mathbf{0 , 0 5})$. 


\subsection{Método Bio-óptico}

Em B3, só foram analisadas 10 de 15 amostras coletadas, devido à perda de material após o experimento devido ao armazenamento inadequado das amostras fora da temperatura ideal (em nitrogênio líquido - ver sessão 4.2.3)

\subsubsection{Coeficientes de absorção espectral de luz pelo fitoplâncton e dos detritos}

A Figura 23 mostra grande variação das magnitudes dos espectros dos coeficientes de absorção espectral de luz pelo fitoplâncton $\left(\mathrm{a}_{\mathrm{ph}}, \mathrm{m}^{-1}\right)$ entre as campanhas realizadas no verão de 2018. Este espectro normalizado pelo coeficiente médio ( $\left\langle\mathrm{a}_{\mathrm{ph}}\right\rangle$, sem dimensões Figura 24$)$, mostra diferenças nos comprimentos de onda menores do que $500 \mathrm{~nm}$. Observa-se também na Figura 24, que em $412 \mathrm{~nm}$, há picos de absorção, o que indica a presença de feopigmentos. Comportamento semelhante é observado pelo espetro de $a_{\text {ph }}$ normalizado pela concentração da clorofila-a $\left(a_{\mathrm{ph}}{ }^{*}, \mathrm{mg}^{-1} \mathrm{~m}^{2}\right.$ - Figura 25$)$, sendo que esta evidencia para 3 curvas um grau de empacotamento de pigmentos maior (veja o achatamento das curvas), que são as réplicas do dia 31 de janeiro de 2018.

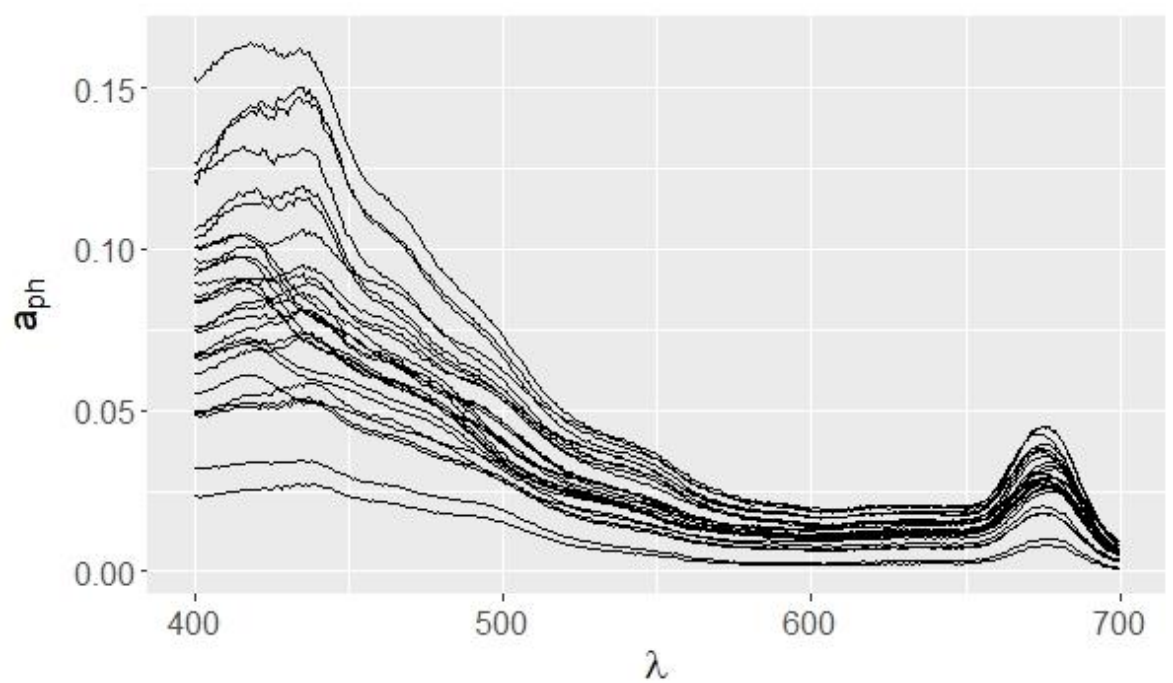

Figura 23. Réplicas das curvas do coeficiente de absorção espectral da luz pelo fitoplâncton (aph $\left.\mathrm{em} \mathrm{m}^{-1}\right)$ das $^{-}$ campanhas realizadas no verão de 2018. 


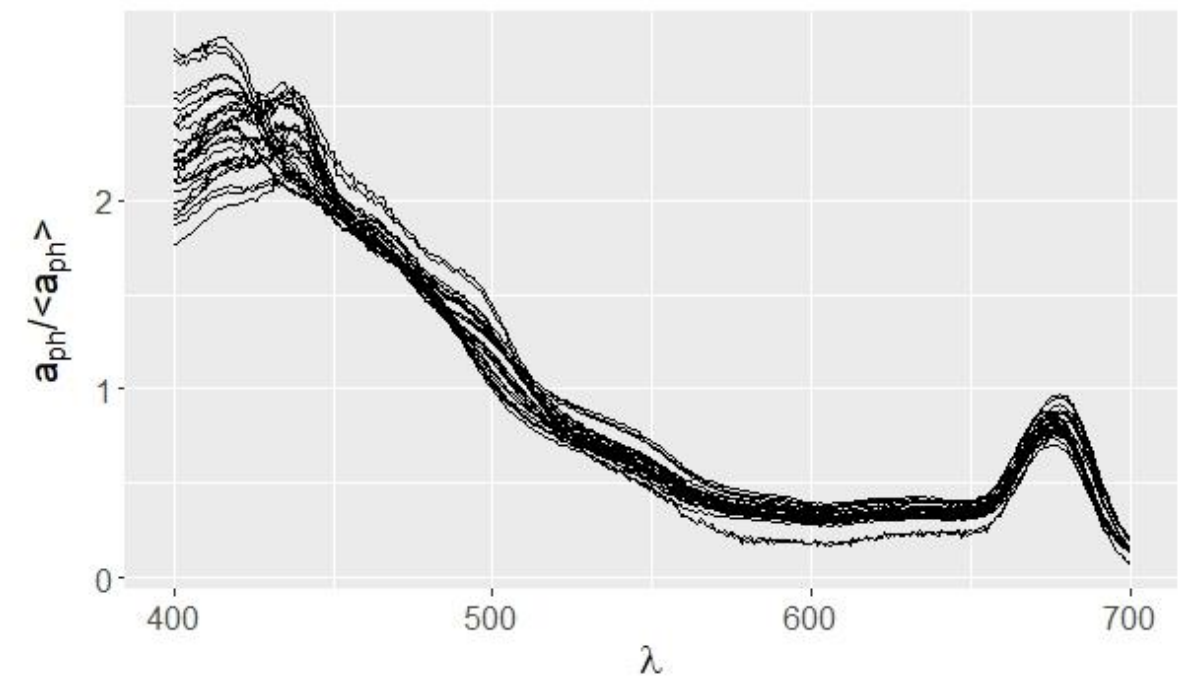

Figura 24. Réplicas das curvas do coeficiente de absorção espectral da luz pelo fitoplâncton $\left(a_{p h} \mathrm{em} \mathrm{m}^{-1}\right)$ normalizado pelo coeficiente médio calculado na faixa no visível do espectro eletromagnético $\left.\left(<\mathrm{a}_{\mathrm{ph}}\right\rangle\right)$ das campanhas realizadas no verão de 2018.

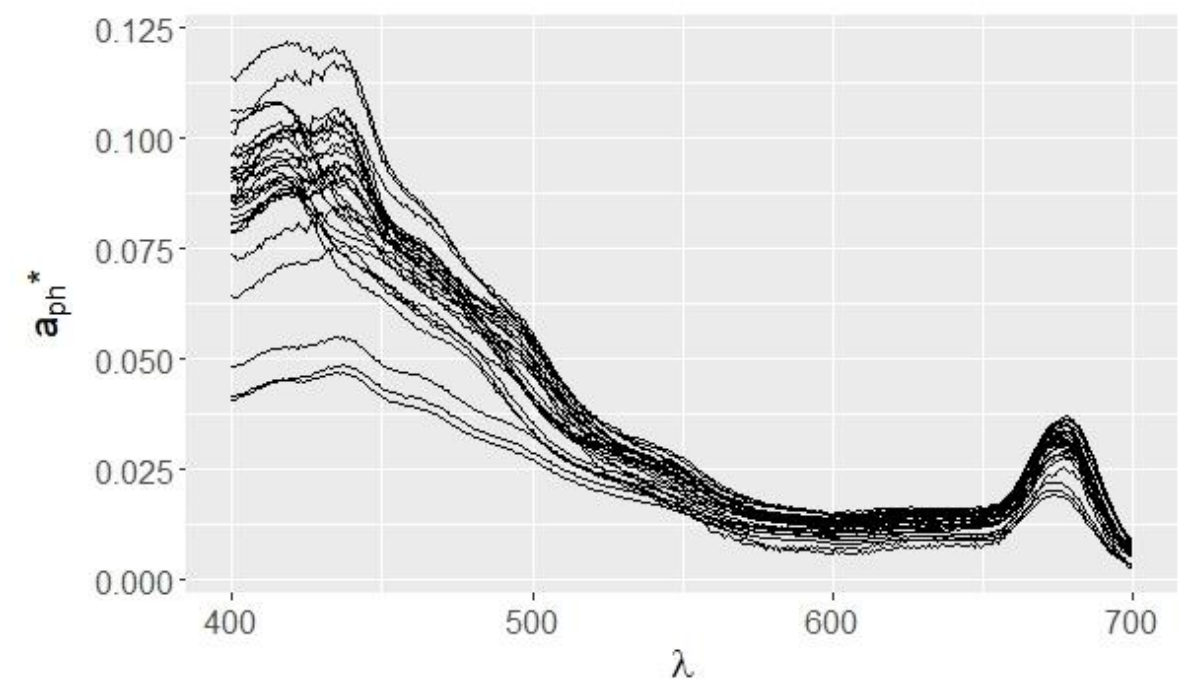

Figura 25. Réplicas das curvas do coeficiente de absorção espectral da luz pelo fitoplâncton $\left(\mathrm{aph}^{\mathrm{em}} \mathbf{m}^{-1}\right)$ normalizado pela concentração de clorofila-a $\left(\mathrm{aph}^{*} \mathrm{em} \mathrm{mg}^{-1} \mathrm{~m}^{2}\right)$ das campanhas realizadas no verão de 2018.

A Figura 26 apresenta relações entre a coeficientes de absorção espectral de luz pelo fitoplâncton e pelos detritos em diferentes comprimentos de onda (440, 443 e $676 \mathrm{~nm})$ em função da concentração da clorofila-a [chl] nos diferentes blocos de dados, sendo 443 e 676 os picos de absorção principal da clorofila-a. Os resultados mostram que $a_{\mathrm{ph}}(676)$ correlaciona-se proporcionalmente com a concentração da clorofila-a, no entanto, essa relação difere entre os blo$\cos \left(\mathrm{R}^{2}=0,95, \mathrm{R}^{2}=0,60\right.$ e $\mathrm{R}^{2}=0,70$ para $\mathrm{B} 1.1, \mathrm{~B} 1.2$ e $\mathrm{B} 3$, respectivamente, sendo todos significativos $\operatorname{com} \mathrm{p}=0)$ do que quando unidos $\left(\mathrm{R}^{2}=0,41 \mathrm{e} \mathrm{p}=0\right.$, Figura 26a). Comportamento semelhante é observado na relação entre a [chl] e os coeficientes $a_{\mathrm{ph}}(440)$ e $\mathrm{a}_{\mathrm{ph}}(443)$ (Figura 
26b e c), no entanto, com os blocos unidos os ajustes lineares não são significativos (p igual a 0,27 e 0,26). Por fim, $a_{\mathrm{ph}}(443)$ versus $\mathrm{a}_{\mathrm{d}}(443)$ que ilustra o grau de covariação entre ambos, não apresenta robustez com blocos unidos $\left(\mathrm{R}^{2}=0,0051 \mathrm{e} \mathrm{p}=0,58\right)$ e em $\mathrm{B} 1.1\left(\mathrm{R}^{2}=0,24\right.$ e p = 0,06), mas sim gradativamente robusto em B1.2 e B3 $\left(R^{2}=0,40\right.$ e $R^{2}=0,82$ em, respectivamente com $p=0$, Figura 26d).
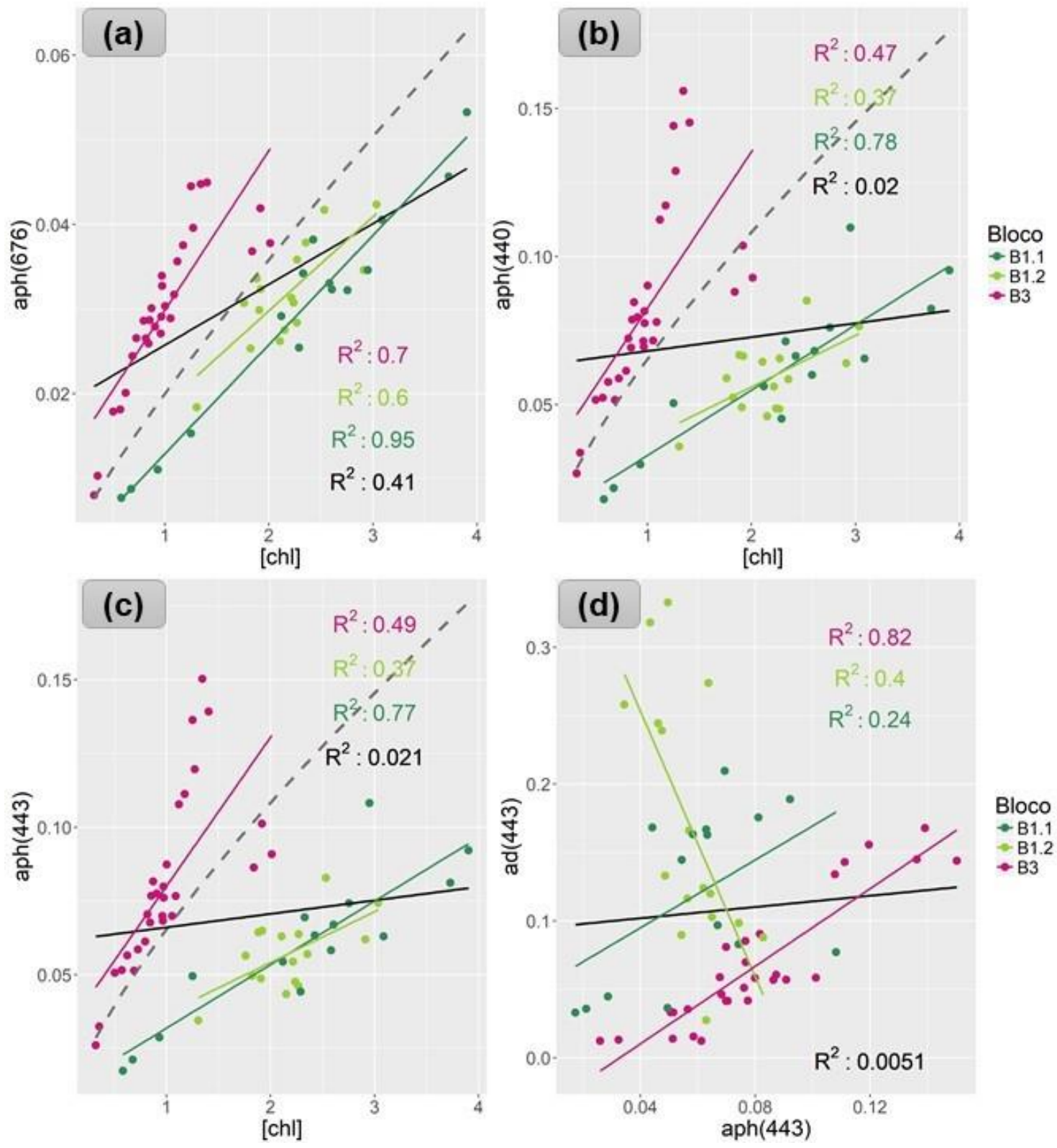

Figura 26. Comparação entre (a) concentração de clorofila-a ([chl] $\mathrm{em} \mathrm{mg} \mathrm{m}^{-3}$ ) e o coeficiente de absorção espectral de luz pelo fitoplâncton $\left(a_{\mathrm{ph}}\right) \mathrm{em} 676 \mathrm{~nm}\left(\mathrm{a}_{\mathrm{ph}}(676) \mathrm{em} \mathrm{m}^{-1}\right)$; (b) a [chl] e o $\mathrm{a}_{\mathrm{ph}} \mathrm{em} 440 \mathrm{~nm}\left(\mathrm{a}_{\mathrm{ph}}(440)\right.$ $\left.\mathrm{em} \mathrm{m}^{-1}\right)$; (c) a [chl] e o $\mathrm{aph}_{\mathrm{ph}} \mathrm{em} 4 \mathrm{~nm}\left(\mathrm{a}_{\mathrm{ph}}(443) \mathrm{em} \mathrm{m}^{-1}\right)$, e; (d) $\mathrm{a}_{\mathrm{ph}}(443)$ e o coeficiente de absorção espectral de luz pelos detritos em $443 \mathrm{~nm}\left(\mathrm{ad}_{(}(443) \mathrm{em} \mathrm{m}^{-1}\right)$, em B1.1, B1.2 e B3. As linhas tracejadas cinzas em (a) e (c) indicam as equações para os comprimentos de ondas obtidos por Bricaud et al. (1995) e Bricaud et al. (2004), respectivamente. A linha preta contínua indica a regressão linear para todos os blocos. 


\subsubsection{Estimativas de produção primária pelo método bio-óptico}

A produção primária pelo método bio-óptico (PPabs, Figura 27) em B3 foi mínima no dia 8 de março de 2018, com 73,7 $\pm 6,9 \mathrm{mg} \mathrm{C} \mathrm{m}^{-3} \mathrm{~d}^{-1}$ e máxima de 454,9 $\pm 25,8 \mathrm{mg} \mathrm{C} \mathrm{m}^{-3} \mathrm{~d}^{-1}$ em 8 de fevereiro de 2018. A média de PPabs foi equivalente a 207,1 $\pm 120,8 \mathrm{mg} \mathrm{C} \mathrm{m}^{-3} \mathrm{~d}^{-1}$.

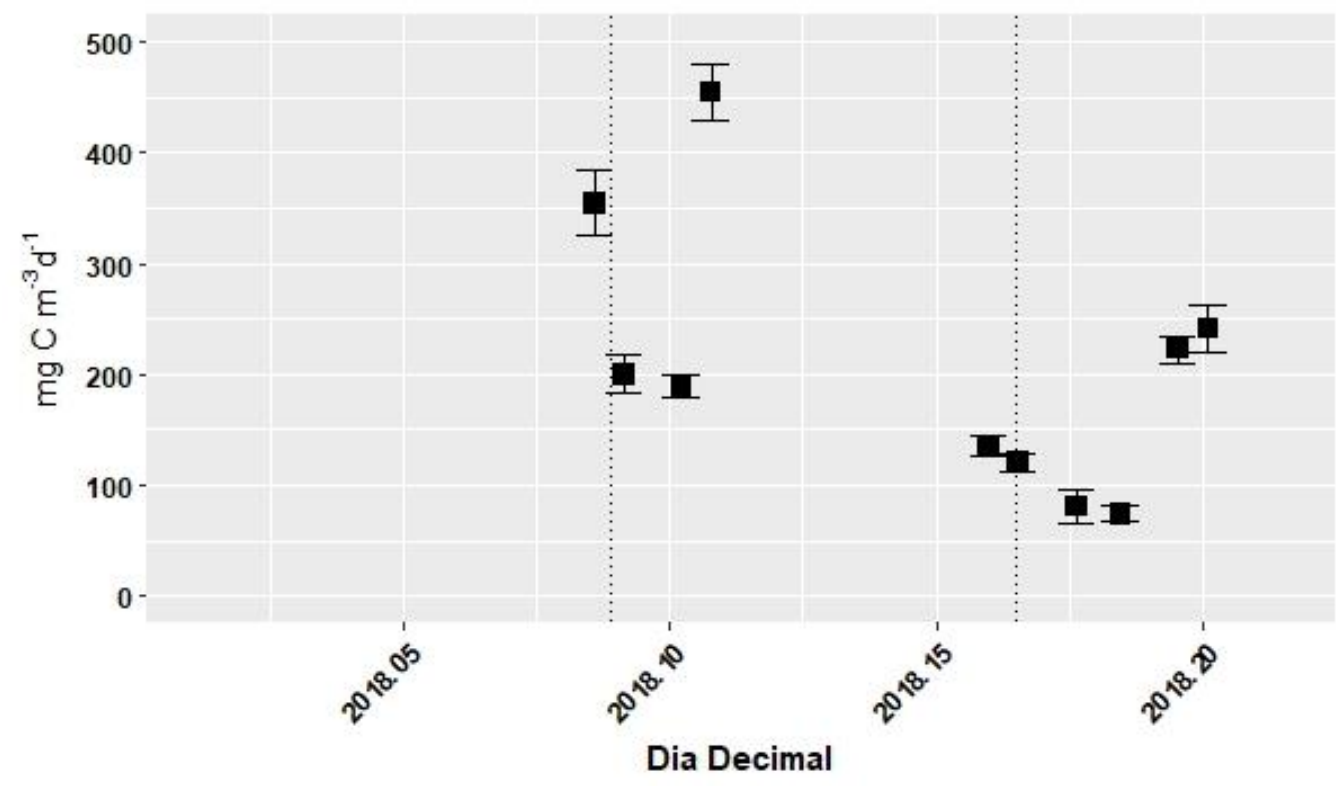

Figura 27. Produção primária (em $\mathrm{mg} \mathrm{C} \mathrm{m}^{-3} \mathrm{~d}^{-1}$ ) pelo método bio-óptico (PPabs) em B3 (janeiro a março de 2018). Vale ressaltar que dos 15 experimentos realizados, apenas 10 foram considerados devido à perda de material.

\subsection{Fluorescência ativa variável}

\subsubsection{Parâmetros fotofisiológicos no canal de São Sebastião}

O maior valor médio do parâmetro que representa a eficiência fotoquímica máxima $\left(\mathrm{F}_{\mathrm{v}} / \mathrm{F}_{\mathrm{m}}\right)$ foi observado durante B2.2 $(0,48 \pm 0,09)$ sendo um valor extremo máximo único $(0,79)$ registrado em 18 de janeiro de 2016 (Tabela 4, Figura 28a), sendo valores acima de 0,6 apenas observados durante B2.2. O valor mínimo de Fv/Fm foi observado durante B3 $(0,26)$ no dia 14 de março de 2018. Já o parâmetro que descreve a área efetiva de absorção de luz pelo fotossis-

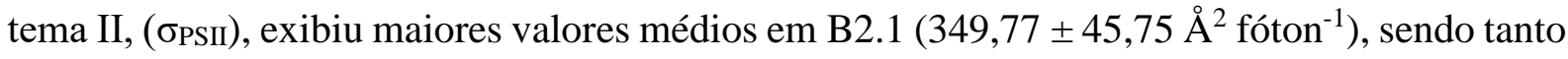
o mínimo como o máximo observados em B2.2 (169,63 $\AA^{2}$ fóton $^{-1}$ e 479,478 $\AA^{2}$ fóton $^{-1}$, respectivamente (Tabela 4, Figura 28b). 
Tabela 4. Valores (mínimos, máximos, média, desvio padrão - DP e o número de amostras) dos parâmetros fotofisiológicos eficiência fotoquímica máxima $\left(F_{\mathrm{v}} / \mathrm{F}_{\mathrm{m}}\right.$ - adimensional) e área efetiva de absorção de luz pelo fotossistema II ( $\sigma$ PSII $-\AA^{2}$ fóton $^{-1}$ ).

\begin{tabular}{ccccccc}
\hline Parâmetro & Bloco & Mínimo & Máximo & Média & Desvio & $\mathbf{N}^{\mathbf{0}}$ amostras \\
\hline \multirow{4}{*}{$\mathbf{F}_{\mathbf{v}} / \mathbf{F}_{\mathbf{m}}$} & $\mathbf{2 . 1}$ & 0,37 & 0,50 & 0,45 & 0,04 & 21 \\
& $\mathbf{2 . 2}$ & 0,31 & 0,79 & 0,48 & 0,09 & 32 \\
& $\mathbf{3}$ & 0,26 & 0,65 & 0,42 & 0,07 & 41 \\
\hline \multirow{3}{*}{ \%PSII } & $\mathbf{2 . 1}$ & 247,30 & 419,81 & 349,77 & 45,57 & 21 \\
& $\mathbf{2 . 2}$ & 169,63 & 479,47 & 335,85 & 70,84 & 32 \\
& $\mathbf{3}$ & 178,64 & 391,37 & 271,20 & 48,07 & 41 \\
\hline
\end{tabular}
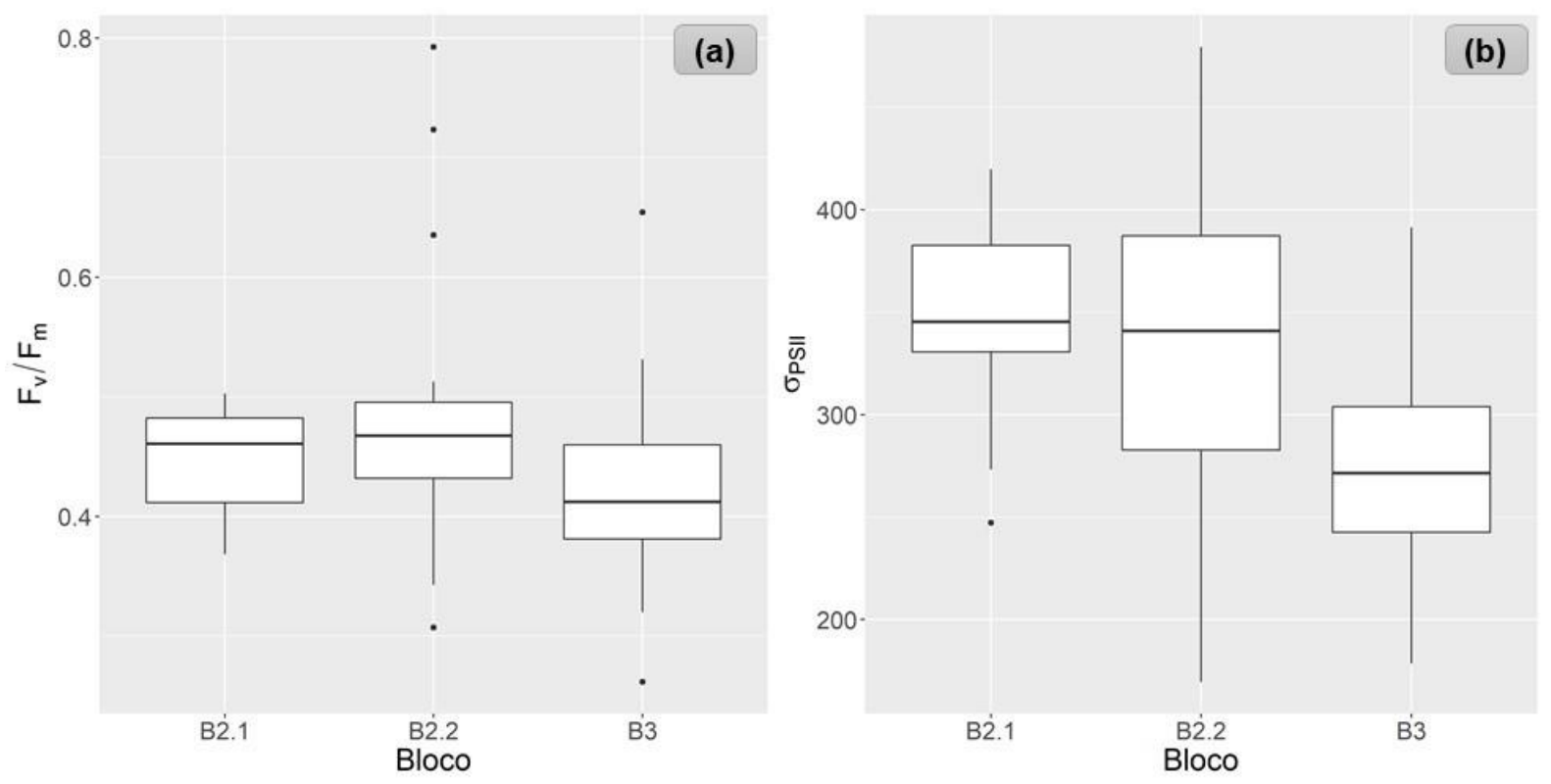

Figura 28. Variação dos parâmetros fotofisiológicos, em (a) a eficiência fotoquímica máxima $\left(F_{v} / F_{m}\right.$ admensional); (b) área efetiva de absorção de luz pelo fotossistema II ( $\sigma$ PSII $-\AA^{2}$ fóton $\left.^{-1}\right)$, nos blocos B2.1 (outubro a dezembro de 2015), B2.2 (janeiro a março de 2016) e B3 (janeiro a março de 2018). 


\subsubsection{Controle de qualidade dos parâmetros fotofisiológicos}

As medidas foram feitas utilizando tréplicas verdadeiras dos parâmetros fotofisiológicos $\left(\mathrm{F}_{0}, \mathrm{Fm}\right.$ e $\left.\sigma_{\mathrm{PSII}}\right)$ e os valores obtidos entre as tréplicas foram comparados por um teste ANOVA bi-fatorial, sendo que os resultados indicaram igualdade entre eles com os valores de p iguais a 0,07, 0,11 e 0,96, respectivamente (Figura 29 a Figura 31). Assim, uma vez estabelecidos os valores de $\mathrm{F}_{0}$, Fm e $\sigma_{\text {PSII, }}$ os valores de produção de carbono por volume de água e unidade de tempo são estimados para cada réplica (ver seção 4.5.4). As curvas de Produção vs. Irradiância, estimadas foram ajustadas a diferentes modelos, comumente utilizados para experimentos de incubação, e como não houve diferença significativa de PP entre os modelos JP e PGH (p = $0,97)$, JP e EP $(p=0,98)$ e PGH e EP $(p=0,99)$ (Figura 32). Desta forma, optou-se pelo ajuste final de todos os pontos obtidos em cada réplica pelo modelo JP, uma vez que é o mais simples de todos, construído pelos parâmetros, $\alpha$ e $\mathrm{E}_{\mathrm{k}}$, que são a inclinação inicial da curva (mg C [Chl] ${ }^{1} \mathrm{~h}^{-1}$ mol quanta $\mathrm{m}^{-2} \mathrm{~s}^{-1}$ ) e a magnitude da irradiância de saturação (mol quanta $\mathrm{m}^{-2} \mathrm{~s}^{-1}$ ), respectivamente.

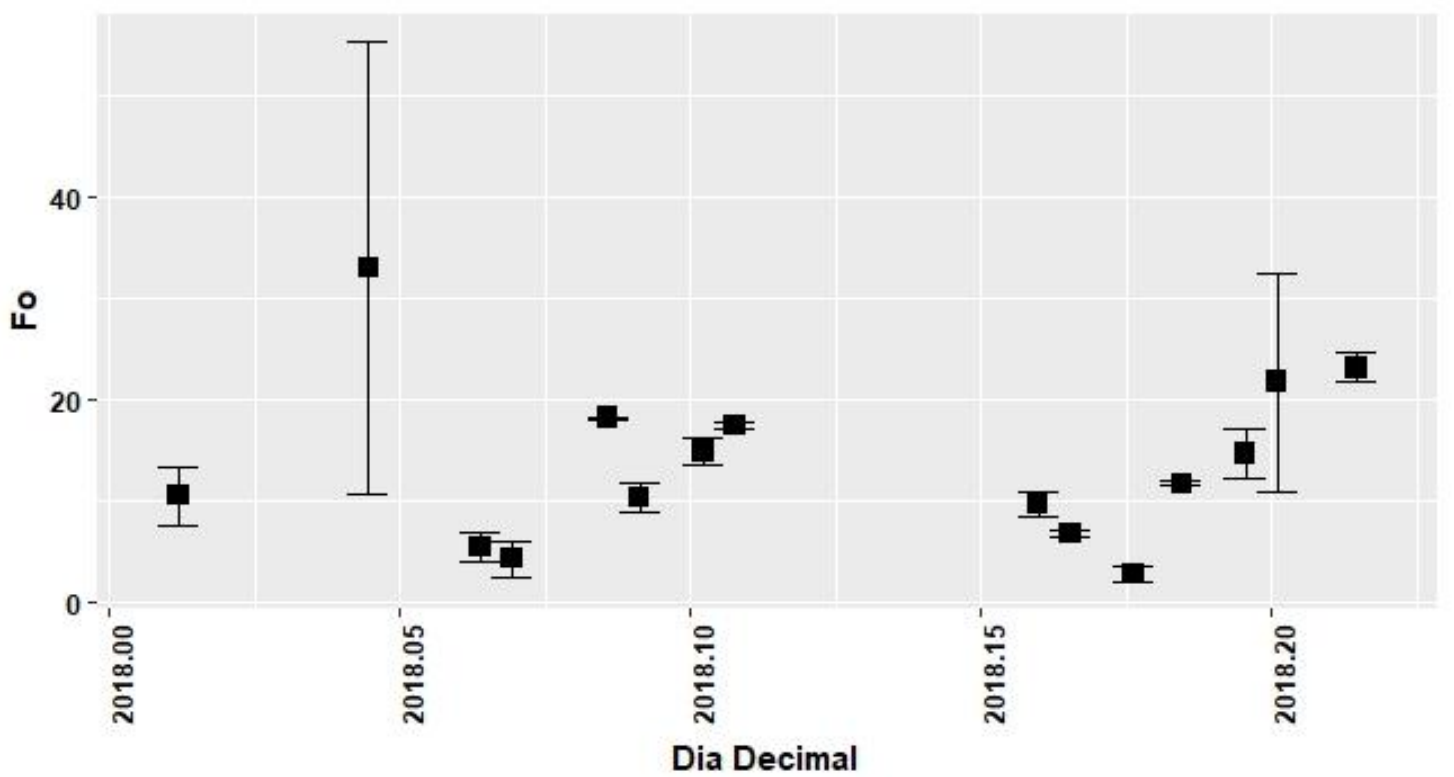

Figura 29. Variação temporal das tréplicas de rendimento mínimo de fluorescência $\left(F_{0}\right.$ - URF) durante B3 (janeiro a março de 2018). 


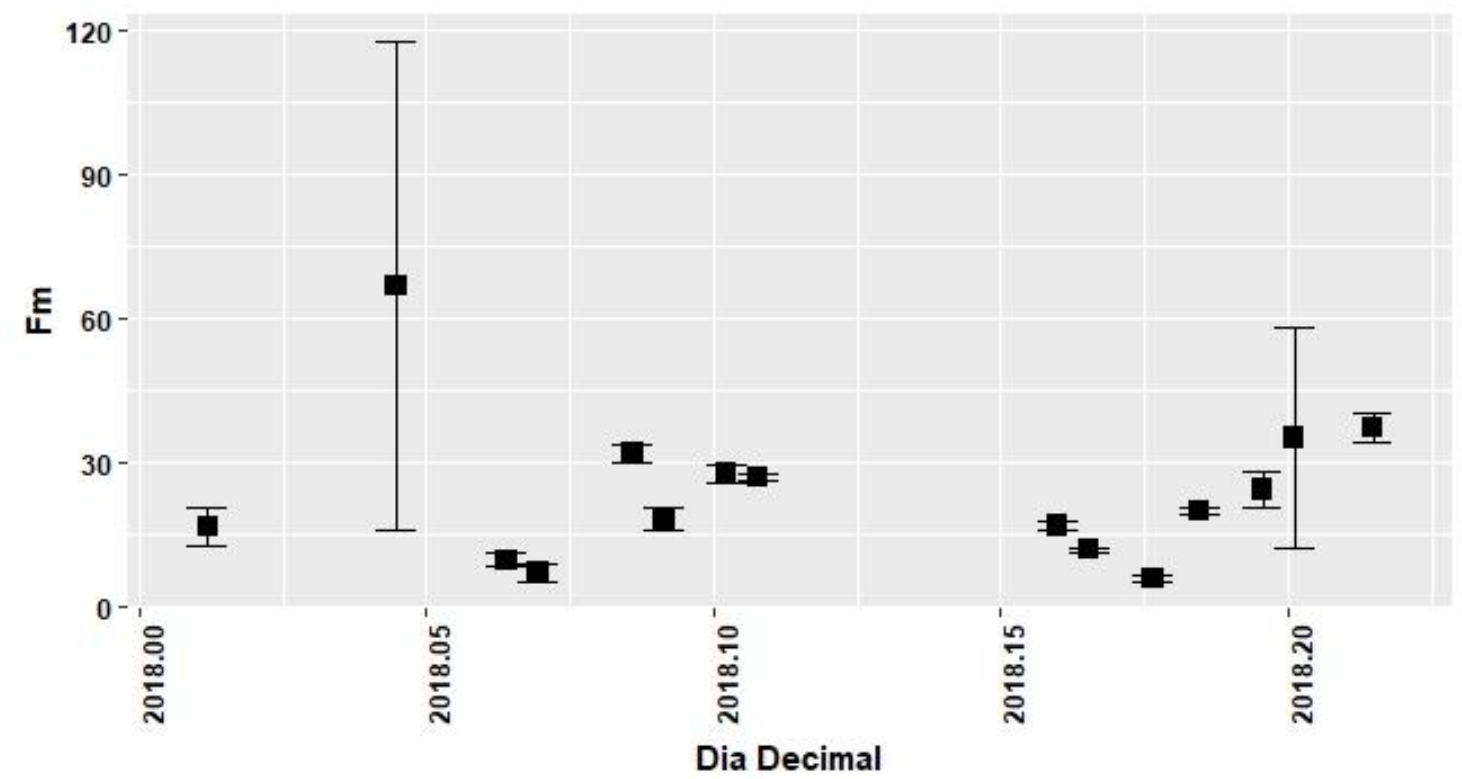

Figura 30. Variação temporal das tréplicas de rendimento máximo de fluorescência $\left(F_{m}\right.$ - URF) durante B3 (janeiro a março de 2018).

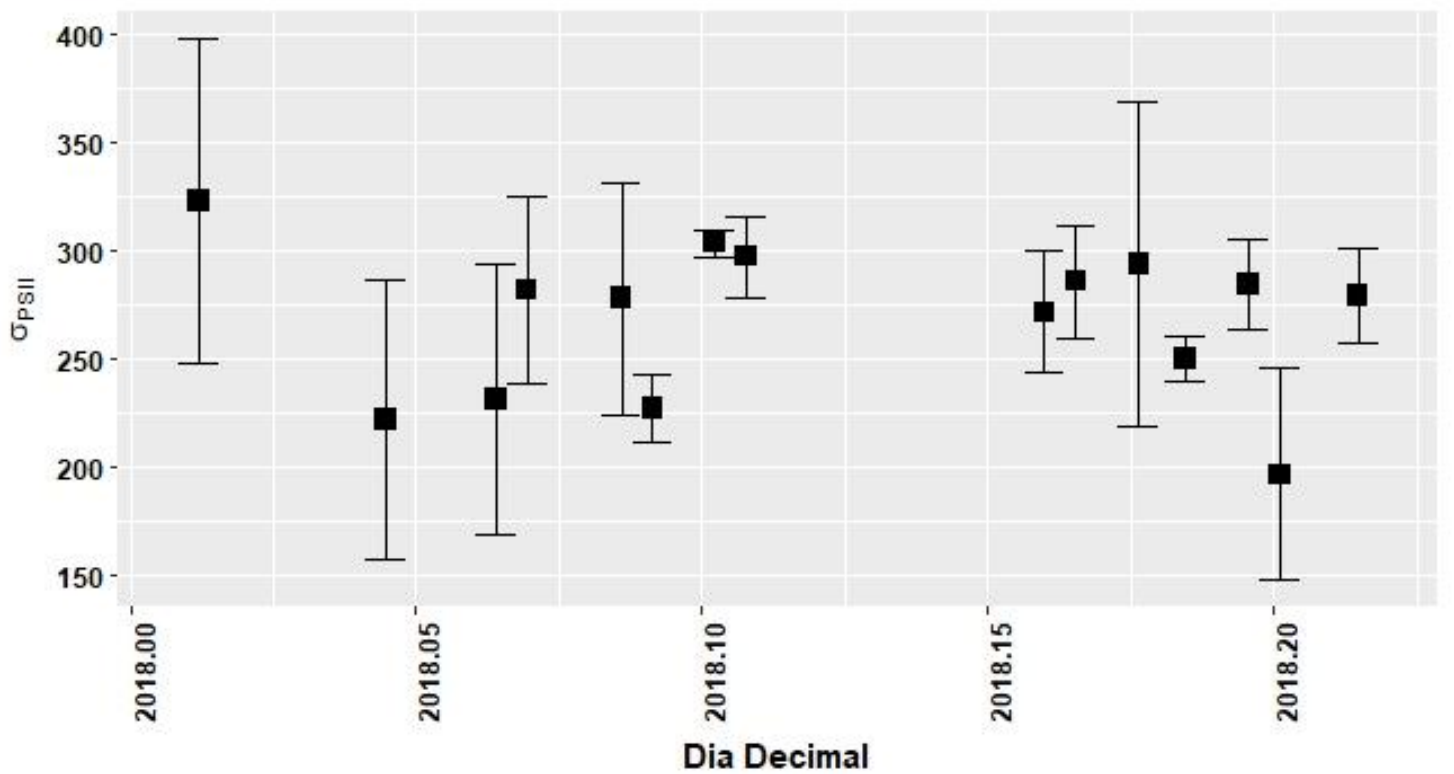

Figura 31. Variação temporal das tréplicas da área efetiva de absorção de luz pelo fotossistema II ( $\sigma$ PSII $\AA^{2}$ fóton $^{-1}$ ) durante $\mathrm{B3}$ (janeiro a março de 2018 ). 


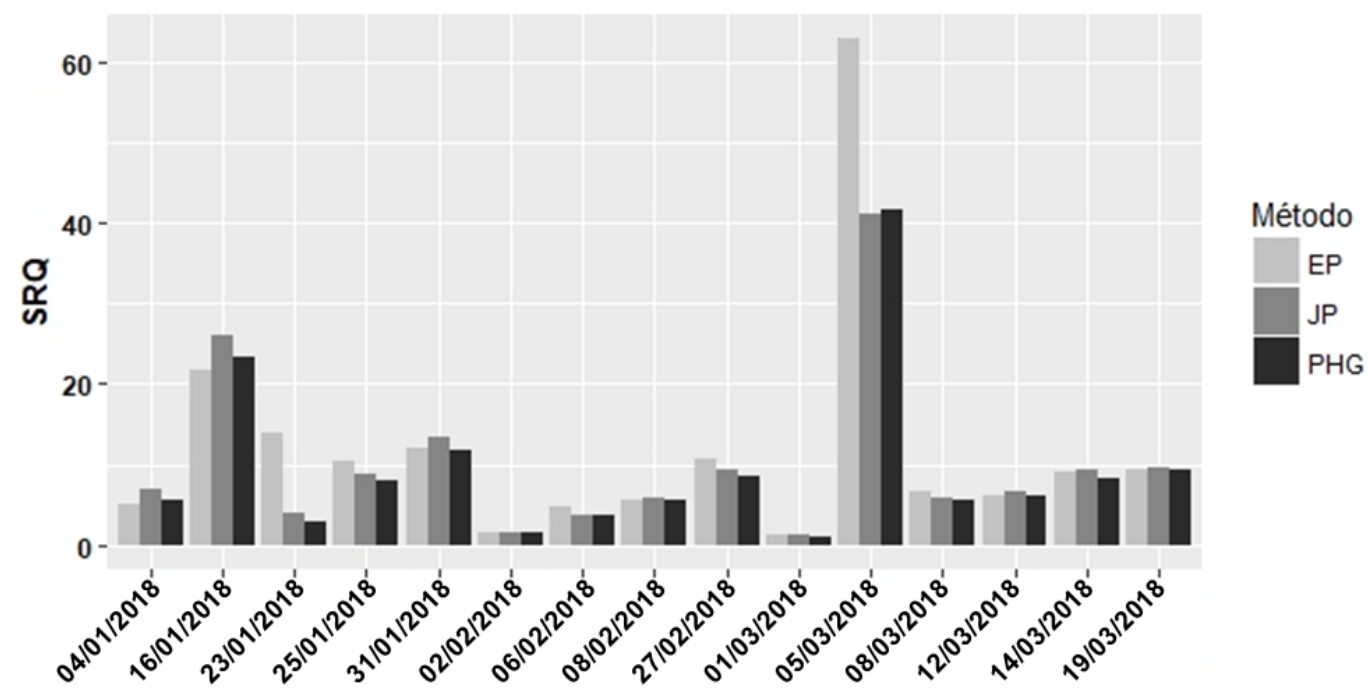

Figura 32. Variação temporal da soma dos resíduos quadráticos (SRQ) para os três modelos de curvas fotossíntese vs. irradiância (P-E), sendo EP, modelo de Eilers \& Peeters (1988); JP, Jassby \& Platt (1976), e; PHG, Platt et al. (1980) em B3 (janeiro a março de 2018).

\subsubsection{Estimativas de produção primária por fluorescência}

A PP pelo método de fluorescência ativa variável (PPFire - Figura 33) obteve média de 28,4 $\pm 13,2 \mathrm{mg} \mathrm{C} \mathrm{m}^{-3} \mathrm{~d}^{-1}$ em B3, variando entre 9,0 e 57,8 $\mathrm{mg} \mathrm{C} \mathrm{m}^{-3} \mathrm{~d}^{-1}$, nos dias 8 de março de 2018 e 16 da janeiro de 2018, respectivamente.

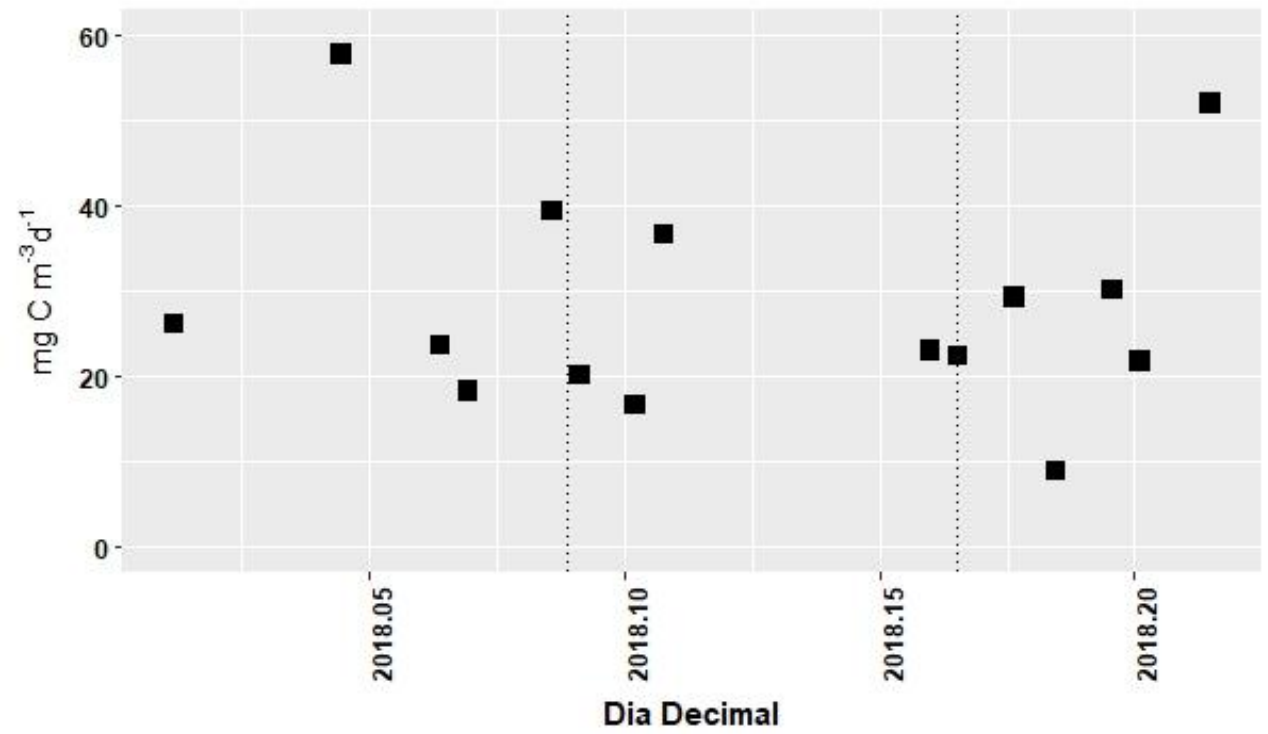

Figura 33. Produção primária (PP em $\mathrm{mg} \mathrm{C} \mathrm{m}^{-3} \mathrm{~d}^{-1}$ ) pelo método de fluorescência ativa variável (PPFire) em B3 (janeiro a março de 2018). Vale ressaltar que as tréplicas dos parâmetros fotofisiológicos utilizados para calcular a PP foram utilizadas para estimar um único ajuste de curva, desta forma, não há desvio padrão de $\mathbf{P P}$. 


\subsection{Comparação entre métodos de produção primária}

A Tabela 5 mostra que, em geral, o coeficiente de atenuação da luz ( $\mathrm{K}_{\mathrm{d}}$, estimado pela turbidez da boia do SIMCosta) pouco varia durante o período de incubação. A Figura 34, apresenta 3 exemplos dessa variação ao longo dos dias 4 de janeiro, 23 de janeiro e 27 de fevereiro de 2018. Observa-se que a variação no primeiro não é a maior observada numericamente $(0,36 \pm 0,12)$, no entanto visivelmente sim (Figura 34). Na segunda data, com maior variação numérica $(0,29 \pm 0,13)$, nota-se um pico por volta da terceira hora de incubação, aumento a variabilidade. Já em 27 de fevereiro pequena variabilidade foi registrada $(0,22 \pm 0,02)$.

Tabela 5. Valores (máximos, mínimos, médias e desvios padrões - DP) do coeficiente de atenuação vertical da luz difusa $\left(K_{d} \mathrm{em} \mathrm{m}^{-1}\right)$ durante o período de incubação de 24 horas em B3. Em 23 de janeiro, foi retirado um valor extremo de $0,83 \mathrm{~m}^{-1}$ devido a incoerência com os outros valores registrados.

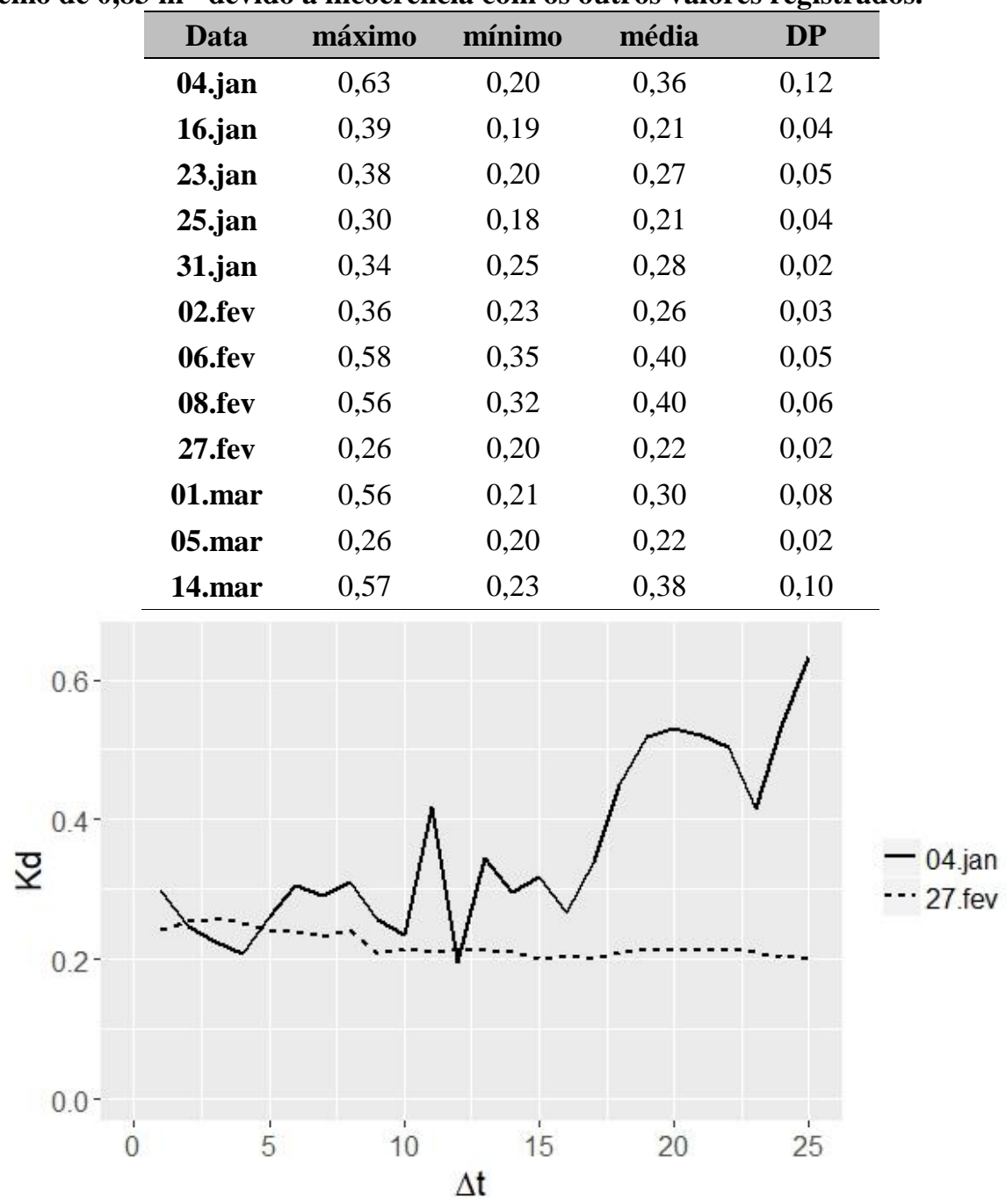

Figura 34. Exemplos de variabilidade do coeficiente de atenuação vertical da luz difusa $\left(K_{d}, m^{-1}\right)$ durante dois períodos de 24 horas de incubação durante o verão de 2018. 


\subsubsection{Alterações dos parâmetros fotofisiológicos em 24 horas}

A Tabela 6 mostra que não há um padrão de variação das médias dos parâmetros fotofisiológicos $\left(\mathrm{F}_{0}, \sigma_{\mathrm{PSII}} \mathrm{e} \mathrm{F}_{\mathrm{v}} / \mathrm{F}_{\mathrm{m}}\right)$ em relação às variáveis oceanográficas entre o início e o final do período de incubação. No entanto, é possível observar que há grande variação de $\mathrm{F}_{0}$ e que esta não acompanha a diferença da fluorescência da clorofila-a (medida por um fluorímetro de mão). Em geral, a temperatura variou menos de $0,50^{\circ} \mathrm{C}$, com exceção do dia 13 de março em que a variação foi de $1,01^{\circ} \mathrm{C}$. Destaca-se a grande variabilidade da profundidade do disco de Secchi entre os dias.

Tabela 6. Média dos parâmetros fotofisiológicos fluorescência mínima (Fo - URF), área efetiva de absorção de luz do fotossistema II ( $\sigma$ PSII - $\AA^{2}$ fóton $\left.^{-1}\right)$, a eficiência fotoquímica máxima $\left(\mathbf{F}_{\mathrm{v}} / \mathbf{F}_{\mathrm{m}}\right.$ - adimensional) e a variação da fluorescência da clorofila-a (FLU em URF), da temperatura ( $\left.\mathrm{T} \mathrm{em}^{\circ} \mathrm{C}\right)$ e profundidade do disco de Secchi (Sec em m) após incubação por 24 horas, durante experimento simultâneo de Taxas Metabólicas. Note que $T_{0}$ é o tempo inicial, e $\mathbf{T}_{24}$ é a medida realizada após às $\mathbf{2 4}$ horas de incubação. Destaca-se que os experimentos ocorreram apenas no ano de 2018.

\begin{tabular}{cccccccccc}
\hline Data & $\mathbf{F}_{\mathbf{0}} \mathbf{T}_{\mathbf{0}}$ & $\mathbf{F}_{\mathbf{0}} \mathbf{T}_{\mathbf{2 4}}$ & $\boldsymbol{\sigma P S I I}_{\mathbf{0}} \mathbf{T}_{\mathbf{0}}$ & $\boldsymbol{\sigma}_{\mathbf{P S I I}} \mathbf{T}_{\mathbf{2 4}}$ & $\mathbf{F}_{\mathbf{v}} / \mathbf{F}_{\mathbf{m}} \mathbf{T}_{\mathbf{0}}$ & $\mathbf{F}_{\mathbf{v}} / \mathbf{F}_{\mathbf{m}} \mathbf{T}_{\mathbf{2 4}}$ & $\Delta \mathbf{F L U}$ & $\Delta \mathbf{T}$ & $\Delta \mathbf{S e c}$ \\
\hline $\mathbf{0 4 . 0 1}$ & $10,5 \pm 2,9$ & $15,8 \pm 4,3$ & $323,0 \pm 75,1$ & $290,0 \pm 0,6$ & $0,37 \pm 0,03$ & $0,47 \pm 0,02$ & 7,0 & $-0,14$ & $-6,5$ \\
$\mathbf{1 6 . 0 1}$ & $20,1 \pm 1,9$ & $19,7 \pm 6,1$ & $185,0 \pm 9,1$ & $218,3 \pm 42,1$ & $0,46 \pm 0,01$ & $0,35 \pm 0,06$ & $-24,7$ & 0,54 & $-0,3$ \\
$\mathbf{2 3 . 0 1}$ & $5,4 \pm 1,4$ & $4,1 \pm 3,9$ & $231,6 \pm 62,1$ & $260,6 \pm 68,4$ & $0,45 \pm 0,08$ & $0,49 \pm 0,06$ & 2,9 & $-0,46$ & 5,7 \\
$\mathbf{2 5 . 0 1}$ & $4,3 \pm 1,7$ & $5,6 \pm 5,0$ & $282,0 \pm 42,1$ & $224,9 \pm 26,5$ & $0,40 \pm 0,07$ & $0,40 \pm 0,05$ & 5,0 & $-0,12$ & 0,5 \\
$\mathbf{3 1 . 0 1}$ & $18,1 \pm 0,1$ & $20,8 \pm 1,1$ & $278,2 \pm 53,1$ & $234,8 \pm 14,7$ & $0,43 \pm 0,03$ & $0,45 \pm 0,04$ & $-6,8$ & 0,37 & $-0,8$ \\
$\mathbf{0 2 . 0 2}$ & $10,3 \pm 1,4$ & $12,8 \pm 2,9$ & $227,3 \pm 15,2$ & $193,1 \pm 40,7$ & $0,44 \pm 0,03$ & $0,43 \pm 0,03$ & 0,2 & $-0,04$ & $-2,4$ \\
$\mathbf{0 6 . 0 2}$ & $14,8 \pm 1,3$ & $13,7 \pm 6,5$ & $303,5 \pm 6,2$ & $207,7 \pm 49,9$ & $0,47 \pm 0,01$ & $0,42 \pm 0,01$ & $-9,9$ & $-0,34$ & $-0,7$ \\
$\mathbf{0 8 . 0 2}$ & $17,4 \pm 0,4$ & $21,0 \pm 8,1$ & $297,4 \pm 18,2$ & $274,2 \pm 45,0$ & $0,35 \pm 0,03$ & $0,35 \pm 0,03$ & $-8,8$ & 0,20 & $-1,2$ \\
$\mathbf{2 7 . 0 2}$ & $9,6 \pm 1,2$ & $17,8 \pm 7,1$ & $271,7 \pm 28,2$ & $187,6 \pm 17,1$ & $0,43 \pm 0,04$ & $0,41 \pm 0,03$ & 11,1 & 0,73 & 6,4 \\
$\mathbf{0 1 . 0 3}$ & $6,8 \pm 0,3$ & $6,8 \pm 1,7$ & $285,9 \pm 26,3$ & $146,3 \pm 38,1$ & $0,43 \pm 0,03$ & $0,24 \pm 0,08$ & 0,9 & $-0,28$ & $-4,8$ \\
$\mathbf{0 5 . 0 3}$ & $2,8 \pm 0,8$ & $7,1 \pm 5,9$ & $294,1 \pm 75,3$ & $172,3 \pm 58,5$ & $0,53 \pm 0,10$ & $0,34 \pm 0,07$ & 4,2 & 0,25 & $-3,0$ \\
$\mathbf{0 8 . 0 3}$ & $11,7 \pm 0,9$ & $15,2 \pm 8,7$ & $250,3 \pm 41,3$ & $226,5 \pm 57,1$ & $0,41 \pm 0,02$ & $0,39 \pm 0,03$ & 0,5 & $-0,47$ & $-0,6$ \\
$\mathbf{1 2 . 0 3}$ & $14,7 \pm 2,4$ & $18,3 \pm 2,1$ & $284,7 \pm 20,3$ & $252,6 \pm 11,4$ & $0,40 \pm 0,01$ & $0,40 \pm 0,05$ & 1,1 & 1,01 & $-0,2$ \\
$\mathbf{1 4 . 0 3}$ & $15,5 \pm 1,6$ & $13,7 \pm 4,8$ & $221,9 \pm 31,3$ & $206,1 \pm 43,5$ & $0,29 \pm 0,04$ & $0,30 \pm 0,05$ & 0,1 & 0,17 & $-0,4$ \\
$\mathbf{1 9 . 0 3}$ & $23,1 \pm 1,4$ & $14,9 \pm 9,6$ & $279,2 \pm 22,3$ & $251,4 \pm 35,7$ & $0,38 \pm 0,02$ & $0,33 \pm 0,04$ & $-10,6$ & $-0,16$ & 0,6 \\
\hline
\end{tabular}

A Tabela 7, mostra que a inclinação inicial da curva $(\alpha)$ e a magnitude da irradiância de saturação (Ek), parâmetros provenientes do ajuste da curva Produção Primária vs. Irradiância (Jassby \& Platt, 1976), pouco variaram em relação ao início e o final do período incubação, sendo que média de $\alpha$ igual a $0,013 \pm 0,006 \mathrm{mg} \mathrm{C}\left[\mathrm{chl}^{-1} \mathrm{~h}^{-1}\right.$ mol quanta $\mathrm{m}^{-2} \mathrm{~s}^{-1}$ e $0,010 \pm 0,003$ $\mathrm{mg} \mathrm{C}[\mathrm{chl}]^{-1} \mathrm{~h}^{-1}$ mol quanta $\mathrm{m}^{-2} \mathrm{~s}^{-1}$, e Ek igual a 223,53 $\pm 71,83$ mol quanta $\mathrm{m}^{-2} \mathrm{~s}^{-1}$ e $220,60 \pm$ 64,94 mol quanta $\mathrm{m}^{-2} \mathrm{~s}^{-1}$, no primeiro e segundo dia, respectivamente. O Teste-t Student 
realizado da PP, calculada por estes parâmetros mostrou que não há diferença significativa entre os mesmos ( $\mathrm{p}=0,22)$, quando os 15 experimentos são comparados. Aplicando o intervalo de confiança da análise, observou-se que nos dias 31 de janeiro e 19 de março, havia diferença entre os valores de PP observados. A Figura 35 mostra 3 exemplos de ajustes do modelo JP as réplicas dos cálculos de produção primária que em alguns dias, este resultado é semelhante, no entanto, em outros dias, como em 19 de março de 2018, a curva P-E apresenta diferentes magnitudes, consequentemente as diferentes estimativas de produção primária.

Tabela 7. Variação entre o início ( $\left.T_{0}\right)$ e o final do período de incubação de 24 horas $\left(T_{24}\right)$ da inclinação inicial da curva ( $\alpha, \mathrm{mg} \mathrm{C}[\mathrm{chl}]^{-1} \mathrm{~h}^{-1}$ mol quanta $\mathrm{m}^{-2} \mathrm{~s}^{-1}$ ) e a magnitude da irradiância de saturação ( $\mathrm{E}_{\mathrm{k}}$, mol quanta $\left.\mathrm{m}^{-2} \mathrm{~s}^{-1}\right)$. Destaca-se que os experimentos ocorreram apenas no ano de 2018.

\begin{tabular}{ccccc}
\hline Data & \multicolumn{2}{c}{$\boldsymbol{\alpha}$} & \multicolumn{3}{c}{$\mathbf{E k}$} \\
& $\mathbf{T}_{\mathbf{0}}$ & $\mathbf{T}_{\mathbf{2 4}}$ & $\mathbf{T}_{\mathbf{0}}$ & $\mathbf{T}_{\mathbf{2 4}}$ \\
\hline $\mathbf{0 4 / 0 1}$ & 0,011 & 0,011 & 215,66 & 248,67 \\
$\mathbf{1 6 / 0 1}$ & 0,027 & 0,018 & 187,61 & 299,34 \\
$\mathbf{2 3} / \mathbf{0 1}$ & 0,011 & 0,011 & 212,91 & 113,73 \\
$\mathbf{2 5 / 0 1}$ & 0,011 & 0,007 & 154,89 & 271,61 \\
$\mathbf{3 1 / 0 1}$ & 0,021 & 0,010 & 168,36 & 141,41 \\
$\mathbf{0 2 / 0 2}$ & 0,009 & 0,014 & 208,73 & 152,96 \\
$\mathbf{0 6} / \mathbf{0 2}$ & 0,010 & 0,010 & 169,74 & 174,96 \\
$\mathbf{0 8} / \mathbf{0 2}$ & 0,015 & 0,010 & 239,43 & 219,67 \\
$\mathbf{2 7 / 0 2}$ & 0,010 & 0,008 & 237,87 & 288,00 \\
$\mathbf{0 1 / 0 3}$ & 0,006 & 0,009 & 419,95 & 306,96 \\
$\mathbf{0 5 / 0 3}$ & 0,015 & 0,007 & 109,40 & 139,59 \\
$\mathbf{0 8} / \mathbf{0 3}$ & 0,009 & 0,009 & 255,26 & 251,93 \\
$\mathbf{1 2} / \mathbf{0 3}$ & 0,011 & 0,011 & 296,88 & 223,61 \\
$\mathbf{1 4} / \mathbf{0 3}$ & 0,011 & 0,008 & 215,53 & 287,85 \\
$\mathbf{1 9 / 0 3}$ & 0,021 & 0,010 & 260,69 & 188,66 \\
\hline
\end{tabular}



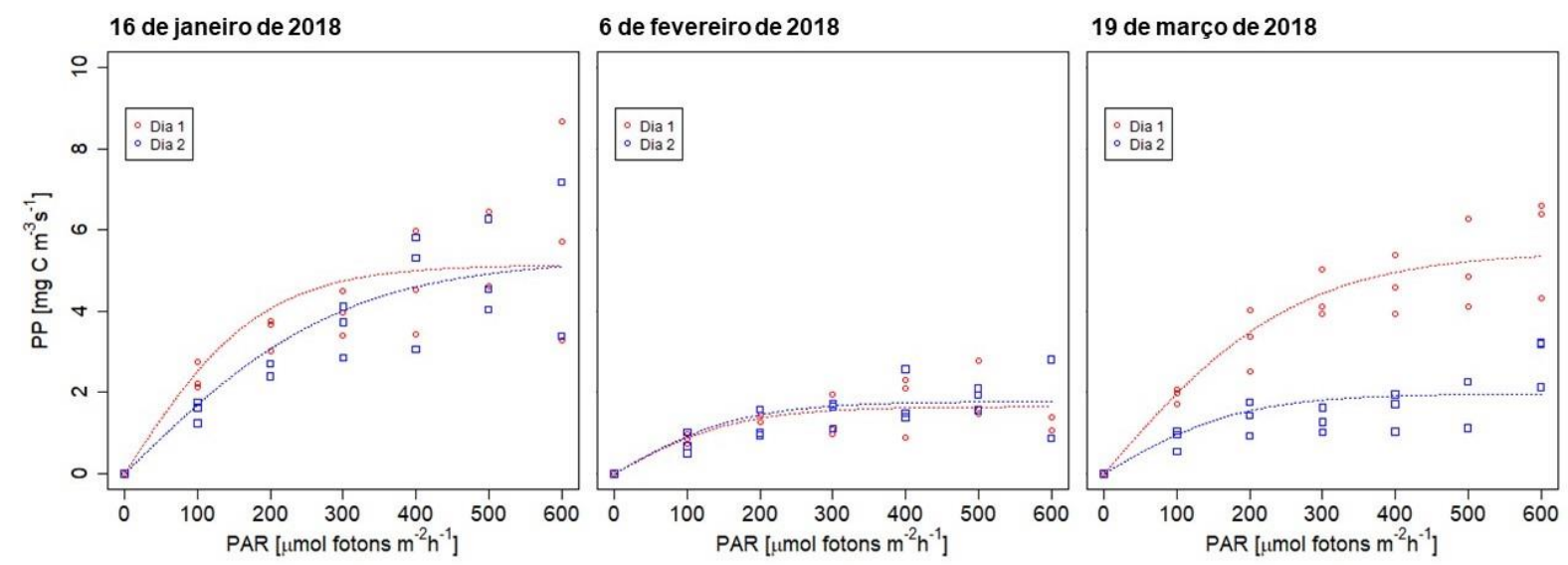

Figura 35. Exemplos de variação das curvas P-E (produção primária vs. irradiância) antes e após a incubação em 16 de janeiro de 2018, em que os valores entre as réplicas parecem divergir; em 6 de fevereiro de 2018, em que apresenta pouca variação entre a PP por réplicas e entre os dias; e em 19 de março de 2018 , que aparenta clara diferença entre os dias de coleta.

\subsubsection{Comparação entre métodos}

Na comparação entre a produção primária bruta (PPB), medida pelo método de metabolismo planctônico, e a PP medida pelo método bio-óptico (PPabs), há uma forte relação significativa entre ambas $\left(\mathrm{R}^{2}=0,62\right.$ e $\mathrm{p}=0,007$, Figura 36). A PPB também apresenta correlação positiva, embora menos robusta $\left(\mathrm{R}^{2}=0,18, \mathrm{p}=0,01\right)$ com a PP medida pelo método de fluorescência ativa variável (PPFire, Figura 37). As magnitudes entre os métodos diferem, sendo que PPB (e PPabs também) apresenta valores cerca de 10 vezes maior do que o PPFire. A PPabs correlaciona-se proporcionalmente com a PPFire $\left(\mathrm{R}^{2}=0,16\right.$ e $\left.\mathrm{p}=0,01\right)$, entretanto, é possível notar que essa relação é mais robusta para os blocos de dados considerados separadamente, onde seus $R^{2}=0,43(p=0,008), R^{2}=0,33(p=0,02)$ e $R^{2}=0,43(p=0,02)$ para B1.1, B1.2 e B3, respectivamente (Figura 38). 


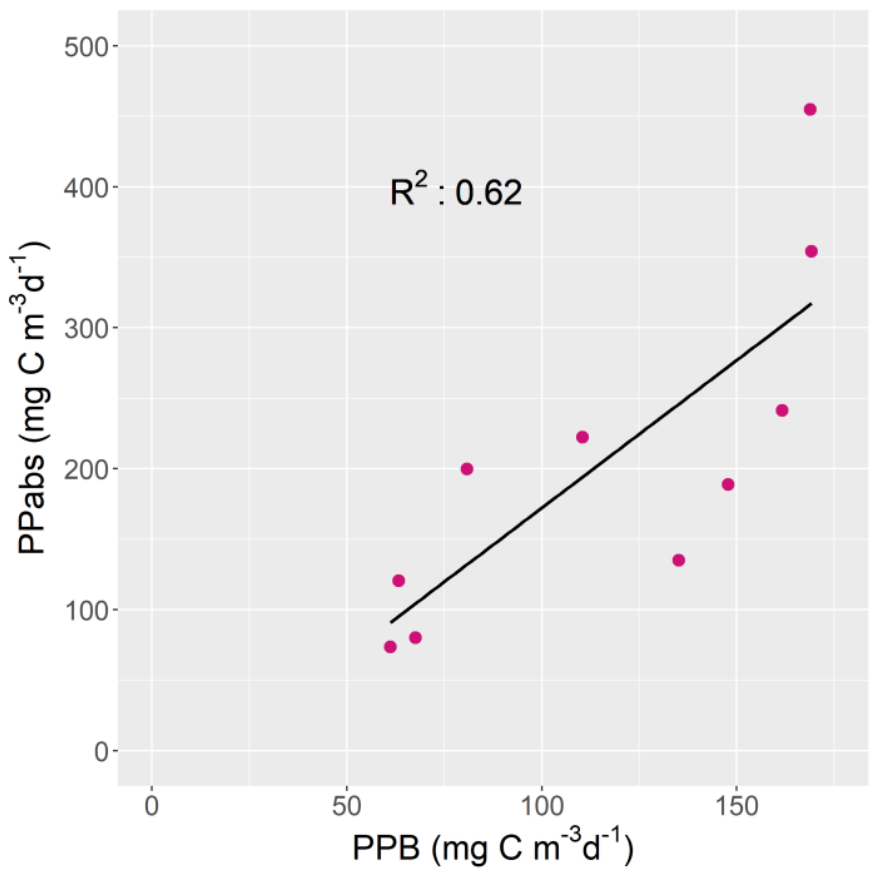

Figura 36. Relação entre estimativas de produção primária pelos métodos de metabolismo planctônico, pela produção primária bruta (PPB) e bio-óptico (PPabs). $O \mathbf{R}^{2}$ é proveniente de ajuste linear entre as produções $\operatorname{com} \mathbf{p}=\mathbf{0 , 0 0 7 )}$.

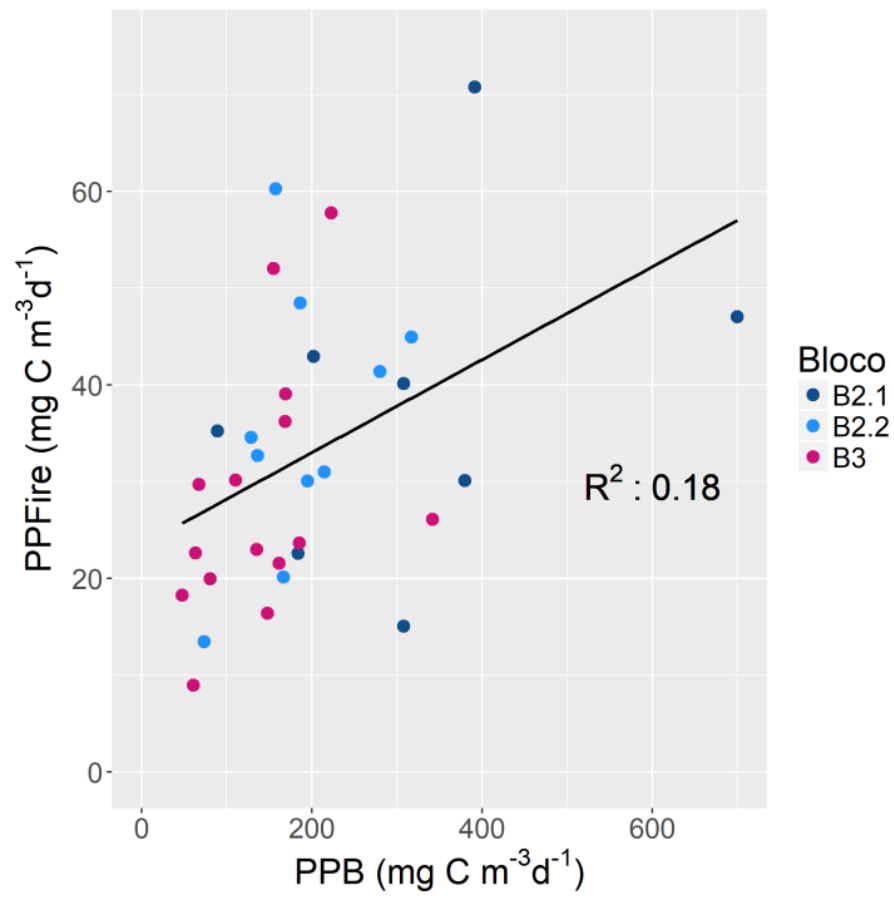

Figura 37. Relação entre estimativas de produção primária pelos métodos de metabolismo planctônico, pela produção primária bruta (PPB) e por fluorescência ativa variável (PPFire). $O \mathbf{R}^{2}$ é proveniente de ajuste linear entre as produções $\operatorname{com} \mathbf{p}=\mathbf{0 , 0 1})$. 


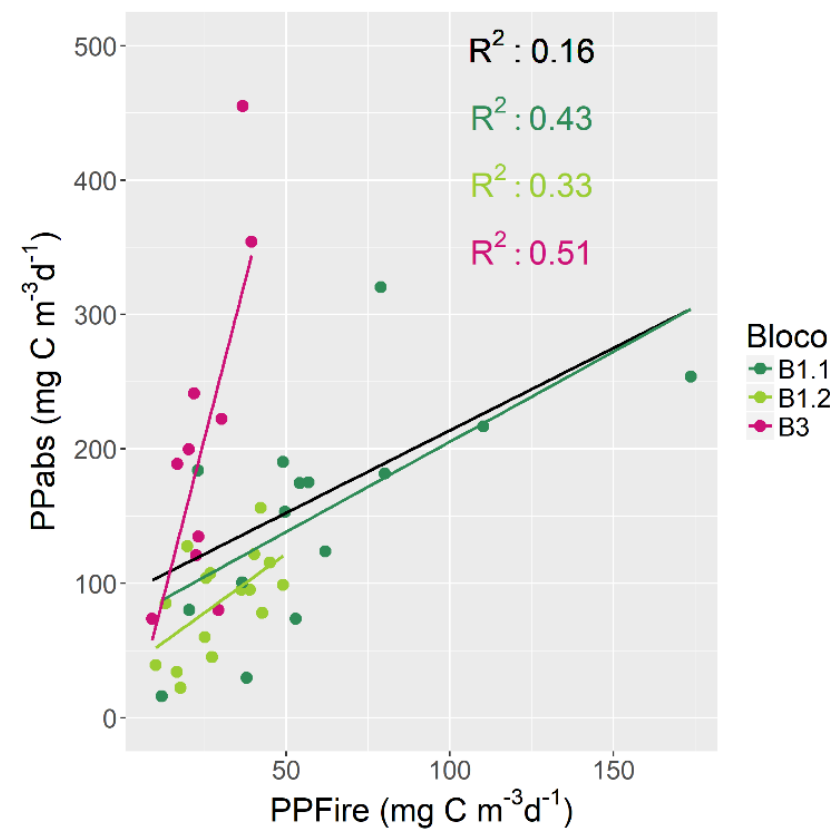

Figura 38. Relação entre estimativas de produção primária pelos métodos de fluorescência ativa variável (PPFire) e bio-óptico (PPabs). $O \mathbf{R}^{2}$ é proveniente de ajuste linear entre as produções com $\mathbf{p}=\mathbf{0 , 0 1}$ para todos os blocos, $\mathrm{p}=0,008, \mathrm{p}=0,02 \mathrm{e} \mathrm{p}=0,02$ para $\mathrm{B1} .1, \mathrm{B1} .2 \mathrm{e} \mathrm{B3}$, respectivamente).

\subsection{Forçantes e sua influência nas amplitudes dos métodos}

A produção primária bruta (PPB) medida por experimentos de taxas do metabolismo planctônico foi significativamente relacionada a temperatura ( $\mathrm{p}=0,002$, Figura 39a), com [chl] (p $=0,008$, Figura 39c) e com $K_{d}(p=0,01$, Figura 39d). Entre os blocos, apenas B3 obteve relação significativa com a temperatura e com a salinidade $(\mathrm{p}<0,001$ e $\mathrm{p}=0,03$, respectivamente, Figura 39a e b). A PPabs com todos os dados foi fracamente relacionada as variáveis (Figura 40), apenas significativa com a temperatura com todos os períodos e em B3 ( $p=0,04$ e $p=$ 0,01, respectivamente, Figura 39a). No entanto, em B1.1 a PPabs correlacionou-se positivamente com [chl] e o $K_{d}(p=0$, Figuras 39c e d). A salinidade foi apenas robusta em B1.2 ( $p=$ 0,003, Figura 39b). Por outro lado, A PPFire, em relação às variáveis oceanográficas, mostrouse apenas relacionada, proporcionalmente pela [chl] $\left(\mathrm{R}^{2}=0,21\right.$ e $\mathrm{p}=0$ Figura 41c). Entre os blocos, destaca-se a relação com a temperatura, [chl] e $\mathrm{K}_{\mathrm{d}}$ em B1.1 ( $\mathrm{p}=0,01, \mathrm{p}=0,02$ e p = 0,03, respectivamente, Figura 41a, c e d); com a [chl] em B3 (p <0,001, Figura 41c), e por fim, com a salinidade em B1.2 e B.2 ( $p=0,006$ e p =0,03, respectivamente, Figura 41b). 
Após análise por regressão múltipla por passos, os modelos preditivos (Tabela 8) - com todos os dados - para a PP por taxas metabólicas e por fluorescência obtiveram como variáveis a temperatura e a [chl] (Equações 10 e 19 - Tabela 8). O modelo para PP por absorção do fitoplâncton, considerou além destas variáveis, a salinidade (Equação 14 - Tabela 8), além disso, a performance do modelo é aperfeiçoada com a retirada dos valores registrados durante o inverno $\left(\mathrm{R}^{2}=0,50\right.$ e $\mathrm{p}=0,002$, Equação 15 - Tabela 8). Os três modelos foram considerados significativos $(\mathrm{p}=0,003, \mathrm{p}<0,001$ e $\mathrm{p}=0,008$, respectivamente). Por blocos (Tabela 8), destacam-se a ausência de variáveis explicativas em B2.1 (Equação 11 - Tabela 8) e a não-significância em B2.1 ( $p=0,07$, Equação 12 - Tabela 8) e em B2.1 por PPFire ( $p=0,22$, Equação 22 - Tabela 8). Observa-se alta significância $\left(\mathrm{R}^{2}=0,89\right.$ e $\left.\mathrm{p}=0\right)$ em B1.1 pelo modelo para a PPabs (Equação 16 - Tabela 8).

Tabela 8. Modelos preditivos para cada método de produção primária, onde $\mathbf{T}$ é a temperatura, $\mathrm{S}$ a salinidade, $K_{d} 0$ coeficiente de atenuação vertical da luz difusa, [chl] a concentração de clorofila-a, para todos os blocos de análise sendo B1.1 correspondente a janeiro a março de 2014; B1.2 de maio a agosto de 2014; B2.1 de outubro a dezembro de 2015; B2.2 de janeiro a março de 2016; B3 de janeiro a março de 2018. Todos* refere-se aos períodos de primavera e verão, ou seja, B1.1 e B3.

\begin{tabular}{|c|c|c|c|c|}
\hline BLOCO & Equação & MODELO & $\mathbf{R}^{2}$ & $\begin{array}{c}\text { P- } \\
\text { VALOR } \\
\end{array}$ \\
\hline \multicolumn{5}{|c|}{ Metabolismo da comunidade planctônica } \\
\hline Todos & 10 & $\mathrm{PPB}=901,27-29,23 \times \mathbf{T}+42,53 \times[\mathbf{c h l}]$ & 0,32 & 0,003 \\
\hline B2.1 & 11 & --- & --- & --- \\
\hline B2.2 & 12 & $\mathrm{PPB}=63,52+81,82 \times[\mathbf{c h l}]$ & 0,35 & 0,071 \\
\hline B3 & 13 & $\mathrm{PPB}=728,13-63,24 \times \mathbf{T}+33,96 \times \mathbf{S}$ & 0,69 & $<0,001$ \\
\hline \multicolumn{5}{|c|}{ Bio-óptico } \\
\hline Todos & 14 & PPabs $=1506,659+13,534 \times \mathbf{T}-52,504 \times \mathbf{S}+46,880 \times[\mathbf{c h l}]$ & 0,27 & 0,008 \\
\hline Todos* & 15 & PPabs $=4193,30-56,21 \times \mathbf{T}-74,64 \times \mathbf{S}+238,98 \times \mathbf{K}_{\mathbf{d}}$ & 0,50 & 0,002 \\
\hline B1.1 & 16 & PPabs $=5497,93-26,76 \times \mathbf{T}-139,14 \times \mathbf{S}+406,12 \times \mathbf{K}_{\mathbf{d}}$ & 0,89 & 0 \\
\hline B1.2 & 17 & PPabs $=5187,279-9,837 \times \mathbf{T}-139,375 \times \mathbf{S}-30,717 \times[\mathbf{c h l}]$ & 0,60 & 0,010 \\
\hline B3 & 18 & PPabs $=-9,534+220,811 \times[$ chl $]$ & 0,65 & 0,005 \\
\hline \multicolumn{5}{|c|}{ Fluorescência Ativa Variável } \\
\hline Todos & 19 & PPfire $=-74,575+3,083 \times \mathbf{T}+18,117 \times[\mathbf{c h l}]$ & 0,37 & 0 \\
\hline B1.1 & 20 & PPfire $=3616,80-40,84 \times \mathbf{T}-69,53 \times \mathbf{S}$ & 0,55 & 0,008 \\
\hline B1.2 & 21 & PPfire $=1157,86-32,69 \times \mathbf{S}$ & 0,42 & 0,006 \\
\hline B2.1 & 22 & PPfire $=29,925+12,424 \times \mathbf{T}-21,405 \times \mathbf{K}_{\mathbf{d}}$ & 0,45 & 0,227 \\
\hline B2.2 & 23 & PPfire $=-626,698+19,233 \times \mathbf{S}+12,137 \times[\mathbf{c h l}]-43,395 \times \mathbf{K}_{\mathbf{d}}$ & 0,74 & 0,033 \\
\hline B3 & 24 & PPfire $=15,081+11,539 \times[$ chl $]$ & 0,63 & $<0,001$ \\
\hline
\end{tabular}



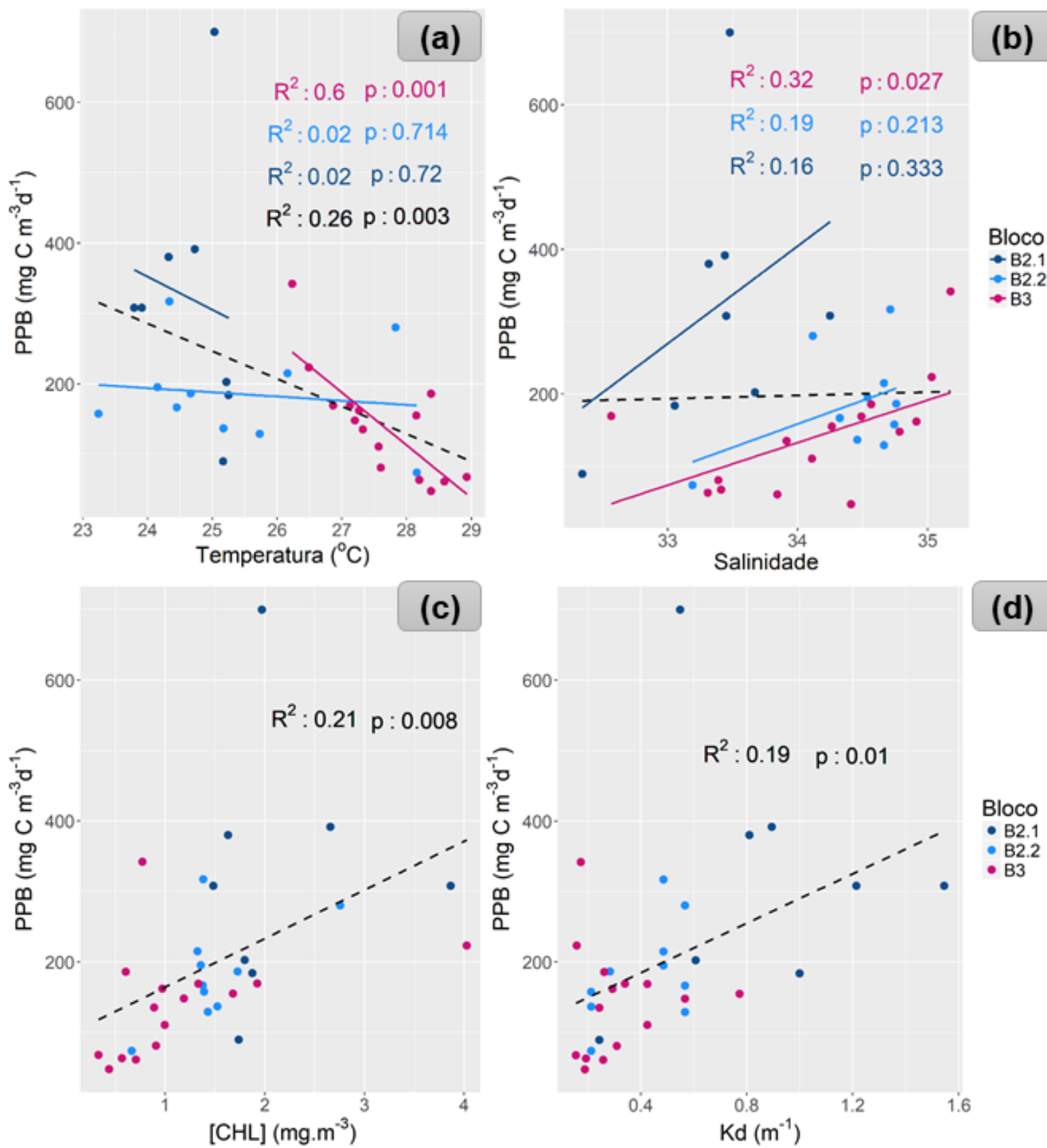

Figura 39. Relação entre a produção primária bruta (PPB em $\left.\mathrm{mg} \mathrm{C} \mathrm{m}^{-3} \mathrm{~d}^{-1}\right)$ e (a) temperatura em ${ }^{\circ} \mathrm{C}$, (b) salinidade, (c) concentração de clorofila-a $\mathrm{em} \mathrm{mg} \mathrm{m}^{-3}$ e (d) profundidade do disco de Secchi em metros. As cores indicam os blocos de dados sendo B1.1 correspondente a janeiro a março de 2014; B1.2 de maio a agosto de 2014; B2.1 de outubro a dezembro de 2015; B2.2 de janeiro a março de 2016; B3 de janeiro a março de 2018. 


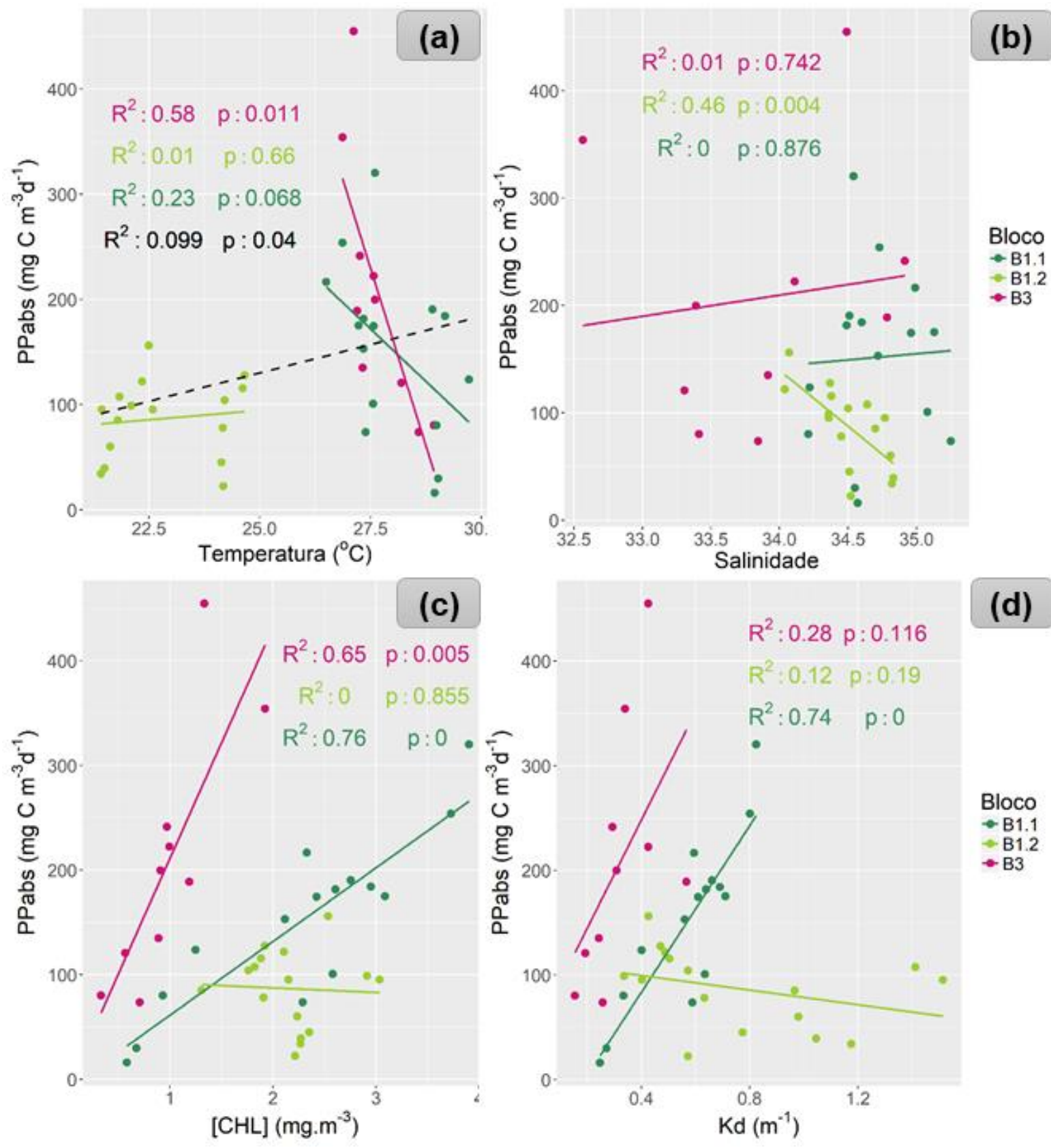

Figura 40. Relação entre a produção primária estimada pelo método bio-óptico (PPabs em $\left.\mathrm{mg} \mathrm{C} \mathrm{m}^{-3} \mathrm{~d}^{-1}\right) \mathrm{e}^{-}$ (a) temperatura em ${ }^{\circ} \mathrm{C}$, (b) salinidade, (c) concentração de clorofila-a em mg. $\mathrm{m}^{-3} \mathrm{e}$ (d) profundidade do disco de Secchi em metros. As cores indicam os blocos de dados sendo B1.1 correspondente a janeiro a março de 2014; B1.2 de maio a agosto de 2014; B2.1 de outubro a dezembro de 2015; B2.2 de janeiro a março de 2016; B3 de janeiro a março de 2018. 

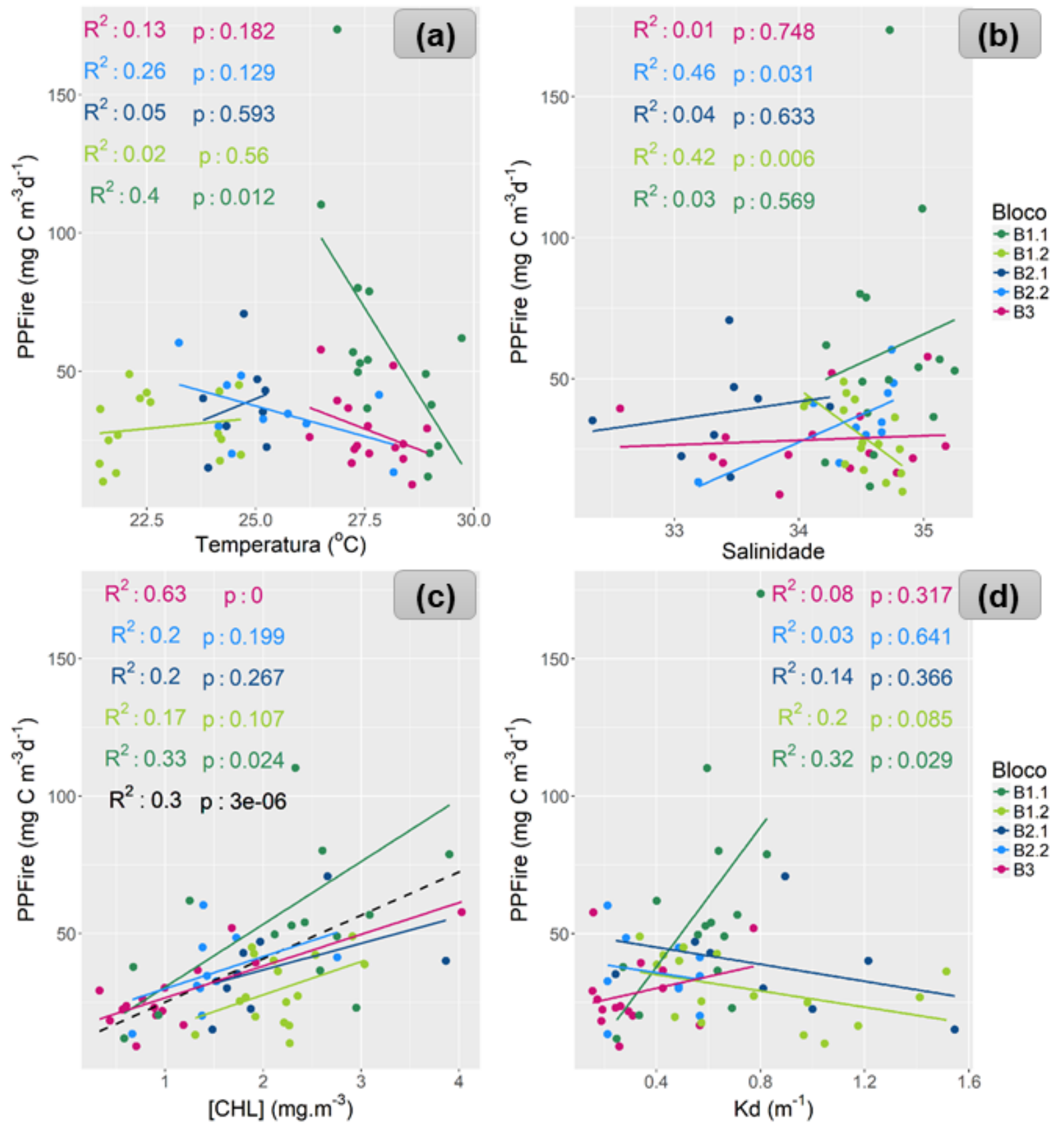

Figura 41. Relação entre a produção primária estimada pelo método de fluorescência ativa variável (PPFire em mg C m$~^{-3} \mathrm{~d}^{-1}$ ) e (a) temperatura em ${ }^{\circ} \mathrm{C}$, (b) salinidade, (c) concentração de clorofila-a em $\mathrm{mg} \mathrm{m}^{-3} \mathrm{e}(\mathrm{d})$ profundidade do disco de Secchi em metros. As cores indicam os blocos de dados sendo B1.1 correspondente a janeiro a março de 2014; B1.2 de maio a agosto de 2014; B2.1 de outubro a dezembro de 2015; B2.2 de janeiro a março de 2016; B3 de janeiro a março de 2018. 


\section{DISCUSSÃO}

Compreender os fatores que regulam a produção primária (PP) em ambientes próximos a costa se tornou fundamental uma vez que dentre outros processos locais ou regionais, essa tem impacto na redução ou emissão de carbono inorgânico para a atmosfera terrestre (Barnes et al., 2015). Assim, se tornou importante desenvolver métodos não invasivos capazes de estimar a PP de forma rápida para cobrir as lacunas espaço-temporais deixadas pelos experimentos clássicos que requerem incubação de amostras por longos períodos (Suggett et al., 2010; Robinson et al., 2017). Porém, a interpretação dos resultados de experimentos conduzidos por diferentes métodos, especialmente em águas costeiras, deve ser feita com cautela, uma vez que as condições ambientais e oceanográficas locais podem variar em curta escala de tempo, ou seja, menores que o tempo de experimento.

Relacionada as condições ambientais e a decorrente variação de taxas de PP, está o estado fisiológico da comunidade fitoplanctônica, em que este pode ser alterado pelo tipo de regime de limitação ou não de nutrientes (oligotrofia a eutrofização), e o tamanho e a composição das espécies (Irwin et al., 2006; Suggett et al., 2009). Esta última, por sua vez, deve ser levada em consideração em experimentos de PP, devido ao seu efeito nas taxas de incorporação de carbono pela respiração (Laws et al., 2000). Além da respiração do próprio fitoplâncton, a respiração e o consumo pelos organismos heterotróficos, ou seja, bactérias e zooplâncton, são essências na interpretação dos resultados, uma vez que também são influenciados por processos no sistema marinho (Laws et al., 2000; Calbet \& Landry, 2004).

\subsection{Variabilidade meteo-oceanográfica}

Os resultados do presente trabalho indicam, como esperado (Ciotti et al, 2018), a variabilidade das condições meteo-oceanográficas em alta frequência observadas no canal de São Sebastião (CSS, Figura 4 a Figura 7 e Figura 9 a Figura 12), e diferenças consistentes entre os períodos amostrados (Figura 8 e Figura 13). Observamos diferenças importantes na estrutura vertical e as condições atmosféricas que atuam no CSS durante as coletas realizadas em meses de primavera e verão em dois anos subsequentes (Figura 14 e Figura 17). Durante períodos de ventos fortes, observamos intensa mistura vertical (período B2.1) representadas pela 
homogeneidade de temperatura e salinidade, condição geralmente característica durante os meses de inverno (Castro, 2014). A entrada de ACAS em subsuperfície, manifestada por valores de salinidade acima de 35 e temperatura abaixo de $21^{\circ} \mathrm{C}$ em nossos resultados (Figura 14a-b e Figura 15a-b) foi também evidente durante as coletas realizadas em B2.2 e esta coincidiu com mínimos de turbidez e máximos de fluorescência da clorofila-a (Figura 16b e Figura 17b). É importante destacar que durante todo o B3, a ACAS esteve ausente, porém ocorreu grande variabilidade da salinidade superficial, indicando a contribuição expressiva de aportes continentais às águas do CSS (Figura 14c e Figura 15c), de origem remota ou difusa.

A variabilidade na temperatura e salinidade no CSS indicam diferenças importantes nas concentrações de nutrientes, como o papel da ACAS na entrada de nitrogênio (ver Flores et al., 2015), evidenciada pela salinidade no canal (Dottori et al., 2015), e mensurado em B1.1 (Ciotti et al., 2018), e em B2.1 e B2.2 (Regaudie-de-Gioux et al., 2017). Em outras regiões sob influência de ressurgência costeira moderada, como na costa do Oregon e Washington, o enriquecimento por nitrogênio decorrente, está fortemente associado ao aumento nas taxas de crescimento do fitoplâncton (Kokkinakis \& Wheeler, 1987). A maior disponibilidade de nitrogênio e aumentos da concentração de clorofila-a associadas a ressurgência de ACAS na costa sudeste do Brasil tem sido observada na região de Cabo Frio (Gonzalez-Rodriguez et al., 1992; Guenther et al., 2008; Coelho-Souza et al., 2017) e Ubatuba (Gaeta et al., 1999; Marcolin et al., 2015), próximo à área desse estudo. Além da injeção de nutrientes pela ACAS, a combinação com a descarga de efluentes domésticos (e.g. emissários) e material orgânico (Barcellos \& Furtado, 2006) pode levar a eutrofização das regiões adjacentes (Andutta et al., 2006; Cury et al., 2011) e a proliferação de algas potencialmente nocivas (Ciotti et al., 2018), uma vez que a massa d'água dificulta a dissipação dos efluentes devido a estratificação vertical (MarquesJúnior et al., 2006).

É importante ressaltar que por problemas logísticos não existem medidas de nutrientes durante as amostragens em B3, mas os decréscimos de salinidade registrados no Canal de São Sebastião nesse bloco são assumidos aqui como períodos associados ao aumento nas concentrações de silicato (Gaeta et al., 1999; Saldanha-Corrêa \& Gianesella, 2004; Ciotti et al., 2018). Situação semelhante ocorre em regiões que recebem grandes aportes continentais, com a pluma do Rio Mississipi, em que o silicato pode se tornar um nutriente limitante para a PP (Dortch \& 
Whitledge, 1992; Lohrenz et al., 1999), e entradas de silicato também foram observadas no canal de SS (Regaudie-de-Gioux et al., 2017).

Observa-se a boa relação geral entre a profundidade de desaparecimento do disco de Secchi e a [chl] (Figura 19), principalmente durante B3, indicando que neste período de águas mais transparentes as propriedades ópticas da coluna d'água estão diretamente associadas ao fitoplâncton. A fraca correlação em B2.1, por sua vez, indica que a transparência da água está associada a outros componentes opticamente ativos, como os sedimentos e o CDOM, que por sua vez, diminuem a disponibilidade de luz na coluna d'água conforme aumentam em concentração. Por outro lado, considerando os registros de irradiância em superfície (Figura 8) semelhantes entre B2.2 e B3, pode-se inferir que no último a disponibilidade de luz para o fitoplâncton aos 0,6 m, foi maior devido a profundidade do disco de Secchi observada (Figura 18b) durante o período.

\subsection{Estimativas de produção primária e suas forçantes}

\subsubsection{O balanço metabólico da comunidade planctônica}

Neste trabalho, a PP estimada com experimentos de balanço metabólico da comunidade fitoplanctônica, ou seja, a Produção Primaria Bruta (PPB), a Respiração (RC) e a Produção Primaria Liquida (PPL) derivada da subtração de PPB e RC, é tida como referência aos outros dois métodos empregados, por se tratar de uma técnica tradicional. Os valores de PPB obtidos por esta técnica em ambientes costeiros, cuja drenagem continental e a influência de marés são importantes, podem chegar a $1310 \mathrm{mg} \mathrm{C} \mathrm{m}^{-2} \mathrm{~d}^{-1}$ (Baia de Chesapeake - Flemer, 1970), $478 \mathrm{mg}$ $\mathrm{C} \mathrm{m}^{-3} \mathrm{~d}^{-1}$ (Laguna de Términos - Rivera-Monroy et al., 1998) e $444 \mathrm{mg} \mathrm{C} \mathrm{m}^{-3} \mathrm{~d}^{-1}$ (Estuário de Schedlt - Gazeau et al., 2005). Para a região de estudo, durante B2.1 e B2.2, Regaudie-de-Gioux et al., (2017) observou PPB média de $371,1 \pm 125,7 \mathrm{mg} \mathrm{C} \mathrm{m}^{-3} \mathrm{~d}^{-1}$, e durante os experimentos conduzidos no presente estudo, em B3, a média foi de 141,3 $\pm 125,7 \mathrm{mg} \mathrm{C} \mathrm{m}^{-3} \mathrm{~d}^{-1}$ (Figura 20). Medidas em ambientes subtropicais oligotróficos reportam valores entre aproximadamente 50 a $250 \mathrm{mg} \mathrm{C} \mathrm{m}^{-3} \mathrm{~d}^{-1}$ (Gazeau et al., 2004), e assim notamos uma amplitude de 47,5 a 700,0 mg $\mathrm{C} \mathrm{m}^{-3} \mathrm{~d}^{-1}$ no CSS, cerca de um fator de 3, com valores que representam ambientes oligotróficos até mesotróficos e eutróficos no canal. 
A Figura 20 mostra que em grande parte das campanhas em B3, a respiração da comunidade (RC) foi superior a produção primária líquida (PPL), o que indica que as comunidades nesta época são mais heterotróficas do que autotróficas, hipótese levantada por Regaudie-de-Gioux et al. (2017) durante períodos de ausência de ACAS no CSS. A RC foi apenas correlacionada positivamente, porém de forma não significativa $(\mathrm{p}=0,20)$, com a salinidade $\left(\mathrm{R}^{2}=0,12\right.$, Figura 21), o que pode indicar que em B3 a mudança da variável pode estar relacionada a alteração da comunidade. A falta de correlação entre a RC e a os previsores oceanográficos é esperada em regiões costeiras, que em geral, tende a ser apenas dependente do tipo de ecossistema (McKinnon et al., 2017). Note que a PPL foi relacionada inversamente a temperatura, e proporcionalmente a [chl] (Figura 22), indicando que as mudanças dessas condições durante o verão, com a diminuição da primeira e aumento da segunda, pelo enriquecimento da ACAS, de fato estão relacionadas a autotrofia do CSS como a hipótese levantada por Regaudie-de-Gioux (2017) durante B2.2.

\subsubsection{Método bio-óptico}

O método bio-óptico apesar de introduzido a pouco mais de uma década por Marra (2007), ainda foi pouco utilizado, sendo que sua premissa é de um melhor poder de estimativa da PP por $\mathrm{a}_{\mathrm{ph}}$ do que pela [chl]. Valores de PP derivados por este método, apresentam média global de 55 Pg C por ano (Ma et al., 2014). Já em menor escala espacial, no canal Inglês foi estimada uma média anual de PP equivalente a 15,1 $\mathrm{g} \mathrm{C} \mathrm{m}^{-3}$ ano $^{-1}$ (Barnes et al., 2015). Em escala de tempo diária, em uma região sob regime de forte drenagem continental e ocorrência de monções (Robinson et al., 2017), numa faixa de latitude $\left(10^{\circ} \mathrm{S}\right.$ a $\left.20^{\circ} \mathrm{S}\right)$, a PP diária máxima foi de aproximadamente $230 \mathrm{mg} \mathrm{C} \mathrm{m}^{-3} \mathrm{~d}^{-1}$, valor próximo aos resultados obtidos pelo presente trabalho (Figura 27). No entanto, notam-se dois valores em nossos resultados cerca de 2 vezes superiores à média registrada em B3, o que pode indicar que o método não desconta o efeito de elevados regimes de luz, uma vez que assume uma relação linear entre a transparência da coluna d’água e a luz disponível para a fotossíntese. Nesse caso, a forte irradiância é prejudicial a fisiologia celular, podendo inibir as células (Platt et al., 1981; Platt et al., 2017). Uma vez que o método não considera o processo de fotoinibição, nestes casos, pode haver superestimava da PP em relação ao método de referência (PPB), em ambientes como o CSS. 
Note que o modelo também depende diretamente das magnitudes de < $\mathrm{a}_{\mathrm{ph}}>$, e já é bem conhecido que os coeficientes de absorção de luz pelo fitoplâncton variam no tempo e no espaço (Bricaud et al., 1995; Bricaud et al., 2004). Nossos resultados mostram diferenças importantes entre os períodos amostrais (Figura 23). Observa-se que o espectro de $\mathrm{a}_{\mathrm{ph}}$ e $\mathrm{a}_{\mathrm{ph}} /\left\langle\mathrm{a}_{\mathrm{ph}}\right\rangle$ apresenta picos de absorção em torno de 412 nm (Figura 23 e Figura 24), evidente por valores mais altos de $a_{p h}(412)$ em relação ao $a_{p h}(443)$ (dados não mostrados) em algumas tréplicas, indicando a presença de feopigmentos, resultado da degradação de pigmentos fitoplanctônicos (Roesler et al., 1989; Cleveland \& Perry, 1994; Wang et al., 2008), e que não são considerados pelo método e podem superestimar a PP. Na Figura 25, destaca-se a diferença de magnitude de $\mathrm{a}_{\mathrm{ph}}$ * principalmente em uma única tréplica, com valores mais baixos, correspondente ao dia $31 \mathrm{de}$ janeiro de 2018. Neste dia a relação entre $\mathrm{a}_{\mathrm{ph}}$ *(675) e a [chl] (dados não mostrados), não seguiu o comportamento da curva dos outros dias, sugerindo efeito de empacotamento de células fitoplanctônicas grandes, como as diatomáceas, que são fontes de variabilidade da absorção de luz pelo fitoplâncton (Bricaud et al., 1995; Ciotti et al., 2002; Bricaud et al., 2004). Em contrapartida, valores altos (>0,03 $\left.\mathrm{mg}^{-1} \mathrm{~m}^{2}\right)$ de $\mathrm{a}_{\mathrm{ph}} *(675)$ (Figura 23), podem indicar o efeito de alta irradiância e menor volume das células, o que pode diminuir o efeito de empacotamento (Allali et al., 1997; Fujiki \& Taguchi, 2002).

O método bio-óptico depende também da composição de partículas e substâncias coloridas que competem por luz com o fitoplâncton, devido a sobreposição da absorção de luz pelos mesmos comprimentos de onda, que podem também superestimar a PP (Barnes et al.,2014). A comparação entre os períodos deixa evidente que durante o bloco correspondente ao verão de 2018, as águas podem ser classificadas por tipo "Caso 1", ou seja, com a absorção espectral associada fortemente com a contribuição apenas do fitoplâncton (Morel \& Prieur, 1977). Este fato pode ser explicado pela forte relação entre a [chl] e $\mathrm{a}_{\mathrm{ph}}(676)$, além da correlação alta entre $\mathrm{a}_{\mathrm{d}}(443)$ e $\mathrm{a}_{\mathrm{ph}}(443)$ (Figura 26). Por outro lado, os dados observados durante 2014 a 2016, indicam maior complexidade óptica, típica de águas costeiras "Caso 2" (Morel \& Prieur, 1977, Figura 26). Assim, em condições de águas "Caso 1", o modelo de PPabs utilizado tende a um melhor funcionamento, uma vez que águas "Caso 2" tem interferência de partículas como o CDOM e os detritos na eficiência de absorção de luz. De fato, Barnes et al. (2014) sugerem aperfeiçoamento do método a partir de equações que considerem estas partículas, ou seja, em 
água com alta complexidade óptica, permitindo a estimativa da PP em águas costeiras por sensores remotos, além de aumentar a resolução espacial e temporal.

\subsubsection{Método de fluorescência ativa variável}

A fluorescência ativa é hoje um dos principais métodos alternativos disponíveis para ampliar o conhecimento sobre a PP nos oceanos (Suggett et al., 2010), pois permite estimar o estado fisiológico das células fitoplanctônicas em escalas de tempo de segundos, o que amplia a resolução espaço-temporal das medidas/observações (Kolber \& Falkowski, 1993). Vários instrumentos são comerciáveis e amplamente utilizados, e o utilizado neste trabalho foi o FIRe (Fluorescence Induction and Relaxation System), um equipamento relativamente antigo, mas que é capaz de simular diferentes intensidades de luz. No entanto, há limitação do equipamento a comprimentos de onda na faixa do azul que faz com que a absorção de luz pelo PSII, por células que possuem o pigmento ficoeritrina, como as cianobactérias (Suggett et al., 2009) abundantes no CSS (Ciotti et al., 2018), altere significativamente a fotofisiologia das células (Campbell et al., 1998).

A PP estimada por esse método requer a aplicação de modelos de ajustes de curvas P-E para gerar os parâmetros $\alpha$ e $\mathrm{E}_{\mathrm{k}}$, e para maior robustez, optou-se por ajustá-los por uma única curva derivada dos parâmetros fotofisiológicos. Os modelos testados não apresentaram diferença significativa, e por este motivo, foi escolhido o modelo clássico e mais simples definido por Jassby \& Platt (1976). Entretanto, o modelo não leva em consideração fotoinibição, da mesma forma que o FIRe tem uma limitação para intensidade luminosa acima de $600 \mu \mathrm{mol}$ fótons $\mathrm{m}^{-2} \mathrm{~h}^{-1}$, pois acima deste limite, as células fitoplanctônicas são fortemente inibidas dentro do equipamento, além do CSS estar submetido por elevadas intensidades luminosas, principalmente durante o verão.

Entretanto, em duas datas, em 16 de janeiro de 2018 e 5 de março de 2018, a soma dos erros quadráticos (SSQ), foi superior as outras datas (Figura 32), coincidentemente o desvio padrão de $F_{0}$ (Figura 29) e $F_{m}$ (Figura 30), são também grandes. A grande variação no dia 16 de janeiro entre as réplicas pode indicar a presença de grandes células fitoplanctônicas, devido ao desvio do feixe de luz incidente ou por afundarem na cubeta de análise, considerando a maior [chl] observada em B3 de 4,03 $\pm 0,26 \mathrm{mg} \mathrm{m}^{-3}$. Porém, no dia 5 de março, a menor [chl] foi registrada $\left(0,33 \pm 0,02 \mathrm{mg} \mathrm{m}^{-3}\right)$ sugerindo que devido ao volume limitado para amostragem 
(cerca de $4 \mathrm{~mL}$ ), células raras, ou seja, que são pouco abundantes, mas são importantes na composição da comunidade (Ignatiades \& Gotsis-Skretas, 2014), podem ter sido as responsáveis pela variação observada entre as réplicas.

Os valores observados durante B2.1 a B3 dos parâmetros fotofisiológicos, $F_{v} / F_{m}$ e $\sigma_{P S I I}$ (Tabela 4, Figura 28), foram superiores à média para o ano todo encontrada por Giannini \& Ciotti (2016), equivalente a 0,39 e $304 \AA^{2}$ fóton $^{-1}$. No entanto, em geral, valores de $F_{v} / F_{m}$ encontram-se dentro da faixa 0,27 a 0,51 e $\sigma_{\text {PSII }}$ entre 200 a $350 \AA^{2}$ fóton $^{-1}$, registrados no Sistema das Agulhas (caracterizada por áreas de ressurgência costeira), cuja a magnitude dos parâmetros foi associada proporcionalmente a PP e ao tamanho das células (Barlow et al., 2010). Além do tamanho, a partir da relação entre os dois parâmetros, é possível identificar uma dependência com os grupos taxonômicos, em que $\sigma_{P S I I}$ até $600 \AA^{2}$ fóton $^{-1}$ e $F_{v} / F_{m}$ entre 0,45 e 0,70 é característico de diatomáceas e $\sigma_{P S I}$ abaixo de $350 \AA^{2}$ fóton $^{-1}$ e $F_{v} / F_{m}$ abaixo de 0,65 podem ser encontradas cianófitas (Suggett el al., 2009). Giannini \& Ciotti (2016) também encontraram correlação com o tamanho da comunidade, porém positiva com $F_{v} / F_{m}$ e negativa com $\sigma_{P S I I}$, em momentos em que a concentração de nutrientes no CSS foi superior aos valores medianos. De-

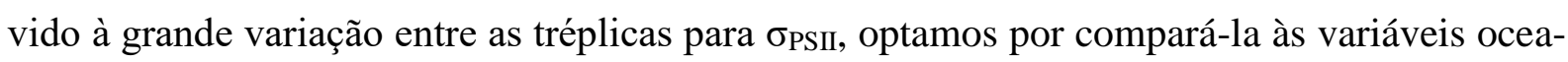
nográficas (dados não mostrados), entretanto não foi encontrada nenhuma relação. Quanto a PP medida pelo método de fluorescência ativa variável (PPFire) identificou-se boa correlação com a temperatura e a salinidade em B2.2 (Figura 41), coincidindo com o período de entrada de ACAS o CSS. A temperatura também foi importante em B1.1, período também sob a influência da massa d'água.

Durante esse trabalho, tivemos a oportunidade de investigar as variações fotofisiológicas ao longo da incubação de 24 horas, e este teste indicou que o estado fisiológico das células é alterado (Tabela 6), como pode ser observado os diferentes valores de $\mathrm{F}_{0}$, indicando diminuição ou aumento da eficiência fotossintética. No entanto, não há uma relação direta entre as condições físicas analisadas (temperatura e penetração da luz pelo disco de Secchi). Durante B3, a diferença entre o coeficiente de atenuação de luz no início e ao final do experimento, durante as 24 horas, não mostrou ser significante nos dias de coleta (Figura 34).

Estudos recentes mostram que para a conversão para a PP por métodos estimados pela a fluorescência da clorofila-a, é necessário obter o fator $K_{c}$ (requerimento de elétrons para a 
fixação de carbono em mol e $\mathrm{e}^{-}[\mathrm{mol} \mathrm{C}]^{-1}$, Lawrenz et al., 2013). O valor de $\mathrm{K}_{\mathrm{c}}$ é influenciado pela fisiologia e composição da comunidade frente a mudanças nas concentrações de nitrogênio na água do mar (Hughes et al., 2018a). Desta forma, considerando o aumento deste nutriente durante eventos de entrada de ACAS no CSS, espera-se que a PP também se altere quando convertida pelo $\mathrm{K}_{\mathrm{c}}$, dando maior robustez as medidas obtidas. Entretanto, no presente trabalho não foi possível estimar este fator devido a problemas logístico durante as coletas.

\subsection{Comparação entre os métodos}

Apesar da disponibilidade atual de diferentes métodos de estimativa de PP, é de extrema importância entender como as mesmas forçantes ambientais (e.g. temperatura, salinidade, [chl], descritores da transparência da água), operam nos diferentes métodos. Ainda assim, considerando o metabolismo planctônico como a base de comparação, por ser o método mais antigo e amplamente utilizado (Suggett et al., 2010), deve-se discutir como as outras metodologias são comparáveis a PP bruta (PPB) ou com a PP líquida (PPL). Além disso, é necessário obter mais informações de como cada método varia no tempo e em quais taxas de aquisição são compatíveis entre si.

Os 3 métodos de estimativa de produção primária escolhidos pelo presente trabalho (Figura 36 a Figura 38) apresentam magnitudes diferentes, como esperado, mas de forma geral se relacionam linearmente. Uma vez que cada uma das técnicas estima a PP em escalas de tempo diferentes, elas medem processos distintos. O método de taxa metabólica do plâncton inclui efeitos de outros componentes da comunidade planctônica que não o fitoplâncton, principalmente, as atividades das bactérias heterotróficas (Williams, 1981; Bonilla-Findji et al., 2010). Por outro lado, experimentos que necessitam de incubação e coleta por garrafas estão suscetíveis ao "efeito de garrafa", uma vez que o volume utilizado pode não representar a população in situ (Bender et al., 1987), havendo exclusão de organismos do zooplâncton maiores e mais ativos (De Bernardi, 1984; Gifford \& Caron, 2000) e os organismos raros do fitoplâncton (Ignatiades \& Gotsis-Skretas, 2014).

O método bio-óptico é de certa forma uma medida instantânea, mas os coeficientes de absorção de luz pelo fitoplâncton $\left(\mathrm{a}_{\mathrm{ph}}\right)$, assim como a [chl], são respostas de muitos processos 
simultâneos (Riley, 1965). No entanto, uma das vantagens de utilizar aph em relação à [chl] é que está traz informações quanto a composição pigmentar do fitoplâncton, podendo sugerir grupos taxonômicos e tamanhos de células (Ciotti et al., 1999; Ciotti et al., 2002) e dependendo do método de aquisição do dado, pode-se incluir a interferência por outras partículas, que não o fitoplâncton, como os detritos, a partir do o comportamento espectral da absorção de luz por amostra, como no método descrito por Tassan \& Ferrari (1995).

No caso do método por fluorescência da clorofila-a, as medidas refletem as condições fisiológicas mais imediatas, além de utilizar um volume reduzido de amostras, que tenderá a excluir espécies mais raras (Ignatiades \& Gotsis-Skretas, 2014) fato de certa forma evidenciado nas diferenças entre as réplicas (e.g., Figura 35). Desta forma, sugerimos aquisição de dados não por cubetas, mas sim em fluxo contínuo, diminuindo a probabilidade de generalização por tamanhos da comunidade, além de aperfeiçoar fluorímetros para aumentar a taxa de aquisição de dados in situ, diminuindo a limitação para volumes pequenos. Importante ressaltar a necessidade da calibração padronizada entre diferentes tipos de fluorímetros, como proposto por Silsbe et al. (2015), com a finalidade de se obter medidas comparáveis ao redor do mundo. Hughes et al. (2018b), sugere etapas para o aperfeiçoamento das técnicas de estimativa de PP por fluorescência da clorofila-a, tanto de laboratório como de campo, de curto (aproximadamente 2 anos) a longo prazo (mais de 5 anos). Além disso, o cálculo utilizado para computar a PP por dia necessita que sejam assumidos que não haja alteração dos parâmetros fisiológicos, temperatura e que a atenuação da luz se mantenha constante, durante as 24 horas, porém neste ambiente dinâmico destacam-se as variações em $\mathrm{F}_{0}$ e na profundidade do disco de Secchi (Tabela 7). Consequentemente, a variação do último indica a importância da variabilidade de $\mathrm{K}_{\mathrm{d}}$ ao longo do dia, podendo interferir na estimativa da PP, como no caso do dia 31 de janeiro (Figura 34).

Considerando estes fatos, supomos então que as técnicas de estimativas de PP são complementares e que estas podem responder de formas variadas frente às rápidas mudanças na disponibilidade de luz e nutrientes por processos de mistura vertical que ocorrem no canal durante pequenas escalas de tempo. Os 3 métodos, considerando toda a base de dados utilizada, mostram-se sensíveis a variação da temperatura (Equações 10, 14 e 19, Tabela 8), indicando que são capazes de identificar a influência de massas d'água, principalmente a ACAS sobre a PP. No entanto, apenas com o método bio-óptico foi possível observar uma relação com a salini- 
dade, ou seja, o único método que pode ser qualificado para explicar a ação de aporte continental, decorrente por exemplo, por importantes eventos de precipitação na região. Considerando, os blocos separadamente (Tabela 7), observa-se variação das 4 variáveis oceanográficas explicativas (temperatura, salinidade, $[\mathrm{chl}]$ e $\mathrm{K}_{\mathrm{d}}$ ) dos métodos de PP, afirmando a sazonalidade e mudanças interanuais das condições oceanográficas no CSS. Além disso, vimos que para cada período definido, as 4 forçantes escolhidas na previsibilidade da PP, ora atuam sozinhas, ora variam sinergicamente com outras, mas nunca as 4 juntas explicaram a PP (Tabela 8).

\section{CONCLUSÕES}

Concluindo, observamos que apesar de encontrarmos diferentes magnitudes paras as taxas de PP entre os três métodos aqui comparados, os métodos não-invasivos (PPabs e PPFire) funcionam com eficiência no CSS, sendo capazes de trazer informações adicionais quanto à composição pigmentar e o estado fisiológico das células do fitoplâncton. Além disso, a partir das quatro forçantes escolhidas, temperatura, salinidade, [chl] e $\mathrm{K}_{\mathrm{d}}$, mostramos que todos os métodos foram sensíveis à entrada de ACAS no canal, entretanto, decréscimos em salinidade foram importantes em apenas alguns períodos. Vimos também, que a influência de uma dada forçante dependeu do método e das condições oceanográficas que regiam o período. Por fim, sugerimos que a combinação entre os métodos não-invasivos, pode ser uma estratégia para o desenvolvimento de modelos de PP regionais. 


\section{REFERÊNCIAS}

AIDAR, E.; GAETA, S. A.; GIANESELLA-GALVÃO, S. M. F.; KUTNER, M. B. B.; et al. Ecossistema costeiro subtropical: nutrientes dissolvidos, fitoplâncton e cloroflla-a e suas relações com as condições oceanográficas na região de Ubatuba, SP. 1993.

ALLALI, K.; BRICAUD, A.; CLAUSTRE, H. Spatial variations in the chlorophyll-specific absorption coefficients of phytoplankton and photosynthetically active pigments in the equatorial Pacific. Journal of Geophysical Research: Oceans, v. 102, n. C6, p. 12413-12423, 1997.

ANDERSON, D. M. Toxic algal blooms and red tides: a global perspective. Red tides: Biology, Environmental Science, and Toxicology, p. 11-16, 1989.

ANDERSON, D. M.; CEMBELLA, A. D.; HALLEGRAEFF, G. M. Progress in Understanding Harmful Algal Blooms: Paradigm Shifts and New Technologies for Research, Monitoring, and Management. Annual Review of Marine Science, v. 4, n. 1, p. 143-176, 2012. Disponível em: <http://www.annualreviews.org/doi/10.1146/annurev-marine-120308-081121>.

ANDUTTA, F. P.; SANTOS, M. R. M.; MIRANDA, L. B.; et al. Monthly Variations of Physical and Chemical Properties Observed in Santos Bay and Santos Estuarine Channel. Proceedings of the Environmental and Health Congress EHWC'2006. Anais. p.80-84, 2006. Santos.

ATKINSON, L. P.; HUTHNANCE, J.; BLANCO, J. L. Circulation, mixing and the distribution of remineralized nutrients. In: A. R. Robinson; J. Mccarthy; B. J. Rothschild (Orgs.); The Sea. 13a ed, v. 13, p.227-268, 2004. New York: John Wiley \& Sons, Inc.

BAKER, N. R. Chlorophyll Fluorescence: A Probe of Photosynthesis In Vivo. Annual Review of Plant Biology, v. 59, n. 1, p. 89-113, 2008. Disponível em: <http://www.annualreviews.org/doi/10.1146/annurev.arplant.59.032607.092759>.

BARBER, R. T.; HILTING, A. K. History of the study of plankton productivity. In: Willians, P.; Thomas, D. N.; Reynolds, C. S (Eds.). Phytoplankton productivity - Carbon assimilation in marine and freshwater ecosystem. Blackwell Science, Cap. 2, p. 16-43, 2002.

BARCELLOS, R. L.; FURTADO, V. V. Organic Matter Contents and Modern Sedimentation at São Sebastião Channel. Journal of Coastal Research, v. 2004, n. 39, p. 1073-1077, 2006.

BARLOW, R.; LAMONT, T.; KYEWALYANGA, M.; SESSIONS, H.; MORRIS, T. Phytoplankton production and physiological adaptation on the southeastern shelf of the Agulhas ecosystem. Continental Shelf Research, v. 30, n. 13, p. 1472-1486, 2010. Disponível em: <http://dx.doi.org/10.1016/j.csr.2010.05.007>. .

BARNES, M. K.; TILSTONE, G. H.; SMYTH, T. J.; et al. Absorption-based algorithm of primary production for total and size-fractionated phytoplankton in coastal waters. Marine Ecology Progress Series, v. 504, p. 73-89, 2014.

BARNES, M. K.; TILSTONE, G. H.; SUGGETT, D. J.; et al. Temporal variability in total, micro- and nano-phytoplankton primary production at a coastal site in the Western English Channel. Progress in Oceanography, v. 137, p. 470-483, 2015. Disponível em: <http://dx.doi.org/10.1016/j.pocean.2015.04.017>. 
BENDER, M.; GRANDE, K.; JOHNSON, K.; et al. A comparison of four methods for determining planktonic community production. Limnology and Oceanography, v. 32, n. 5, p. 10851098, 1987.

BLAUW, A. N.; BENINCÀ, E.; LAANE, R. W. P. M.; et al. Dancing with the Tides: Fluctuations of Coastal Phytoplankton Orchestrated by Different Oscillatory Modes of the Tidal Cycle. PLoS ONE, v. 7, n. 11, 2012.

BOKUNIEWICZ, H.; TANIGUCHI, M.; ISHITOIBI, T.; et al. Direct measurements of submarine groundwater discharge (SGD) over a fractured rock aquifer in Flamengo Bay Brazil. Estuarine, Coastal and Shelf Science, v. 76, n. 3, p. 466-472, 2008.

BONILLA-FINDJI, O.; GATTUSO, J. P.; PIZAY, M. D.; et al. Autotrophic and heterotrophic metabolism of microbial planktonic communities in an oligotrophic coastal marine ecosystem: Seasonal dynamics and episodic events. Biogeosciences, v. 7, n. 11, p. 3491-3503, 2010.

BRICAUD, A.; BABIN, M.; MOREL, A.; et al. Variability in the chlorophyll-specific absorption coefficients of natural phytoplankton: Analysis and parameterization. Journal of Geophysical Research, v. 100, n. C7, p. 13321, 1995. Disponível em: <http://doi.wiley.com/10.1029/95JC00463>. .

BRICAUD, A.; CLAUSTRE, H.; RAS, J.; et al. Natural variability of phytoplanktonic absorption in oceanic waters: Influence of the size structure of algal populations. Journal of Geophysical Research: Oceans, v. 109, n. 11, p. 1-12, 2004.

BRINK, K. H. Coastal ocean physical processes. Reviews of Geophysics, v. 25, n. 2, p. 204 $216,1987$.

BROWN, C. J.; FULTON, E. A.; HOBDAY, A. J.; et al. Effects of climate-driven primary production change on marine food webs: Implications for fisheries and conservation. Global Change Biology, v. 16, n. 4, p. 1194-1212, 2010.

BUITENHUIS, E. T.; HASHIOKA, T.; QUÉRÉ, C. LE. Combined constraints on global ocean primary production using observations and models. Global Biogeochemical Cycles, v. 27, n. August, p. 847-858, 2013.

CALBET, A.; LANDRY, M. R. Phytoplankton growth, microzooplankton grazing, and carbon cycling in marine systems. Limnology and Oceanography, v. 49, n. 1, p. 51-57, 2004. Disponível em: 〈https://doi.org/10.4319/lo.2004.49.1.0051>.

CAMPBELL, J.; ANTOINE, D.; ARMSTRONG, R.; et al. Comparison of algorithms for estimating ocean primary production from surface chlorophyll, temperature, and irradiance. Global Biogeochemical Cycles, v. 16, n. 3, p. 9-1-9-15, 2002. Disponível em: <http://doi.wiley.com/10.1029/2001GB001444>.

CAMPBELL, D.; HURRY, V.; CLARKE, A. K.; et al. Chlorophyll fluorescence analysis of cyanobacterial photosynthesis and acclimation. Microbiology and molecular biology reviews: MMBR, v. 62, n. 3, p. 667-83, 1998. Disponível em: <http://www.ncbi.nlm.nih.gov/pubmed/9729605\%0Ahttp://www.pubmedcentral.nih.gov/articlerender.fcgi?artid=PMC98930>. . 
CAMPOS, P. C.; MÖLLER, O. O.; PIOLA, A. R.; et al. Seasonal variability and coastal upwelling near Cape Santa Marta (Brazil). Journal of Geophysical Research: Oceans, v. 118, n. 3, p. 1420-1433, 2013.

CARPENTER, J. H. The accuracy of the Winkler method for dissolved oxygen analysis. Limnology and Oceanography, v. 10, n. 1, p. 135-140, 1965. Disponível em: <http://doi.wiley.com/10.4319/lo.1965.10.1.0135>.

CARR, M. E.; FRIEDRICHS, M. A. M.; SCHMELTZ, M.; et al. A comparison of global estimates of marine primary production from ocean color. Deep-Sea Research Part II: Topical Studies in Oceanography, v. 53, n. 5-7, p. 741-770, 2006.

CASTRO, B. M.; LORENZETTI, J. A.; DA SILVEIRA, I. C. A.; et al. Estrutura termohalina e circulação na região entre o Cabo de São Tomé (RJ) e o Chuí (RS). In: Rossi-Wongtschowski, C. L. D. B.; Madureira, L. S. P. (Eds.). O ambiente oceanográfico da Plataforma Continental e do Talude na região sudeste-sul do Brasil. Editora da Universidade de São Paulo, Cap. 1, p. 11$120,2006$.

CASTRO, B. M. Summer/winter stratification variability in the central part of the South Brazil Bight. Continental Shelf Research, v. 89, p. 15-23, 2014. Elsevier. Disponível em: <http://dx.doi.org/10.1016/j.csr.2013.12.002>. .

CHEUNG, W. W. L.; DUNNE, J.; SARMIENTO, J. L.; et al. Integrating ecophysiology and plankton dynamics into projected maximum fisheries catch potential under climate change in the Northeast Atlantic. ICES Journal of Marine Science, v. 68, n. 6, p. 1008-1018, 2011.

CIOTTI, A. M.; ODEBRECHT, C.; FILLMANN, G.; et al. Freshwater outflow and Subtropical Convergence influence on phytoplankton biomass on the southern Brazilian continental shelf. Continental Shelf Research, v. 15, p. 1737-1756, 1995.

CIOTTI, A. M.; CULLEN, J. J.; LEWIS, M. R. A semi-analytical model of the influence of phytoplankton community structure on the relationship between light attenuation and ocean color. Journal of Geophysical Research, v. 104, n. C1, p. 1559-1578, 1999.

CIOTTI, A. M., LEWIS, M. R. AND CULLEN, J. Assessment of the relationships between dominant cell size in natural phytoplankton... Limnology and Oceanography, v. 47, n. 2, p. 404417, 2002.

CIOTTI, Á. M.; FERREIRA, A.; GIANNINI, M. F. C. Seasonal and event-driven changes in the phytoplankton communities in the Araçá Bay and adjacent waters. Ocean and Coastal Management, v. 164, n. August 2017, p. 14-31, 2018. Elsevier. Disponível em: <https://doi.org/10.1016/j.ocecoaman.2018.03.024>.

CLEVELAND, J. S.; PERRY, M. J. A model for partitioning particulate absorption into phytoplanktonic and detrital components. Deep-Sea Research Part I, v. 41, n. 1, p. 197-221, 1994.

CLOERN, J. E.; GRENZ, C.; VIDERGAR-LUCAS, L. An empirical model of the phytoplankton chlorophyll: carbon ratio - the conversion factor between productivity and growth rate. Limnology and Oceanography, v. 40, n. 7, p. 1313-1321, 1995. 
CLOERN, J. E. Our evolving conceptual model of the coastal eutrophication problem. Marine Ecology Progress Series, v. 210, p. 223-253, 2001.

CLOERN, J. E.; FOSTER, S. Q.; KLECKNER, A. E. Phytoplankton primary production in the world's estuarine-coastal ecosystems. Biogeosciences, v. 11, n. 9, p. 2477-2501, 2014.

COELHO-SOUZA, S. A.; PEREIRA, G. C.; LOPEZ, M. S.; et al. Seasonal sources of carbon to the Brazilian upwelling system. Estuarine, Coastal and Shelf Science, v. 194, p. 162-171, 2017. Elsevier Ltd. Disponível em: 〈http://dx.doi.org/10.1016/j.ecss.2017.06.013〉.

CURY, J. C.; ARAUJO, F. V.; COELHO-SOUZA, S. A.; et al. Microbial diversity of a Brazilian coastal region influenced by an upwelling system and anthropogenic activity. PLoS ONE, v. 6, n. 1, 2011.

DE BERNARDI, R. Methods for the estimation of zooplankton abundance. In: J. A. Downing; F. H. Rigler (Orgs.); A manual on methods for the assessment of secondary productivity in fresh waters. 2o ed, p.59-86., 1984. Oxford: Blackwell Scientific Publications.

DEBES, H.; GAARD, E.; HANSEN, B. Primary production on the Faroe shelf: Temporal variability and environmental influences. Journal of Marine Systems, v. 74, n. 1-2, p. 686-697, 2008. Elsevier B.V. Disponível em: 〈http://dx.doi.org/10.1016/j.jmarsys.2008.07.004>.

DENMAN, K. L.; GARGETT, A. E. Time and space scales of vertical mixing and advection of phytoplankton in the upper ocean. Limnology and Oceanography, v. 28, n. 5, p. 801-815, 1983.

DHN - DIRETORIA DE HIDROGRAFIA E NAVEGAÇÃO. 2013. Carta náutica número 1644 - Canal de São Sebastião (parte Norte). Disponível em: <https://www.marinha.mil.br/chm/dados-do-segnav/cartas-raster>.

DHN - DIRETORIA DE HIDROGRAFIA E NAVEGAÇÃO. 2016. Carta náutica número 1643 - Canal de São Sebastião (parte Sul). Disponível em: <https://www.marinha.mil.br/chm/dados-do-segnav/cartas-raster>.

DORTCH, Q.; WHITLEDGE, T. E. Does nitrogen or silicon limit phytoplankton production in the Mississippi River plume and nearby regions? Continental Shelf Research, v. 12, n. 11, p. 1293-1309, 1992.

DOTTORI, M.; SIEGLE, E.; CASTRO, B. M. Hydrodynamics and water properties at the entrance of Araçá Bay, Brazil. Ocean Dynamics, v. 65, n. 12, p. 1731-1741, 2015.

EILERS, P. H. C.; PEETERS, J. C. H. A model for the relationship between light intensity and the rate of photosynthesis in phytoplankton. Ecological Modelling, v. 42, n. 3-4, p. 199-215, 1988.

EMÍLSSON, I. The shelf and coastal waters off southern Brazil. Boletim do Instituto Oceanográfico, v. 11, n. 2, p. 101-112, 1961. Disponível em: <http://www.scielo.br/scielo.php?script=sci_arttext\&pid=S037355241961000100004\&lng=en\&tlng=en>. 
EPPLEY, R.; STEWARD, E.; ABBOTT, M.; et al. Estimating ocean primary production from satellite chlorophyll: introduction to regional differences and statistics for the Southern California Bight. Journal of Plankton Research, v. 7, p. 57-70, 1985.

ESTÉVEZ-BLANCO, P.; CERMEÑO, P.; ESPIÑEIRA, M.; et al. Phytoplankton photosynthetic efficiency and primary production rates estimated from fast repetition rate fluorometry at coastal embayments affected by upwelling (Rías Baixas, NW of Spain). Journal of Plankton Research, v. 28, n. 12, p. 1153-1165, 2006.

FALKOWSKI, P. G.; OWENS, T. G. Effects of light intensity on photosynthesis and dark respiration in six species of marine phytoplankton. Marine Biology, v. 45, n. 4, p. 289-295, 1978.

FALKOWSKI, A. J.; BARBER, D. S.; SMETACEK. Biogeochemical Controls and Feedbacks on Ocean Primary Production. Science, v. 281, n. 5374, p. 200-207, 1998. Disponível em: <http://www.ncbi.nlm.nih.gov/pubmed/9660741>. .

FIELD, C. B. Primary Production of the Biosphere: Integrating Terrestrial and Oceanic Components. Science, v. 281, n. 5374, p. 237-240, 1998. Disponível em: <http://www.sciencemag.org/cgi/doi/10.1126/science.281.5374.237>. .

FIGUEIRAS, F. G.; LABARTA, U.; FERN, M. J. Coastal upwelling, primary production and mussel growth in teh Rías Baixas of Galicia. Hydrobiologia, v. 484, p. 121-131, 2002.

FLEMER, D. A. Primary Production in the Chesapeake Bay. Chesapeake Science, v. 11, n. 2, p. 117, 1970. Disponível em: <http://link.springer.com/10.2307/1350486>.

FLORES, A. A. V.; CHRISTOFOLETTI, R. A.; PERES, A. L. F.; et al. Interactive effects of grazing and environmental stress on macroalgal biomass in subtropical rocky shores: Modulation of bottom-up inputs by wave action. Journal of Experimental Marine Biology and Ecology, v. 463, p. 39-48, 2015. Elsevier B.V. Disponível em: <http://dx.doi.org/10.1016/j.jembe.2014.11.001>.

FUJIKI, T.; TAGUCHI, S. Variability in chlorophyll a specific absorption coefficient in marine phytoplankton as a function of cell size and irradiance. Journal of Plankton Research, v. 24, n. 9, p. 859-874, 2002. Disponível em: <https://academic.oup.com/plankt/articlelookup/doi/10.1093/plankt/24.9.859>.

GAARDER, T.; GRAN, H. H. Investigations of the production of plankton in the Oslo Fjord. Rapports et Procès-Verbaux des Réunions, v. 42, p. 1-52, 1927.

GAETA, S. A.; ABE, D. S.; SUSINI, S. M.; et al. Produtividade primária, plâncton e covariáveis ambientais no Canal de São Sebastião durante o outono. Revista Brasileira de Biologia, v. 40, n. 4, p. 963-974, 1990.

GARVINE, R. W. Estuary plumes and fronts in shelf waters: A layer model. Journal of Physical Oceanography, v. 1987, p. 1877-1896, 1987.

GAZEAU, F.; SMITH, S. V.; GENTILI, B.; et al. The European coastal zone: Characterization and first assessment of ecosystem metabolism. Estuarine, Coastal and Shelf Science, v. 60, n. 4, p. 673-694, 2004. 
GAZEAU, F.; GATTUSO, J. P.; MIDDELBURG, J. J.; et al. Planktonic and whole system metabolism in a nutrient-rich estuary (the Scheldt estuary). Estuaries, v. 28, n. 6, p. 868-883, 2005 .

GIANESELLA, S. M. F.; KUTNER, M. B. B.; SALDANHA-CORRÊA, F. M. P.; et al. Assessment of plankton community and environmental conditions in São Sebastião Channel prior to the construction of a produced water outfall. Revista Brasileira de Oceanografia, v. 47, n. 1, p. 29-46, 1999. Disponível em: <http://www.scielo.br/pdf/bjoce/v47n1/03.pdf\%0Ahttp://www.scielo.br/scielo.php?script=sci_arttext\&pid=S1413-

$77391999000100003 \& \operatorname{lng}=\mathrm{en} \& \operatorname{tlng}=\mathrm{en}>$. .

GIANESELLA, S. M. F. Variabilidade da camada de clorofila máxima na região de quebra de Plataforma Continental Sudeste Brasileira. Tese (Doutorado) - Curso de Oceanografia, Departamento de Oceanografia Biológica, Universidade de São Paulo, São Paulo, 2000. 166 f.

GIANNINI, M. F. C.; CIOTTI, Á. M. Parameterization of natural phytoplankton photo-physiology: Effects of cell size and nutrient concentration. Limnology and Oceanography, v. 61, n. 4, p. 1495-1512, 2016.

GIFFORD, D. J.; CARON, D. A. Sampling, preservation, enumeration and biomass of marine protozooplankton. In: R. Harris; J. Lenz; M. Huntley; P. Wiebe; H. R. Skjoldal (Orgs.); ICES Zooplankton Methodology Manual. p.193-221, 2000. Academic Press. Disponível em: <http://linkinghub.elsevier.com/retrieve/pii/B9780123276452500062>.

GLÉ, C.; DEL AMO, Y.; SAUTOUR, B.; et al. Variability of nutrients and phytoplankton primary production in a shallow macrotidal coastal ecosystem (Arcachon Bay, France). Estuarine, Coastal and Shelf Science, v. 76, n. 3, p. 642-656, 2008.

GOES, J. I.; GOMES, H. DO R.; CHEKALYUK, A. M.; et al. Influence of the Amazon River discharge on the biogeography of phytoplankton communities in the western tropical north Atlantic. Progress in Oceanography, v. 120, p. 29-40, 2014. Elsevier Ltd. Disponível em: <http://dx.doi.org/10.1016/j.pocean.2013.07.010>.

GONZALEZ-RODRIGUEZ, E.; VALENTIN, J. L.; ANDRÉ, D. L.; et al. Upwelling and downwelling at Cabo Frio (Brazil): Comparison of biomass and primary production responses. Journal of Plankton Research, v. 14, n. 2, p. 289-306, 1992.

GORMAN, D.; TURRA, A.; CONNOLLY, R. M.; et al. Monitoring nitrogen pollution in seasonally-pulsed coastal waters requires judicious choice of indicator species. Marine Pollution Bulletin, v. 122, n. 1-2, p. 149-155, 2017. Elsevier. Disponível em: <http://dx.doi.org/10.1016/j.marpolbul.2017.06.042>.

GUENTHER, M.; GONZALEZ-RODRIGUEZ, E.; CARVALHO, W. F.; et al. Plankton trophic structure and particulate organic carbon production during a coastal downwellingupwelling cycle. Marine Ecology Progress Series, v. 363, n. Malone 1980, p. 109-119, 2008.

HALSEY, K. H.; MILLIGAN, A. J.; BEHRENFELD, M. J. Physiological optimization underlies growth rate-independent chlorophyll-specific gross and net primary production. Photosynthesis Research, v. 103, n. 2, p. 125-137, 2010. 
HARRIS, G. P.; LOTT, J. N. A. Light intensity and photosynthetic rates in phytoplankton. Journal of the Fisheries Research Board of Canada, v. 30, n. 12, p. 1771-1778, 1973. Disponível em: <http://www.nrcresearchpress.com/doi/10.1139/f73-286>.

HUGHES, D. J.; VARKEY, D.; DOBLIN, M. A.; et al. Impact of nitrogen availability upon the electron requirement for carbon fixation in Australian coastal phytoplankton communities. Limnology and Oceanography, n. C, p. 1891-1910, 2018a.

HUGHES, D. J.; CAMPBELL, D. A.; DOBLIN, M. A.; et al. Roadmaps and detours: active chlorophyll- a assessments of primary productivity across marine and freshwater systems. Environmental Science and Technology, v. 52, n. 21, p. 12039-12054, 2018 b.

IGNATIADES, L.; GOTSIS-SKRETAS, O. The contribution of rare species to coastal phytoplankton assemblages. Marine Ecology, v. 35, n. 1, p. 132-145, 2014.

IOCCG - International Ocean-Colour Coordinating Group. Remote Sensing of ocean color in coastal, and other optically-complex, waters. Reportts of the International Ocean-Colour Coordinating Group, Dartmouth, Canada, n.3, p. 1-140, 2000.

IRWIN, A. J.; FINKEL, Z. V.; SCHOFIELD, O. M. E.; et al. Scaling-up from nutrient physiology to the size-structure of phytoplankton communities. Journal of Plankton Research, v. 28, n. 5, p. 459-471, 2006.

ITO, A. A historical meta-analysis of global terrestrial net primary productivity : are estimates converging? Global Change Biology, v. 17, p. 3161-3175, 2011.

JASSBY, A. D.; PLATT, T. Phytoplankton Mathematical formulation of the relationship between photosynthesis and light for phytoplankton. Limnology and Oceanography, v. 21, n. 4, p. 540-547, 1976.

KÄMPF, J.; CHAPMAN, P. The functioning of coastal upwelling systems. In: J. Kampf; P. Chapman (Orgs.); Upwelling Systems of the World: A Scientific Journey to the Most Productive Marine Ecosystems. XV ed., p.31-65, 2016. Springer. Disponível em: <http://www.springer.com/978-3-319-42522-1>.

KASSAMBARA, A. Machine learning essentials: Practical guide in R. Marseille: STHDA, 2018, 209p.

KIRK, J T O. Light and Photosynthesis in Aquatic Ecosystems. 2. ed. Cambrigde: Cambridge University Press, 1994. 509 p.

KOKKINAKIS, S. A.; WHEELER, P. A. Nitrogen uptake and phytoplankton growth in coastal upwelling regions. Limnology and Oceanography, v. 32, n. 5, p. 1112-1123, 1987.

KOLBER, Z.; FALKOWSKI, P. G. Use of active fluorescence to estimate photosynthesis in situ. Limnology and Oceanography, v. 38, n. 8, p. 1646-1665, 1993.

LOHRENZ, S. E.; FAHNENSTIEL, G. L.; REDALJE, D. G.; et al. Nutrients, irradiance, and mixing as factors regulating primary production in coastal waters impacted by the Mississippi River plume. Continental Shelf Research, v. 19, n. 9, p. 1113-1141, 1999. 
LAWRENZ, E.; SILSBE, G.; CAPUZZO, E.; et al. Predicting the Electron Requirement for Carbon Fixation in Seas and Oceans. PLoS ONE, v. 8, n. 3, 2013.

LAWS, E. A.; LANDRY, M. R.; BARBER, R. T.; et al. Carbon cycling in primary production bottle incubations: inferences from grazing experiments and .... Deep-Sea Research Part II, v. 47, p. 1339-1352, 2000. Disponível em: <http://www.ncbi.nlm.nih.gov/entrez/query.fcgi? $\mathrm{db}=$ pubmed $\& \mathrm{cmd}=$ Retrieve $\&$ dopt $=$ Abstract -

Plus\&list_uids=12024808410952148660related:tKbuIoqz4KYJ\%5Cnpapers2://publication/uuid/CC7C98C3-ED15-4B4C-A9DAFE603975F871>.

LUTZ, V.; SEGURA, V.; DOGLIOTTI, A.; et al. Overview on primary production in the Southwestern Atlantic. In: M. Hoffmeyer; M. Sabatini; F. Brandini; D. Calliari; N. Santinelli (Orgs.); Plankton Ecology of the Southwestern Atlantic: From the Subtropical to the Subantarctic Realm. p.101-126, 2018. Springer.

MA, S.; TAO, Z.; YANG, X.; et al. Estimation of marine primary productivity from satellitederived phytoplankton absorption data. IEEE Journal of Selected Topics in Applied Earth Observations and Remote Sensing, v. 7, n. 7, p. 3084-3092, 2014. IEEE.

MACÍAS, D.; FRANKS, P. J. S.; OHMAN, M. D.; et al. Modeling the effects of coastal windand wind-stress curl-driven upwellings on plankton dynamics in the Southern California current system. Journal of Marine Systems, v. 94, p. 107-119, 2012. Elsevier B.V. Disponível em: <http://dx.doi.org/10.1016/j.jmarsys.2011.11.011>.

MACINTYRE, H. L.; KANA, T. M.; ANNING, T.; et al. Photoacclimation of photosynthesis irradiance response curves and photosynthetic pigments in microalgae and cyanobacteria. Journal of Phycology, v. 38, p. 17-38, 2002.

MALCHOW, H. Nonlinear plankton dynamics and pattern formation in an ecohydrodynamic model system. Journal of Marine Systems, v. 7, p. 193-202, 1996.

MARCOLIN, C. R.; GAETA, S.; LOPES, R. M. Seasonal and interannual variability of zooplankton vertical distribution and biomass size spectra off Ubatuba, Brazil. Journal of Plankton Research, v. 37, n. 4, p. 808-819, 2014.

MARQUES-JR, A. N.; CRAPEZ, M. A. C.; BARBOZA, C. D. N. Impact of the Icaraí Sewage Outfall in Guanabara Bay, Brazil. Brazilian Archives of Biology and Technology, v. 49, n. 4, p. 643-650, 2006.

MARRA, J. Approaches to the measurement of plankton production. In: Willians, P.; Thomas, D. N.; Reynolds, C. S (Eds.). Phytoplankton productivity - Carbon assimilation in marine and freshwater ecosystem. Blackwell Science, Cap. 4, p. 78 -108, 2002.

MARRA, J.; TREES, C. C.; O'REILLY, J. E. Phytoplankton pigment absorption: A strong predictor of primary productivity in the surface ocean. Deep-Sea Research Part I: Oceanographic Research Papers, v. 54, n. 2, p. 155-163, 2007.

MASTERMAN, D.; REDDING, K. Biology with Vernier: Biology experiments using Vernier sensors. 1. ed. Beaverton: Vernier Software \& Technology, 2007. 
MAXWELL, K.; JOHNSON, G. N. Chlorophyll fluorescence - A practical guide. Journal of Experimental Botany, v. 51, n. 345, p. 659-668, 2000.

MCKINNON, A. D.; DUGGAN, S.; LOGAN, M.; et al. Plankton Respiration, Production, and Trophic State in Tropical Coastal and Shelf Waters Adjacent to Northern Australia. Frontiers in Marine Science, v. 4, n. October, 2017. Disponível em: <http://journal.frontiersin.org/article/10.3389/fmars.2017.00346/full>.

MIRANDA, L. B. D. E.; IKEDA, Y.; CASTRO FILHO, B. M.; et al. Note on the Occurrence of Saline Fronts in the Ilha Grande (Rj ) Region. Boletim do Instituto Oceanográfico, v. 24, n. December, p. 249-256, 1977.

MÖLLER, O. O.; PIOLA, A. R.; FREITAS, A. C.; et al. The effects of river discharge and seasonal winds on the shelf off southeastern South America. Continental Shelf Research, v. 28, n. 13, p. 1607-1624, 2008.

MONBET, Y. Control of Phytoplankton Biomass in Estuaries: A Comparative Analysis of Microtidal and Macrotidal Estuaries. Estuaries, v. 15, n. 4, p. 563, 1992. Disponível em: $<$ http://link.springer.com/10.2307/1352398>.

MOREL, A.; PRIEUR, L. Analysis of variations in ocean color. Limnology and Oceanography, v. 22, n. 4, p. 709-722, 1977.

MOREL, A. Optical modeling of the upper ocean in relation to its biogenous matter content (case I waters). Journal of Geophysical Research, v. 93, n. C9, p. 10749-10768, 1988. Disponível em: <http://doi.wiley.com/10.1029/JC093iC09p10749>.

MORRIS, I. Paths of Carbon Assimilation in Marine Phytoplankton. In: FALKOWSKI, P G (Ed.). Primary Productivity in the Sea. Boston: Springer, 1980. p. 139-159. (Environmental Science Research).

O'BRIEN, J. J.; WROBLEWSKI, J. S. On advection in phytoplankton models. Journal of Theoretical Biology, v. 38, n. 1, p. 197-202, 1973. Disponível em: <http://linkinghub.elsevier.com/retrieve/pii/002251937390235X>.

OUDOT, C.; GERARD, R.; MORIN, P.; et al. Precise shipboard determination of dissolved oxygen (Winkler procedure) for productivity studies with a commercial system. Limnology and Oceanography, v. 33, n. 1, p. 146-150, 1988.

PAERL, H. W.; HALL, N. S.; PEIERLS, B. L.; et al. Evolving Paradigms and Challenges in Estuarine and Coastal Eutrophication Dynamics in a Culturally and Climatically Stressed World. Estuaries and Coasts, v. 37, n. 2, p. 243-258, 2014.

PAIXÃO, S. V. Transporte de volume e condições hidrográficas no Canal de São Sebastião. 2008. 210 f. Dissertação (Mestrado em Oceanografia Física) - Instituto Oceanográfico, Universidade de São Paulo, São Paulo, 2008.

PENNA, N.; CAPELLACCI, S.; RICCI, F. The influence of the Po River discharge on phytoplankton bloom dynamics along the coastline of Pesaro (Italy) in the Adriatic Sea. Marine Pollution Bulletin, v. 48, n. 3-4, p. 321-326, 2004. 
PERES, A. L. F. Efeito de diferentes massas de água nas classes de tamanho da biomassa fitoplanctônica na região de desembocadura da Baía do Araçá (Canal de São Sebastião - SP) durante o verão e inverno de 2012. Dissertação mestrado, Faculdade de Filosofia Ciências e Letras de Ribeirão Preto- USP, 56p., 2013.

PIOLA, A. R.; ROMERO, S. I.; ZAJACZKOVSKI, U. Space-time variability of the Plata plume inferred from ocean color. Continental Shelf Research, v. 28, n. 13, p. 1556-1567, 2008.

PLATT, T.; GALLEGOS, C. L.; HARRISON, W. G. Photoinhibition of photosynthesis in natural assemblages of marine phytoplankton. Boletin de instituto del mar del peru, 1981.

PLATT, T.; SATHYENDRANATH, S.; WHITE, G. N.; et al. Primary Production: Sensitivity to Surface Irradiance and Implications for Archiving Data. Frontiers in Marine Science, v. 4, n. December, p. 1-9, 2017. Disponível em: <http://journal.frontiersin.org/article/10.3389/fmars.2017.00387/full>.

RABALAIS, N. N.; TURNER, R. E.; DÍAZ, R. J.; et al. Global change and eutrophication of coastal waters. ICES Journal of Marine Science, v. 66, n. 7, p. 1528-1537, 2009.

REGAUDIE-DE-GIOUX, A.; LASTERNAS, S.; AGUSTÃ-, S.; et al. Comparing marine primary production estimates through different methods and development of conversion equations. Frontiers in Marine Science, v. 1, n. July, p. 1-14, 2014. Disponível em: <http://journal.frontiersin.org/article/10.3389/fmars.2014.00019/abstract>.

REGAUDIE-DE-GIOUX, A.; CASTAGNA, A.; FERREIRA, A.; et al. Influence of mixed upwelled waters on metabolic balance in a subtropical coastal ecosystem: São Sebastião Channel, southern Brazil. Marine Ecology Progress Series, v. 573, p. 61-72, 2017.

RILEY, G. A. A mathematical model of regional variations in plankton. Limnology and Oceanography, v. 10, p. 202-215, 1965.

RIVERA-MONROY, V. H.; MADDEN, C. J.; DAY J.W., J.; et al. Seasonal coupling of a tropical mangrove forest and an estuarine water column: Enhancement of aquatic primary productivity. Hydrobiologia, v. 379, n. 1995, p. 41-53, 1998.

ROBINSON, A. R. On the theory of advective effects on biological dynamics in the sea. Proceedings of the Royal Society A: Mathematical, Physical and Engineering Sciences, v. 453, p. 2295-2324, 1997.

ROBINSON, C. M.; CHERUKURU, N.; HARDMAN-MOUNTFORD, N. J.; et al. Phytoplankton absorption predicts patterns in primary productivity in Australian coastal shelf waters. Estuarine, Coastal and Shelf Science, v. 192, p. 1-16, 2017. Elsevier Ltd. Disponível em: <http://dx.doi.org/10.1016/j.ecss.2017.04.012>.

ROESLER, C. S.; PERRY, M. J.; CARDER, K. L. Modeling in situ phytoplankton absorption from total absorption spectra in productive inland marine waters. Limnology and Oceanography, v. 34, n. 8, p. 1510-1523, 1989. Disponível em: </data/aaworks/SeaWiFS_bio/doc/Thesis/pdf_ref/Roesler et al 1989_LO.pdf>. 
ROESLER, C.; UITZ, J.; CLAUSTRE, H.; et al. Recommendations for obtaining unbiased chlorophyll estimates from in situ chlorophyll fluorometers: A global analysis of WET Labs ECO sensors. Limnology and Oceanography: Methods, v. 15, n. 6, p. 572-585, 2017.

RUSSONIELLO, C. J.; FERNANDEZ, C.; BRATTON, J. F.; et al. Geologic effects on groundwater salinity and discharge into an estuary. Journal of Hydrology, v. 498, p. 1-12, 2013. Elsevier B.V. Disponível em: <http://dx.doi.org/10.1016/j.jhydrol.2013.05.049>.

SALDANHA-CORREAA, F. M. P.; GIANESELLA, S. M. F. A microcosm approach on the potential effects of the vertical mixing of water masses over the primary productivity and phytoplankton biomass in the southern brazilian coastal region. Brazilian Journal of Oceanography, v. 52, n. 3/4, p. 167-182, 2004.

SAWYER, A. H.; MICHAEL, H. A.; SCHROTH, A. W. From soil to sea: the role of groundwater in coastal critical zone processes. Wiley Interdisciplinary Reviews: Water, v. 3, n. 5, p. 21, 2016.

SHOAF, W. T.; LIUM, B. W. Improved extraction of chlorophyll a and b from algae using dimethyl sulfoxide. Limnology and Oceanography, v. 21, n. 6, p. 926-928, 1976.

SILSBE, G. M.; OXBOROUGH, K.; SUGGETT, D. J.; et al. Toward autonomous measurements of photosynthetic electron transport rates: An evaluation of active fluorescence-based measurements of photochemistry. Limnology and Oceanography: Methods, v. 13, n. 3, p. 138$155,2015$.

SILVA, S.; MIRANDA, L. B. DE; CASTRO FILHO, B. M. Numerical study of circulation and thermohaline structure in the São Sebastião channel. Revista Brasileira de Geofísica, v. 23, n. 4, p. 407-425, 2005.

SIMPSON, John H.; SHARPLES, Jonathan. Introduction to the physical and biological oceanography of shelf seas. New York: Cambrigde University Press, 2012. 424 p.

SMITH, V. H.; TILMAN, G. D.; NEKOLA, J. C. Eutrophication: impacts of excess nutrient inputs on freshwater, marine, and terrestrial ecosystems. Environmental Pollution, v. 100, p. 179-196, 1999.

STEEMANN-NIELSEN, E. The use of radio-active carbon (C14) for measuring organic production in the Sea. ICES Journal of Marine Science, v. 18, n. 2, p. 117-140, 1952.

SUGGETT, D. J.; MOORE, C. M.; HICKMAN, A. E.; et al. Interpretation of fast repetition rate (FRR) fluorescence: Signatures of phytoplankton community structure versus physiological state. Marine Ecology Progress Series, v. 376, p. 1-19, 2009.

SUGGETT, D. J.; PRASIL, O.; BOROWITZKA. Chlorophyll a Fluorescence in Aquatic Sciences: Methods and Applications. Dordrecht: Springer Netherlands, 2010.

TASSAN, S.; FERRARI, G. M. An alternative approach to absorption measurements of aquatic particles retained on filters. Limnology and Oceanography, v. 40, n. 8, p. 1358-1368, 1995. 
TASSAN, S.; FERRARI, G. M.; BRICAUD, A.; et al. Variability of the amplification factor of light absorption by filter-retained aquatic particles in the coastal environment. Journal of Plankton Research, v. 22, n. 4, p. 659-668, 2000.

TASSAN, S.; FERRARI, G. M. A sensitivity analysis of the "Transmittance-Reflectance" method for measuring light absorption by aquatic particles. Journal of Plankton Research, v. 24, n. 8, p. 757-774, 2002. Disponível em: <p:\%5CLiterature\%5Cpdf\%5Ctassan and ferrari 2002.pdf\%5Cnhttp://plankt.oupjournals.org/cgi/content/abstract/24/8/757\%0Ahttp://www.plankt.oupjournals.org/cgi/doi/10.1093/plankt/24.8.757>. .

THIMIJAN, R. W.; HEINS, R. D. Photometric, radiometric, and quantum light units of measure: a review. HortScience, v. 18, n. 6, p. 818-822, 1983.

TOCCI, B. R. C. Ocorrência e coexistência de cianobactérias diazotróficas no Canal de São Sebastião-SP com o aumento da pluviosidade. 2016. 86 f. Dissertação (Mestrado em Oceanografia Biológica) - Instituto Oceanográfico, Universidade de São Paulo, São Paulo, 2016.

TOMCZAK, M.; GODFREY, J. S. Regional oceanography: an Introduction. Oxford: Pergamon, pdf version 1.2, 422 p., 2002.

VAN DE MERWE, J. P.; LEE, S. Y.; CONNOLLY, R. M.; et al. Assessing temporal and spatial trends in estuarine nutrient dynamics using a multi-species stable isotope approach. Ecological Indicators, v. 67, p. 338-345, 2016. Elsevier Ltd. Disponível em: <http://dx.doi.org/10.1016/j.ecolind.2016.02.058> .

VOLLENWEIDER, R. A.; GIOVANARDI, F.; MONTANARI, G.; et al. Characterization of the trophic conditions of marine coastal waters with special reference to the NW Adriatic Sea: Proposal for a trophic scale, turbidity and generalized water quality index. Environmetrics, v. 9, n. 3, p. 329-357, 1998.

WAFAR, M. V. M.; LE CORRE, P.; BIRRIEN, J. L. Nutrients and primary production in permanently well-mixed temperate coastal waters. Estuarine, Coastal and Shelf Science, v. 17, n. 4, p. 431-446, 1983.

WANG, G.; CAO, W.; YANG, D.; et al. Partitioning particulate absorption coefficient into contributions of phytoplankton and nonalgal particles: A case study in the northern South China Sea. Estuarine, Coastal and Shelf Science, v. 78, n. 3, p. 513-520, 2008.

WEGER, H. G.; HERZIG, R.; FALKOWSKI, P. G.; et al. Respiratory losses in the light in a marine diatom: Measurements by short-term mass spectrometry. Limnology and Oceanography, v. 34, n. 7, p. 1153-1161, 1989.

WELSCHMEYER, N. A. Fluorometric analysis of chlorophyll a in the presence of chlorophyll b and pheopigments. Limnology and Oceanography, v. 39, n. 8, p. 1985-1992, 1994. Disponível em: <http://doi.wiley.com/10.4319/lo.1994.39.8.1985>.

WILLIAMS, P. J. Microbial contribution to overall marine plankton metabolism: direct measurements of respiration. Oceanologica Acta, v. 4, n. 3, p. 359-364, 1981. Disponível em: <http://archimer.ifremer.fr/doc/00131/24204/22197.pdf>. . 
ZOPPINI, A.; PETTINE, M.; TOTTI, C.; et al. Nutrients, standing crop and primary production in western coastal waters the Adriatic Sea. Estuarine, Coasral and Shelf Science, v. 41, p. 493$513,1995$. 